\title{
Efficiency of Dutch hospitals
}

Citation for published version (APA):

Ludwig, M. (2008). Efficiency of Dutch hospitals. [Doctoral Thesis, Maastricht University]. Universiteit Maastricht. https://doi.org/10.26481/dis.20081128ml

Document status and date:

Published: 01/01/2008

DOI:

10.26481/dis.20081128ml

Document Version:

Publisher's PDF, also known as Version of record

\section{Please check the document version of this publication:}

- A submitted manuscript is the version of the article upon submission and before peer-review. There can be important differences between the submitted version and the official published version of record.

People interested in the research are advised to contact the author for the final version of the publication, or visit the DOI to the publisher's website.

- The final author version and the galley proof are versions of the publication after peer review.

- The final published version features the final layout of the paper including the volume, issue and page numbers.

Link to publication

\footnotetext{
General rights rights.

- You may freely distribute the URL identifying the publication in the public portal. please follow below link for the End User Agreement:

www.umlib.nl/taverne-license

Take down policy

If you believe that this document breaches copyright please contact us at:

repository@maastrichtuniversity.nl

providing details and we will investigate your claim.
}

Copyright and moral rights for the publications made accessible in the public portal are retained by the authors and/or other copyright owners and it is a condition of accessing publications that users recognise and abide by the legal requirements associated with these

- Users may download and print one copy of any publication from the public portal for the purpose of private study or research.

- You may not further distribute the material or use it for any profit-making activity or commercial gain

If the publication is distributed under the terms of Article $25 \mathrm{fa}$ of the Dutch Copyright Act, indicated by the "Taverne" license above, 


\section{Efficiency of Dutch hospitals}


(C) Martijn Ludwig, Leiden

Printed by Datawyse, Maastricht, The Netherlands

Ludwig, Martijn

Efficiency of Dutch hospitals

Doctoral dissertation Maastricht University - With ref. - With summary in Dutch 


\section{Efficiency of Dutch hospitals}

\section{PROEFSCHRIFT}

ter verkrijging van de graad van doctor aan de Universiteit Maastricht, op gezag van de Rector Magnificus, prof. mr. G.P.M.F. Mols volgens het besluit van het College van Decanen, in het openbaar te verdedigen op vrijdag 28 november 2008 om 14.00 uur

door

Martijn Ludwig 


\section{Promotores}

Prof. Dr. G.G. van Merode

Prof. Dr. W.N.J. Groot

\section{Beoordelingscommissie}

Prof. Dr. F.C. Palm (voorzitter)

Prof. Dr. R.T.J.M. Janssen (Universiteit van Tilburg)

Prof. Dr. A.P.W.P. van Montfort (Universiteit van Twente)

Prof. Dr. G.A. Pfann

Prof. Dr. C. Spreeuwenberg

Prof. Dr. G.P. Westert (Universiteit van Tilburg) 


\section{CONTENT TABLE}

$\begin{array}{ll}\text { ABSTRACT } & 7\end{array}$

SAMENVATTING 11

1 GENERAL INTRODUCTION 15

$\begin{array}{ll}1.1 \text { Introduction } & 15\end{array}$

1.2 Hospitals from an economic point of view 18

$\begin{array}{ll}1.3 \text { Defining efficiency } & 20\end{array}$

$\begin{array}{ll}1.4 \text { Measuring hospital efficiency } & 22\end{array}$

1.5 Explaining hospital efficiency 23

$\begin{array}{ll}1.6 \text { Outline } & 26\end{array}$

2 DATA AND METHOD 27

2.1 Data $\quad 27$

2.2 Method $\quad 35$

3 HOSPITAL EFFICIENCY: THE EFFECTS OF TIME AND CASE MIX 41

Abstract $\quad 41$

3.1 Introduction $\quad 42$

3.2 Estimation results $\quad 54$

3.3 Discussion $\quad 59$

4 PRINCIPAL AGENT ISSUES IN HOSPITALS: EXPLAINING EFFICIENCY 63 Abstract $\quad 63$

4.1 Introduction $\quad 64$

$\begin{array}{ll}4.2 & \text { Estimation results }\end{array}$

$\begin{array}{ll}4.3 \text { Discussion } & 77\end{array}$

Appendix: Direct and indirect costs per department $\quad 79$

5 HOSPITAL EFFICIENCY: THE EFFECTS OF TRANSACTION COSTS 83 $\begin{array}{ll}\text { Abstract } & \mathbf{8 3}\end{array}$

5.1 Introduction $\quad 84$

$\begin{array}{ll}5.2 \text { Data and method } & 87\end{array}$

$\begin{array}{ll}5.3 \text { Estimation results } & 88\end{array}$

$\begin{array}{ll}5.4 \text { Discussion } & 94\end{array}$ 
$\begin{array}{llr}6 & \text { SYNTHESIS } & 97\end{array}$

$\begin{array}{ll}6.1 \text { Introduction } & 97\end{array}$

6.2 Main findings $\quad 98$

6.3 Political and managerial implications 103

$\begin{array}{ll}\text { 6.4 Methodological considerations } & 107\end{array}$

$\begin{array}{ll}6.5 \text { Concluding remarks } & 111\end{array}$

7 REFERENCES 113

$\begin{array}{ll}\text { DANKWOORD } & 117\end{array}$ 


\section{Abstract}

\section{Introduction}

Nowadays health care expenditures in the Netherlands represent more than $9 \%$ of Dutch Gross Domestic Product (GDP). Furthermore, the costs of health care more than doubled between 1991 and 2004.

These figures help to explain why both researchers and policy makers search for ways to increase (cost) efficiency in the health care sector in general and specifically in the hospital sector, since the latter is the largest and most complex sector in health care.

This search for efficiency in the hospital sector has led to a number of studies in health economics examining efficiency, both national and international. Most of the recent studies are based on frontier methods, both parametric and nonparametric. This thesis uses the parametric Stochastic Frontier Analysis to estimate efficiency, and attempts to explain differences in efficiency between hospitals. More specifically this thesis formulates answers to two questions about this issue:

- How efficient are Dutch hospitals?

- Why does hospital inefficiency occur?

This thesis starts with a short overview of parametric frontier studies in the hospital sector.

Next, the first question is answered by using a stochastic frontier approach based on panel data to measure the efficiency of Dutch hospitals. A time-varying efficiency component is included in the study. Two different models are estimated. The first model measures output based on the classical budget parameters (admissions, patient days and first outpatient visits) for Dutch hospitals. The second model measures output based on case mix (using Diagnostic Related Groups: DRGs) weighted admissions. These were not previously available for Dutch hospitals.

To answer the second question three issues are examined:

1. The relationship between efficiency and quality.

2. Opening the black box of the hospital organization by examining efficiency at a department level.

3. The efficiency rationale of making or buying hospital services.

Ad 1

Efficiency and quality are amongst the most pressing issues in health care. Whether quality and efficiency are complements or substitutes is however not straightforward. 
This study includes quality measures, from the stakeholder's, i.e. managers, medical specialists, nurses and general practitioners, perspective.

\section{Ad 2}

The insights of Neo Institutional Economics (NEI) are used to examine efficiency on a lower level within the hospital, the facilitating departments. The efficiency of intermediate hospital services: the ward, the outpatient department, the operating theatre, the radiology department, the laboratory and the physiotherapy department is estimated. The efficiency estimates of these departments are related to the efficiency estimate of the total hospital.

\section{Ad 3}

The make-or-buy decision is the archetypical issue of Transaction Cost Economics (TCE). Besides it is an important issue for numerous hospital boards. In this thesis the relationship between the "make-or-buy" decision of 10 different services and the efficiency of a hospital, is analyzed.

\section{Results}

The most important lessons learned from the literature review are:

1. Individual efficiency estimates are significantly affected by distributional assumptions and the way output is measured. Using individual efficiency estimates for funding purposes for example should therefore be treated with extreme care.

2. The average efficiency of groups of hospitals within the same study is less affected by different estimation techniques.

3. The efficiency estimates based on panel data outperform estimates based on cross-section data because of the robustness of the estimates.

4. The average efficiency of hospitals varies in most studies between $80 \%$ and $90 \%$, with a number of outliers below and above. Theoretically Data Envelopment Analysis (DEA) produces lower efficiency estimates since, in contrast with Stochastic Frontier Analysis (SFA), chance is interpreted as inefficiency as well.

5. No clear answer to the question of whether a parametric or a non-parametric approach should be used can be given.

6. It appears that in most studies the efficiency of hospitals increases over time.

This study adds the following results. The average efficiency of Dutch hospitals between 1998 and 2002 is $84 \%$ when output is measured by the case mix weighted number of patients. The average efficiency is considerably lower when output is not weighted by case mix. Further the ranking of hospitals by their efficiency score is changed as well when output is not weighted by case mix. This finding leads us to conclude that not taking case mix into account leads to biased efficiency estimates. Furthermore, when output is measured by the nonweighted number of patients, Dutch hospitals have become less efficient over time. When weighted for case mix differences the average efficiency increases 
compared to the first model, but a decreasing efficiency over time is still found. This finding differs from most international studies. This finding can first be explained by the fact that salaries of hospital staff are raised in the period measured. Second no major policy measures to increase efficiency were taken in the period measured.

Contrary to the critics of the stochastic frontier method, which state that inefficiency is just capturing better quality, a positive relationship between efficiency and quality is found, supporting the theory that hospitals with more efficient processes have a higher quality as well.

The efficiency of departments in a hospital is only slightly related to the efficiency of both other departments in the same hospital and the efficiency in the total hospital organization. This result might look surprising, since one might expect that hospitals with efficient departments are more efficient hospitals. Support for this finding is found in the Principal Agent theory, department managers of efficient departments are only concerned with their own efficiency and not with the efficiency of the total hospital. We find that efficient departments within efficient hospitals have a better score on the measure for cooperation than hospitals with efficient departments in less efficient hospitals.

The efficiency of the hospital is hardly affected by the make-or-buy decision. Services for which outsourcing is more efficient are mostly outsourced yet. This finding shows that the effort of hospitals to decide whether or not to outsource is hardly supported by efficiency reasons. Incorporating the size of the hospital, we find that large hospitals tend to outsource less. This decision is supported by efficiency reasons, because larger hospitals do have fewer problems with economies of scale compared to the market.

In general we find that inefficiency exists within Dutch hospitals and that it is not easy to find the sources of inefficiency. It was found that in contrast with common belief inefficiency can hardly be explained by the make-or-buy decision of hospitals or by the quality of hospitals. Also the inefficiency on department level explains just a small part of hospital inefficiency. Further studies examining different organizational forms of hospitals and comparing different countries might help to provide more insights in the sources of hospital inefficiency. 


\section{Samenvatting}

\section{Inleiding}

De kosten van de Nederlandse gezondheidszorg bedragen meer dan $9 \%$ van het Bruto Nationaal Product (BNP). Deze kosten groeien nog steeds sterk, tussen 1991 en 2004 zijn de kosten verdubbeld. Onder meer vanwege de hoge kostenstijging, specifiek in de ziekenhuissector, zijn zowel beleidsmakers als onderzoekers veelal bezig met onderzoek naar de efficiëntie van ziekenhuizen. De zoektocht naar efficiëntie heeft geresulteerd in een groot aantal nationale en internationale onderzoeken naar de hoogte van de efficiëntie van ziekenhuizen. Het merendeel van de recente onderzoeken maakt gebruik van de zogenaamde 'frontier' methodes, parametrisch en/of niet-parametrisch om efficiëntie te schatten. Dit proefschrift beschrijft onderzoek naar de efficiëntie van ziekenhuizen, gebaseerd op de parametrische "Stochastic Frontier Analyse". Twee onderzoeksvragen staan centraal:

1 Hoe efficiënt zijn Nederlandse ziekenhuizen?

2 Waarom ontstaat inefficiëntie in Nederlandse ziekenhuizen?

Dit proefschrift start met een kort overzicht van eerdere (internationale) 'frontier' onderzoeken naar de efficiëntie van ziekenhuizen.

Vervolgens wordt het antwoord op de eerste onderzoeksvraag gevonden door het toepassen van een 'stochastic frontier methode' gebaseerd op panel data voor de Nederlandse ziekenhuizen. Het model wordt in- en exclusief een over de tijd variërende component geschat. Daarnaast zijn twee verschillende output maten gebruikt. In het eerst model wordt output gemeten met de traditionele output maatstaven uit het Functioneel Budget. In het tweede model wordt output gecorrigeerd voor case mix gebaseerd op DRGs, een nieuwe manier van meten voor Nederlandse ziekenhuizen.

Voor de tweede onderzoeksvraag worden drie elementen onderzocht:

1 De relatie tussen kwaliteit en efficiëntie.

2 De efficiëntie op afdelingsniveau van ziekenhuizen.

3 De efficiëntie van het uitbesteden of zelf uitvoeren van een tiental ziekenhuisfuncties.

\section{Ad 1}

Twee van de belangrijkste pijlers van een gezondheidsstelsel zijn kwaliteit en efficiëntie. De relatie tussen kwaliteit en efficiëntie is een belangrijk onderwerp in een aantal onderzoeken, hoe deze relatie loopt is echter niet duidelijk. Kwaliteit wordt in dit onderzoek gemeten vanuit het perspectief van de stakeholder. 
Ad 2

De theorie van de Neo Institutionele Economie is gebruikt om de efficiëntie van de afdelingen van ziekenhuizen te onderzoeken. De efficiëntie van de verpleegafdeling, de polikliniek, de operatiekamer, de röntgenafdeling, het laboratorium en de fysiotherapie wordt geschat en gerelateerd aan de efficiëntie van het totale ziekenhuis.

Ad 3

De 'make-or-buy' beslissing is het archetypische vraagstuk van de Transactiekosten Economie. Ook in de praktijk steken ziekenhuizen veel inspanning in deze beslissing. In dit proefschrift wordt de relatie tussen efficiëntie en de 'makeor-buy' beslissing van tien ziekenhuisfuncties geanalyseerd.

\section{Resultaten}

De belangrijkste conclusies van dit literatuuronderzoek zijn:

1 Schattingen van de efficiëntie van individuele instellingen worden significant beïnvloed door de veronderstellingen over de verdelingsfunctie van de storingsterm en de wijze waarop output wordt gemeten. Voorzichtigheid bij het gebruik van individuele efficiëntie schattingen is daarom geboden.

2 De gemiddelde efficiëntie van groepen van ziekenhuizen wordt minder beïnvloed door de gebruikte schattingstechnieken.

3 Het gebruik van panel-data leidt tot robuustere schattingen dan het gebruik van cross-sectie data.

4 De gemiddelde efficiëntie van ziekenhuizen varieert in de meeste onderzoeken tussen $80 \%$ en $90 \%$. Theoretisch leidt het gebruik van nietparametrische DEA tot lagere schattingen voor efficiëntie, omdat DEA toeval ook interpreteert als inefficiëntie.

5 Het is niet mogelijk om een duidelijk antwoord te geven of de parametrische SFA-methode, of de niet-parametrische DEA methode moet worden gebruikt.

6 In de meeste internationale onderzoeken blijkt de efficiëntie in de tijd toe te nemen.

Als output wordt gemeten op basis van DRGs dan bedraagt de gemiddelde efficiëntie van Nederlandse ziekenhuizen $84 \%$. De gemiddelde efficiëntie is lager wanneer output wordt gemeten op basis van de 'oude' Functioneel Budget (FB)parameters. Deze bevinding geeft aan dat het niet corrigeren van output voor case mix leidt tot onjuiste conclusies over de efficiëntie van groepen van instellingen en individuele instellingen.

Verder zien we dat als output wordt gemeten op basis van de oude FBparameters de efficiëntie van een ziekenhuis daalt in de tijd. Hetzelfde geldt wanneer output wordt gemeten op basis van DRGs, al is deze laatste bevinding niet statistisch significant. Deze bevinding is in tegenstelling tot de bevindingen van de meeste internationale studies, waarin een stijgende efficiëntie wordt gevonden. Voor dit verschil zijn twee verklaringen. Ten eerste zijn de salarissen 
van ziekenhuispersoneel meer dan de inflatie gestegen in de meetperiode 19982002. Ten tweede hebben er in de meetperiode geen beleidsmaatregelen plaatsgevonden om efficiëntie te verhogen.

Verder blijken efficiëntie en kwaliteit geen tegenstellingen, zij gaan eerder samen. Dit in tegenstelling tot wat een aantal critici van de "stochastic frontier methodes" stelt, namelijk dat gemeten inefficiëntie kan worden verklaard door een verschil in kwaliteit.

De efficiëntie van de afdelingen in ziekenhuizen is slechts zwak gerelateerd met de efficiëntie van zowel de totale ziekenhuisorganisatie als andere afdelingen. Dit resultaat kan worden verklaard vanuit de Principaal Agent theorie. Afdelingsmanagers van efficiënte afdelingen zijn niet per definitie ook bezig met de efficiëntie van het totale ziekenhuis. We zien ook dat ziekenhuizen met efficiënte afdelingen in een efficiënt ziekenhuis beter scoren op de factor samenwerking dan ziekenhuizen met efficiënte afdelingen in minder efficiënte ziekenhuizen. Deze bevinding bevestigt de Principaal Agent Theorie.

De efficiëntie van ziekenhuizen heeft weinig tot geen relatie met de 'make-orbuy' beslissing. Verder zien we dat grote ziekenhuizen minder uitbesteden dan kleine ziekenhuizen. Deze beslissing wordt ondersteund uit efficiëntie overwegingen.

We kunnen concluderen dat er sprake is van inefficiëntie in Nederlandse ziekenhuizen en dat het niet eenvoudig is verklaringen te vinden voor deze inefficiëntie. In tegenstelling tot wat velen verwachten, is er bijna geen relatie tussen de 'make-or-buy' beslissing en de efficiëntie van ziekenhuizen. Ook zien we dat er slechts een beperkte relatie is tussen de efficiëntie van ziekenhuizen en de efficiëntie van de afdelingen in ziekenhuizen. Inefficiëntie en een gebrek aan kwaliteit ontstaan door een gebrekkige samenwerking in het ziekenhuis.

Verder onderzoek naar de relatie tussen de organisatievorm van ziekenhuizen en efficiëntie en het vergelijken van efficiëntie tussen landen kan bijdragen aan een diepgaander inzicht in de efficiëntie van ziekenhuizen. 



\section{General Introduction}

\subsection{Introduction}

The health care sector in the Netherlands has been growing rapidly. Measured in billions of euro the sector more than doubled from 26.1 billion euro to 47.5 billion euro between 1992 and 2004, see figure 1.

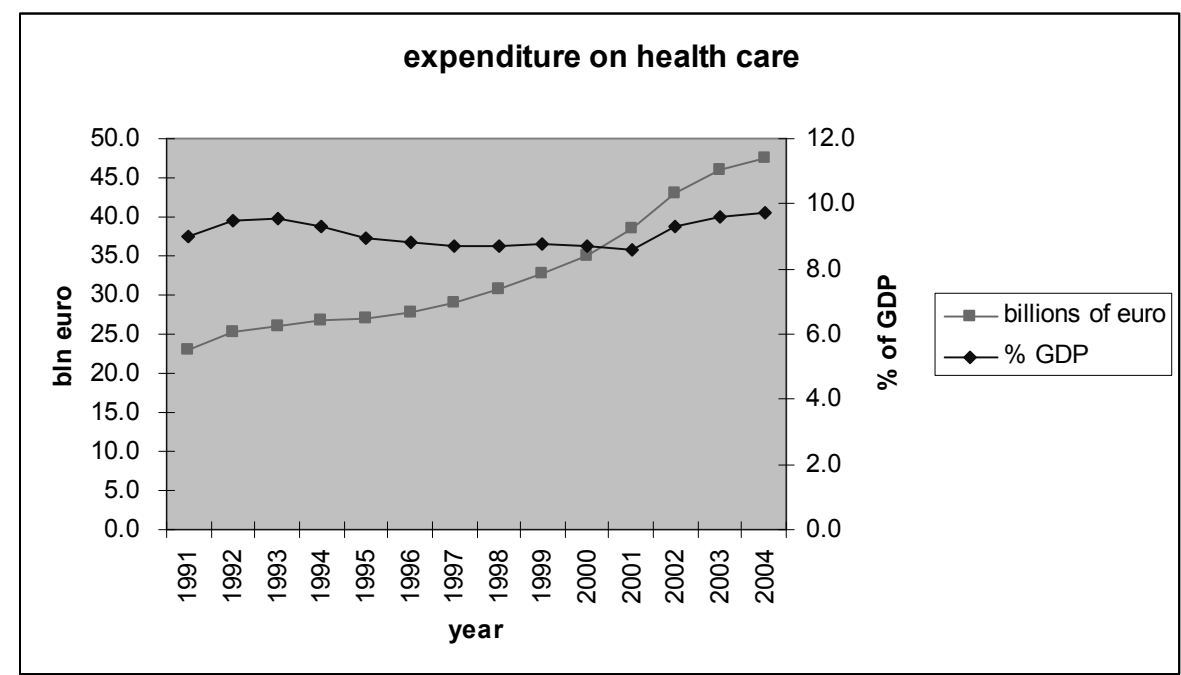

Figure 1: Governmental expenditure on Dutch health care (Data: CPB, 2007; CPB, 2006a)

Figure 1 provides an overview of the costs of Dutch health care. The total public expenditure on Dutch health care is presented in billions of Euros and as a percentage of GDP. Measured as a percentage of GDP the trend is towards a slight decrease between 1993 and 2001. Since 2001 the costs as a percentage of GDP are increasing again. Furthermore the Dutch Central Planning Bureau (CPB) has predicted an increased growth rate of about 1 percent point per year until 2011 (Douven et al., 2005). Some scenarios of the CPB estimate that $25 \%$ of all available personnel in the Netherlands will work in the health care sector by 2025.

The rapid growth of costs has a number of well known explanations: the increase of the number of the elderly (both in absolute numbers and as a percentage of the total population), and new medical technology. These factors are not under control of politicians and health care management. Supply side factors are more interesting from a cost containment perspective. If health care could be organized more efficiently, a significant amount of money can be saved. 
The majority of health care costs are incurred in hospitals (CPB, 2006a), therefore increasing efficiency in hospitals is most likely to offer a good potential for cost containment, assuming that inefficiency exists in hospitals. As shown for example by Blank et al. (2002) costs of Dutch hospitals are partly incurred by inefficiency. International studies (e.g. Hollingsworth, 2003) also show that $10 \%$ to $20 \%$ of hospital costs are spent on inefficiency.

In the Netherlands four extensive studies have been performed on the costs of hospitals. First, van Aert (1977) wrote a thesis about cost functions in Dutch hospitals. Second, van Montfort (1980) studied the applicability of production functions to Dutch hospitals in his thesis. Van Montfort (1980) and van Aert (1977) provide important contributions because they extensively show how costs and production of Dutch hospitals can be measured and how this measurement can be improved. Third, more recently Blank et al. (1998a) estimated cost and production functions of Dutch hospitals. The aim of this study was first to acquire knowledge about the relationship between assets and production, and second to show how adjustments in production and policy measures can improve efficiency. Fourth, in the second study of Blank et al. (2002) efficiency played a more prominent role (especially allocation efficiency) and an extensive description of (the measurement of) efficiency is given. Van Aert (1977) and van Montfort (1980) use the classical cost function approach, where the average cost function is estimated. No comparisons with the optimal cost situation are provided. Blank et al. (1998a) analyze the nature of inefficiency by using, among other techniques, Data Envelopment Analysis (DEA) to estimate efficiency of Dutch hospitals. DEA is one of the possible modern estimation techniques for the estimation of efficiency. The other one is the parametric Stochastic Frontier Analysis (SFA) method. SFA and DEA both aim to estimate efficiency and both have their advantages and disadvantages. Jacobs et al. (2006) give an extensive overview of these differences. Their main recommendation is to analyze the results of both techniques since results can differ significantly. The parametric approach, SFA, to estimate efficiency has however not been applied to Dutch hospitals yet. This thesis will fill this gap. Furthermore, this thesis adds to the explanation of (in)efficiency in Dutch hospitals. The question why hospital inefficiency in Dutch hospitals occurs has received little attention. Even in the last study by Blank et al. (2002) where efficiency plays a major role hardly any explanation is given for inefficiency. 
This thesis is concerned with efficiency in Dutch hospitals. It tries to explain differences in efficiency between hospitals, and attempts to answer two questions concerning hospital efficiency:

1. How efficient are Dutch hospitals?

2. Why does hospital inefficiency occur?

This introduction focuses on definition and measurement issues regarding both efficiency and hospitals. In the following two sections definitions of a hospital and of efficiency are discussed. Next, the measurement of efficiency is discussed in section 4. Section 5 describes potential explanations of hospital efficiency. This introduction ends in section 6 with an outline of the thesis. 


\subsection{Hospitals from an economic point of view}

One of the two main goals in this study is to analyze the origins of efficiency within hospital organizations. To do so an organizational theory, like Neo Institutional Economics (NEI), is needed. Where (Neo) classical economics views organizations (including hospitals) as an entity which strives towards one common goal, organizational theories like NEI, view organizations as entities with many different people with many different goals. NEI rejects the assumption of one common goal in an organization (Tijdink, 1996) and can thereby be helpful to explain the origin of (in)efficiency within hospitals.

NEI encompasses three main theories:

1. Property rights theory.

2. Principal agent theory.

3. Transaction Cost Economics (TCE).

The property rights theory challenges (neo) classical economic theory by considering the different legal rights of goods: the right to use it for oneself, the right to use it to earn an income, and the right to change or sell goods. The property rights theory is not used in this thesis, because the legal rights of goods in hospitals is less of an issue in efficiency considerations, as hospitals in the Netherlands are (almost) all not-for-profit hospitals with ownership with foundations and not with shareholders.

Principal agent theory challenges the classical economic theory by stating that an organization consists of different people with different interests. It views the organization as a set of agents who are paid by principals to undertake activities in the interest of the principal. Since the agent has his or her own interests that are at least partly different from the principal, individuals in organizations, and therefore organizations, are not striving towards one common goal. A core element of the principal agent theory is the rejection of the assumption that members of organizations share and pursue one common goal. The analyses of hospital inefficiency from the principal agent perspective are found in chapter 4.

TCE has first been introduced by Coase (1937). He poses the question why organizations exist, since transactions could be conducted by the market more efficiently. His answer to this question is that market transactions have costs linked to them, just as there are costs linked to internal coordination within organizations. Therefore Coase (1937) concludes that it is more efficient to have an organization if costs of internal coordination are lower than costs of market transactions. Williamson (1975, 1985 and 1998) further developed TCE by examining the internal costs and the costs of market transactions. He concluded that the key issue in this decision is the so-called asset specificity (Williamson, 1975). Asset specificity can be defined as the extent to which investments made to support a particular transaction have a higher value to that transaction than if they would have been redeployed for any other purpose (McGuiness, 1994). 
Williamson $(1975,1985)$ reasoned that transaction-specific assets are nonredeployable physical and human investments that are specialized and unique to a task. In general, TCE states that if asset specificity is not important, it is more efficient to buy services because of bureaucratic costs of internal governance. Internal delivery of services is favored when asset specificity is high. In chapter 5 the issue of making or buying hospital services and its relation with efficiency is analyzed from a TCE perspective. 


\subsection{Defining efficiency}

In the theory of production and costs of organization, three aspects of efficiency are mostly used, see for example Blank (1998):

1. technical efficiency;

2. allocative efficiency;

3. economic efficiency.

A technical efficient organization is mostly defined as an organization for which it is not possible to reduce all input factors proportionally without reducing output (Blank et al., 1998b). Economic efficiency is defined as the ratio of the optimal costs (or profits, or revenue, depending on the assumptions made about the economic behavior of the organization) and the actual costs. Allocative efficiency is defined as the ratio between economic and technical efficiency. Allocative efficiency refers to the difference between the actual used mix of input factors and the optimal use of input factors to produce the same output.

To study the efficiency of hospital (organizations) three issues deserve further discussion.

- What are inputs, and how do we measure them?

- What are outputs, and how do we measure them?

- What efficiency benchmark group will be used to compare the output divided by input measure?

- Jacobs et al. (2006) distinguish a fourth issue: the environmental constraints. Since the health care market in the Netherlands can be seen as one local market this is a less important issue in this study.

Measuring inputs of hospitals is considered as a less complex issue than measuring output(s) of hospitals although still a number of choices have to be made (Jacobs et al., 2006). The usual inputs for organizations are capital, staff and materials. With respect to these inputs the most challenging question is: Which input factors can and cannot be influenced by the hospital management? (Which inputs are exogenous and which inputs are endogenous?). In general we can state that prices (and even costs) of capital are exogenous to Dutch hospitals (see a broader description of this issue in the next chapter). With respect to inputs in Dutch hospitals, costs of staff and materials are largely endogenous to the hospital management. Prices though are another issue, whether or not prices are given (see data section).

If we apply the concept of efficiency to hospitals, the most frequently discussed issue is how to measure outputs of a hospital. This issue is explored further in chapter 3 of this thesis. In summary: the output of a hospital should be health gain. However health gains are difficult to measure. Even if health gain could be measured, it is difficult to measure which part of health gain can be attributed to the hospital. In empirical studies output is therefore mostly measured by the number of patients. Patients do however vary in their diseases and treatments, 
therefore the resources required vary as well. For example, a patient requiring a coronary bypass needs more resources than a patient scheduled for a vasectomy. Therefore patients are weighted. First a distinction between out- and inpatients is made. Further distinctions can be made by the number of ward days or other activities per patient, as is the case in the Dutch capitation model. In the Netherlands, this model is being replaced nowadays by a Prospective Payment System (PPS) based on products, Diagnose Behandeling Combinaties (DBCs). One reason for this change is that in the old system differences between patients are not taken into account well enough. Output measured by the number of products is expected to provide better insight in the true production of Dutch hospitals. If this is really the case efficiency differences are expected when output is measured differently. Chapter 4 of this thesis deals with the differences in efficiency when using different output measures.

In this study the level of efficiency in a certain hospital is estimated by comparing it to other hospitals. In most efficiency studies the group of hospitals analyzed, is usually a group of hospitals in the same country, or in the case of the US, the same state. This means that the efficiency of hospitals is measured relative to other hospitals within the same country. This implies that the (average) efficiency of the hospital sector in a country has only itself as a benchmark. Little or no results are available for differences in efficiency between countries; the question whether, for example, Dutch hospitals are more efficient than American ones, is a question still to be answered. Comparing differences between countries is until now still too difficult because differences in measured in- and outputs are too big to provide meaningful results. Another issue is the comparability of the systems. Health care systems differ: which parts of health care are provided by hospitals and which parts are provided by other health care providers like elderly care institutions and general practitioners?

It is appealing to compare hospitals within one country because of its practical relevance: Real life efficiency solutions exist within the same system. Therefore the efficiency gains are actually achievable and not merely a theoretical concept. 


\subsection{Measuring hospital efficiency}

From a measurement perspective, efficiency can be divided in technical and economic efficiency. Technical efficiency refers to the ability to minimize input in the production of a given output vector, or the ability to obtain maximum output from a given input vector. Technical efficiency imposes no behavioral objective on the organization since the output (or the input) is considered given (Blank, 1998a). Economic efficiency imposes a behavioral objective on the organization: cost minimizing behavior, profit maximizing behavior or revenue maximizing behavior are most often assumed. The difference between technical efficiency and economic efficiency is that economic efficiency takes the mix of input factors and its prices into account, whereas technical efficiency does not. The efficiency of the input mix used is called allocation efficiency. As in most other efficiency studies in health care the focus in this thesis lies on cost minimization behavior. The main reason that most models build on this assumption is that many health care systems hospitals have no incentives to pursue profit maximization. Until recently this was also true for the Netherlands. If we have no information on, or if we do not make an assumption about hospital behavior, we can only measure technical efficiency.

The simplest efficiency measure would be to calculate the input/output ratio. This ratio is however too restrictive because:

- $\quad$ multiple outputs are produced;

- $\quad$ multiple inputs are used;

- $\quad$ scale and scope effects are neglected;

- $\quad$ no distinction between chance and (in)efficiency can be made.

To measure technical efficiency production functions are estimated. Basically, a production function estimates the relation between the production $(Y)$ and the input factors used, mostly labor (I), material (m) and capital (c): $Y=f(l, m, c)$. To estimate the relation between costs as the dependent variable and the outputs produced, together with the prices $(P)$ of the inputs used as the independent variables a cost function is estimated: $C=f\left(Y_{1}, \ldots, Y_{n}, P_{l}, P_{m}, P_{c}\right)$. Next, a certain functional form for the cost function should be chosen, as well as the assumptions about the error structure imposed. See for further discussion about this subject chapter 3 . 


\subsection{Explaining hospital efficiency}

The issue of hospital inefficiency becomes of more practical relevance when we know where and why inefficiency occurs. This issue is not often mentioned in hospital efficiency studies. Most studies estimating the efficiency of hospitals do not go further than estimating the efficiency of hospitals. Why (in)efficiency occurs seems to be a too complicated issue. The study examining efficiency of Dutch hospitals by Blank et al. (1998a), is extensive in its description of in- and outputs and functional forms used. Explaining why (in)efficiency exists is hardly a topic in this study of Blank et al. (1998a). Addressing explanatory variables for hospital (in)efficiency is of more practical interest, since it makes it possible to implement policy and managerial measures to improve efficiency.

The main reason that the explanations for hospital inefficiency receive less attention might be the lack of using an economic theory for these explanations. Estimating the efficiency of total hospitals implicitly uses the assumption of the (neo) classical economic theory that all participants within the organization strive towards one common goal. Although as argued in paragraph 1.2 the neo classical economic theory can be used to estimate inefficiency, neo classical economy is not designed to use for explaining reasons of efficiency within organizations. To explain reasons of efficiency within organizations, organizational (institutional) theories are more useful. The insights of the neo institutional economics, more specifically the transaction cost theory and the principal agent theory are used in this study to explain differences in efficiency. Chapters 4 and 5 of this study use these theories to explain inefficiency. Mainly based on these theories, this thesis explores some explanations for hospital inefficiency.

\section{Principal agent theory and efficiency}

In economic theory we define an agency relation as an agreement in which the principal delegates certain responsibilities to the agent for which the agent receives a certain reward (Jensen and Meckling,1976). The agency literature emphasizes that the agent has his own utility function, which he maximizes. This utility function may partly coincide with the utility function of the principal, but may in part also differ. See for a more extensive description chapter 4 . A clear example of this relation between the hospital and its clients, the patients, is found in the quality of care. Patients desire a high quality of care. However since patients have only limited information about quality it can be expected to be relatively easy for the hospital to save on quality and become more efficient. Newhouse (1994) builds on this idea. He states that differences in efficiency between hospitals are actually differences in quality. Subsequently a number of studies have tested this hypothesis. Blank et al. (1998a) use a derived measure for quality: the wages paid to nurses in Dutch hospitals. This is based on the assumption that higher paid nurses provide better quality care. Although their attempt to account for quality of care is laudable, their approach has some disadvantages. The main disadvantage is that higher wages for nurses may 
reflect a concern for higher quality. But it is more likely that higher wages for nurses are a reflection of the tightness of the regional labor market situation for nurses or the relative bargaining power of employees/employers. Another interpretation could be that nurses are being overpaid or underpaid. Other efficiency studies have taken other quality measures into account. Outcome measures, like death rates or re-admission rates have frequently been used as quality measures. As we can see in chapter 4 most studies find no relation between efficiency and quality of hospitals. Measuring quality by analyzing the outcome also has its disadvantages, as is shown in the data section in chapter 2. Therefore it is proposed to use a more process oriented quality measurement, as developed by the weekly magazine Elsevier (2004). Process indicators are less case mix dependent and better reflect the quality contribution of the hospital. In chapter 2 of this thesis we estimate the relationship between these quality measurements and efficiency.

Milgrom and Roberts (1992, p.22) define allocative efficiency of organizations as: "There is no available alternative that is usually preferred in terms of the goals and preferences of the people involved". The reference to the people involved in this definition indicates the necessity to go deeper into the organization to explain efficiency. As does the principal agent theory since it states that the interests of people within the organization differ. Therefore we abandon the assumption that the hospital is one entity that strives to one common goal. The hospital is considered as a set of individuals organized in management, facilitating departments and specialisms. It is assumed that the general board, the principal, has interests in efficient patient treatment, but the various departments, as agents, have their own interests. They strive towards efficiency of their own department, since the internal budgeting system rewards this local optimizing behavior. In chapter 4 the efficiency of individual departments is estimated. Following this the relation between the department efficiency and the efficiency of the total hospital is analyzed. The outcome of this analysis answers the question to what extent the efficiency of individual departments adds to the efficiency of the hospital.

The advantage of considering the efficiency of departments is that we only have to assume that people in one department strive towards one common goal. Within a department fewer agency problems are assumed to arise. It is investigated whether inefficiency exists at the department level, or that inefficiency is more present between departments.

\section{The make-or-buy decision and efficiency}

In TCE efficiency issues are about economizing on transaction costs. Optimal efficiency exists when transaction costs are lowest. Since transaction costs can hardly be directly measured, this implies that empirical applications of transaction costs have to rely on comparisons of different alternatives to produce the same goods. Existing comparisons are often between buying goods on the market and producing them within the organization. Williamson therefore states 
that the archetypical efficiency issue of TCE is the make-or-buy decision (Williamson, 1998). He further states that goods should be bought when asset specificity is low and be made internally when asset specificity is high. Thus from a TCE point of view an explanation of efficiency lies in the decision to make-orbuy goods.

Measuring transaction costs is not straightforward and empirical applications of TCE therefore mostly rely on comparative analyses: a comparison in costs between organizations which choose to buy or make certain goods or services. In chapter 5 we see that hospitals do not outsource their most cost-intensive departments (ward, theatre, and outpatient). It is likely that the reason for this is that the asset specificity of those departments is too high. Comparative analyses of the make-or-buy decision of these services are therefore not possible. Other patient related departments like the laboratory, the radiology and the physiotherapy department are sometimes outsourced. Non-patient treatment departments like the kitchen, the laundry and the cleaning department are more often outsourced, probably because those departments are less asset specific.

The issue to make-or-buy hospital goods is prioritized in Dutch hospitals nowadays as well. So both for theoretical and practical reasons the make-or-buy decision is a potential explanatory factor for inefficiency. The relation between transaction costs measured by the make-or-buy decision of 10 different hospital services is analyzed in chapter 5 . 


\subsection{Outline}

This thesis is organized as follows. Chapter 2 describes the methods and data used in the analyses in the subsequent chapters. Chapter 4 analyzes the efficiency of Dutch hospitals in recent years. This chapter starts with an extensive review of earlier (international) studies on efficiency of hospitals using stochastic frontier analysis. Next, a stochastic frontier analysis on Dutch hospitals is applied to answer three questions: "how efficient are Dutch hospitals and to what extent is this efficiency comparable with efficiency estimates in international studies?", "how has this efficiency changed over time?", "does the way output is measured influence the efficiency of a hospital." The following chapters (4 and 6) go deeper into the question: "why does (in)efficiency exists in hospital organizations?" Chapter 4 uses the principal agent theory to explain inefficiency. This chapter answers the questions: "Does inefficiency of hospitals reflect merely differences in quality, as for example, Newhouse (1994) states, or do efficiency and quality come together?" Next it relates the departmental efficiency to the efficiency of the entire hospital organization, as analyzed in chapter 4. By this analysis we are also able to answer the question whether hospital efficiency occurs within departments or between departments. In chapter 6 we analyze the relation between the make-or-buy decision and the efficiency of hospitals. Finally in chapter 7 this thesis ends with a discussion of the methodological, theoretical and politi$\mathrm{cal} /$ managerial implications of the analyses performed in chapters 4 to 5 . 


\section{Data and Method}

\subsection{Data}

For this study we use a database constructed from annual national hospital inquiries on financial, personnel and production data. This database consists of 108 cross-sections with in total 424 observations for the years 1998-2002.

One of the main reasons for the lack of studies examining the efficiency of hospital departments is the lack of available data to perform this kind of analysis. In the Netherlands, however, data are available at a department level. We use these data to examine the efficiency of hospital departments. Complete data are not available for all departments, therefore the number of observations per department can be less than 424 .

In this section we describe the main input and output parameters of our study.

\section{Input prices}

The usual inputs for hospitals are capital, staff and materials. First, we discuss the price of capital. It is most frequently measured by the costs of depreciation and interest divided by a measure of the size of the hospital, mostly the number of beds (see for example Zuckerman et al. , 1994 and Rosko and Chilingerian, 1999). In the Dutch capitation system for hospitals, capital for investments in buildings is provided by the government under strict regulations. Both the investments in capital and the loans for these investments have to be approved by the Dutch government. After approval these costs are financed by the Dutch government. Hospital management has thus little influence on the costs of capital. Because of this the price of capital is of little interest from a managerial perspective. Therefore, we exclude costs and prices of capital from this study.

Second, we discuss the prices of staff. We distinguish six categories of staff: administrative staff, technical staff, support staff (for example psychologists and physiotherapists), nurses, student nurses, and external staff. Since external staff is a broad category and represents less than $3 \%$ of total staff, this category is left out of this study. Administrative staff and technical staff are combined into one category to obtain a category with a significant size (about $5 \%$ of total staff). The price of staff is not directly available. It is calculated by dividing the total amount spent on staff by the number of full time equivalents. A price parameter of staff is included in the analysis of each department if the number of staff in the category is above $5 \%$ of the total number of staff.

A large part of hospital costs, approximately $60 \%$, are costs of staff, mainly wages. A debatable issue in efficiency studies is whether the price of staff is 
exogenous or endogenous to the hospital. To measure the price of staff, two approaches can be distinguished in efficiency studies. In the first approach, the average price of the individual hospital is used. In this approach wages are assumed to be exogenous to the hospital. In the second approach, the average national price is used. In this approach the difference between the average national wage and the average wage of the individual hospital is assumed to be endogenous to the hospital. This study assumes wages to be exogenous since the largest part of wages is determined by central negotiations between the labor unions and the Dutch national association of hospitals. A third, more sophisticated approach, would be to use regional prices. Regional differences in prices are exogenous to hospitals, while differences between regional and actual prices are endogenous to the hospital. Regional differences in prices can be estimated by a regression equation using time dummies and regional dummies (in the Netherlands, 27 health regions are distinguished). We have estimated those equations. The results show that for all prices in most (four or less) regions there are no significant price differences. A Hausman test used for testing the results of both the model used in this thesis and the model using regional prices showed no statistically significant difference between the models. This finding is in line with the study of Blank et al. (1998a) who use a comparable dataset for earlier years. Therefore in this study regional differences in prices are ignored.

Third, next to the prices of capital and staff, the price of materials is an input parameter. In the dataset total costs of materials are available. Separate information on prices and quantities is not available. In order to estimate the price of material, a unit price is chosen in the base year 1998. In subsequent years, the price of material is calculated by adjusting prices by the price index for government expenditure in the Netherlands (Centraal Plan Bureau, 2006b).

\section{Departments}

This study distinguishes the following direct patient treatment departments within a hospital:

1. ward;

2. outpatient department;

3. operating theatre;

4. radiology;

5. laboratory;

6. physiotherapy.

\section{Costs}

The dataset contains information on the number of staff per category per department. Of each category of staff, the average annual wage is calculated per hospital. The costs of staff per department are calculated by multiplying the average price per staff by the number of staff members. This provides the direct costs of staff per department. 
Because of differences in organizational structures and differences in calculation methods between hospitals, it is necessary to make an assumption about the allocation of the costs of indirect staff members, such as the costs of administration and technical staff. The costs of nurses and student nurses are allocated to the direct patient treatment departments based on the number of FTE nurses at the direct patient treatment departments. The costs of other staff are allocated to the direct patient treatment departments based on the total number of FTE at the direct patient treatment departments. On average, we see that the majority of costs of staff $(73.9 \%$ of total wage costs, varying from at most $74.6 \%$ in 1999 to at least $72.8 \%$ in 2002) concern costs of direct staff.

The costs of materials are not directly available per department. The Dutch national cost-calculation scheme for calculating the costs of materials per department is used. This calculation scheme has been developed to introduce case mix based funding in the Netherlands. It provides guidelines to allocate costs of materials to direct patient treatment departments. For example, allocation of the costs of cleaning is based on the number of square meters per department. Since it is obligatory for hospitals to have an extensive cost administration we are able to use a detailed allocation.

Table 1: Cost allocation scheme of material costs

\begin{tabular}{|c|c|c|c|}
\hline Costs & Allocation & $\begin{array}{l}\text { Average costs } \\
\text { as } \% \text { of total costs }\end{array}$ & $\begin{array}{c}\text { SD costs } \\
\text { as } \% \text { of total costs }\end{array}$ \\
\hline Food & $\begin{array}{l}50 \% \text { ward, } 50 \% \text { number } \\
\text { of FTE }\end{array}$ & $1.9 \%$ & $0.6 \%$ \\
\hline Cleaning beds & Ward & $1.4 \%$ & $0.4 \%$ \\
\hline Other cleaning costs & Number of FTE & $1.8 \%$ & $0.8 \%$ \\
\hline General administration costs & Number of FTE & $6.6 \%$ & $1.4 \%$ \\
\hline Patient research & $\begin{array}{l}50 \% \text { radiology, } 50 \% \\
\text { theatre }\end{array}$ & $4.5 \%$ & $1.3 \%$ \\
\hline Medicine & Pharmacy & $4.1 \%$ & $1.5 \%$ \\
\hline $\begin{array}{l}\text { Other patient related products } \\
\text { (blood, implants) }\end{array}$ & Operating theatre & $5.6 \%$ & $1.5 \%$ \\
\hline Material therapy costs & Physiotherapy & $0.0 \%$ & $0.1 \%$ \\
\hline Material nursing costs & Ward & $0.4 \%$ & $0.4 \%$ \\
\hline Other patient related costs & Number of FTE & $1.7 \%$ & $1.1 \%$ \\
\hline $\begin{array}{l}\text { Patient related instruments and } \\
\text { machines }\end{array}$ & $\begin{array}{l}50 \% \text { ward, } 50 \% \\
\text { operating theatre }\end{array}$ & $1.9 \%$ & $0.6 \%$ \\
\hline Patient activity costs & Ward & $0.1 \%$ & $0.3 \%$ \\
\hline Energy & Number of FTE & $2.9 \%$ & $0.8 \%$ \\
\hline $\begin{array}{l}\text { Depreciation patient related } \\
\text { machines }\end{array}$ & $\begin{array}{l}50 \% \text { radiology, } 50 \% \\
\text { operating theatre }\end{array}$ & $1.4 \%$ & $1.0 \%$ \\
\hline Depreciation inventory & Number of FTE & $4.5 \%$ & $1.2 \%$ \\
\hline
\end{tabular}

Source: Enquête Jaarcijfers Nederlandse Vereniging van Ziekenhuizen 1998-2002.

Table 1 contains an overview of the percentage of costs of material per department. In general, about $40 \%$ of total costs are costs of materials. In the opera- 
ting-theatre and radiology department the costs of materials are more than $50 \%$ of total costs. The standard deviation is relatively low compared to the average. No large differences between hospitals in the percentage of material costs per department are found. Including the allocated costs, the six departments distinguished in this study cover, on average, more than $90 \%$ of total hospital costs (excluding costs of capital). As argued before the costs of capital for buildings are left out of the analysis. This implies that on average $12 \%$ of the total costs are left out of the analysis.

\section{Outputs}

\section{Hospital}

To measure the output of hospitals five output parameters are used. First DRG weighted admissions are used. Although the DRG system was developed more than 25 years ago by Fetter et al. (1980), this way of measuring output is new for Dutch hospitals. In 2002, a Dutch version of the International Refined (IR)-DRG grouper was developed, which is used in this study. The Dutch version of the IRDRG grouper uses the International Classification of Diseases (ICD)-9 diagnosis codes and the Dutch Classificatie Van Verrichtingen (CVV) procedure codes which are comparable to ICD procedure codes.

This study uses the Dutch DRG cost-weights calculated by Vandermeulen et al. (2004) for both admissions and day-care admissions. Since no DRGs exist for outpatient visits, the non-weighted number of first outpatient visits is used as an output measure as well.

Besides curing patients, hospitals have two other important outputs: research and teaching. Research is mainly done by university hospitals, which are excluded from this study. Teaching on the contrary is performed by 83 of the 108 non-university hospitals represented in our database. Teaching is measured by the average number of medical specialists who are trained in the hospital.

As a last output variable a dummy for the existence of an emergency department is included. A dummy variable is chosen for two reasons. First, the availability of the emergency department and the number of specialists and nurses working there is important in itself, even if no patients turn up. Second, the registration of the production of emergency departments is of poor quality and therefore underestimated by the available data.

\section{Departments}

The outputs of similar departments in different hospitals are more homogeneous than the outputs of total hospitals. The outputs of hospital departments are equal to the outputs charged to patients and insurance companies. Therefore the outputs per department used in this study are reliable and valid measures. The outputs per department are briefly discussed. 


\section{Ward}

The most straightforward production of the ward is the number of ward days. Ward days can be distinguished in an inpatient setting, a day-care setting and an intensive care setting. Since previous studies have shown that the workload differs between the first ward day and the following ward days, four different categories of ward days are distinguished:

- $\quad$ first ward days;

- following ward days;

- day-care ward days;

- $\quad$ intensive care ward days.

The outputs require inputs from all four different categories of staff. Therefore four input prices are distinguished as input measures for the ward.

\section{Outpatient department}

Most patients start their treatment in a hospital by visiting the outpatient department. The follow-up treatments and checks are also performed in the outpatient department. Small operations, such as vasectomy, are increasingly being performed at the outpatient department as well. Summarizing, we distinguish three different output measures:

- $\quad$ first outpatient visits;

- $\quad$ other outpatient visits;

- small operations.

The operations are weighted by the operation's tariff. These tariffs are determined by the Dutch Central Organization of Tariffs (CTG). In the outpatient department staff mostly consists of general staff, support staff and nurses. The prices of these three kinds of staff are used for this department.

\section{Operating theatre}

Most operations are performed in the operating theatre. We use the weighted number of operations performed as an output measure of the operating theatre. These operations are weighted by its tariffs. In the operating theatre staff inputs mostly consist of nurses, general staff and support staff. The prices of these three categories of staff are used for this department.

\section{Radiology}

The radiology department produces X-rays. We use the total number of X-rays, including MRI- and CT-scans as an output measure. The $\mathrm{X}$-rays are weighted by its tariffs. In the radiology department the staff in most hospitals consists of general staff and support staff. The prices of these two categories of staff are used for this department.

\section{Laboratory}

Two types of laboratories can be distinguished: the laboratory for clinical chemistry and the pathology laboratory. We only include the laboratory of clinical chem- 
istry in this study, because too few hospitals possess a pathology laboratory. The outputs for the laboratory are lab-tests. The lab-tests are weighted by its tariffs. In the laboratory the staff consists in most hospitals of support staff and general staff. The prices of these two categories of staff are used for this department.

\section{Physiotherapy}

The physiotherapy department consists mainly of occupational and physical therapists. The main output of the physiotherapy department is hours of individual physiotherapeutic treatment. Next to individual physiotherapeutic treatments, there are other outputs produced, such as physiotherapeutic research and physiotherapeutic treatment in groups. These outputs are taken together and weighted by its tariff and form one output measure. In the physiotherapy department the staff consists in most hospitals of support staff and general staff. The prices of these two categories of staff are used for this department.

\section{Quality}

There are few indicators that are widely recognized as measures of quality of hospitals. These indicators mostly measure outcome and include, for example, the number of readmissions, death-rates and complications. In fact, they measure quality as the outcome of the medical process. Davies and Crombie (1995) give two reasons why outcomes as a measure of quality should be treated with care. First, outcome indicators depend on case mix. Hospitals treating more complicated diseases have higher death- and complication-rates, irrespective of their quality. When the quality of the whole hospital is the unit of measurement case mix, adjusted quality measures are needed. Second, outcome indicators have less than optimal validity and reliability as they are often hard to measure. Third, as shown by Mant and Nicks (1995) outcome indicators can fail to reveal process differences. For example, big differences in processes for the treatment of acute myocardial infarction are not found when comparing death rates. Even when a process is known to be better, death-rates do not show these differences.

Because of the disadvantages of outcome indicators, process indicators have become more important as a measure of quality of health care. In this study we use process indicators as measures of quality. We use the quality measures developed by the Dutch weekly paper Elsevier (2004). Elsevier is a large Dutch news weekly, comparable to Time or Newsweek. Elsevier has measured hospital quality since 1997. Between 1997 and 2001, only half or less of Dutch hospitals were included in the study. Since 2002 the percentage of participating hospitals has increased until approximately $80 \%$ of all Dutch hospitals. Quality is measured by a survey conducted among general practitioners, medical staff, nurses and managers of the hospital. These stakeholders are best informed about the quality of the hospital. They can help to reduce the information asymmetry between the patient and the hospital. Each of these stakeholders is asked a number of questions about the hospital they are involved with. On every question 
they are asked whether the situation is appropriate to their hospital. A hospital receives one point if on a positive item $20-32 \%$ of the respondents perceives it as being appropriate, 2 points if between $33 \%$ and $49 \%$ of the respondents finds the situation appropriate and 3 points if $50 \%$ of more finds the situation appropriate. On weak items the same holds with negative scores. In 2004 the survey is divided into 4 factors:

- $\quad$ Medical and nursing quality (quality of the emergency department, operating theatre, nursing staff).

- $\quad$ Organizational quality (well organized and a good employer).

- Quality of care process (cooperation with general practitioners and nursing homes).

- Quality of patient care (patient friendly).

Factor 1: Medical and nursing quality is measured by 6 positively and 2 negatively formulated questions. The score on this factor is therefore between -6 and 18. Questions in this part of the survey refer to medical and nursing expertise, quality of the operating theatre and medical mistakes.

Factor 2: Organizational quality is measured by 6 positively and 6 negatively formulated questions. The score on this factor is therefore between -18 and +18 . Questions on this part of the survey refer to: quality of management, quality of $\mathrm{IT}$, preparation for changing demographic factors (growing age of the population), bad financial situation, internal problems, and lack of staff.

Factor 3: Quality of the care process is measured by 6 positively and 3 negatively formulated items. The score on this factor is therefore between -9 and 18 . Questions in this part of the survey refer to: cooperation with general practitioners and nursing homes, good coordination with general practitioners, slow and arrogant medical specialists.

Factor 4: Quality of patient care is measured by 8 positively and 2 negatively formulated questions. The score on this factor can therefore be between -6 and 24. Questions in this part of the survey refer to: being friendly to the patient, appreciated by the patient, friendly staff, patient friendly planning and long waiting lists.

In 2004 the questionnaire was sent to 5578 respondents, of which $25 \%$ replied. At least 15 respondents are required before the results of a hospital are presented. In earlier years fewer factors and questions were used. Moreover in 2004 more hospitals are included. Because of these two reasons we use the outcomes of the year 2004 as quality measures in this study. Using the quality measure of just one year comes with the disadvantage of assuming quality does not change over time. We prefer using the better quality of data in 2004 over using a time varying measure which is available for fewer hospitals and is of lesser quality. We use all four quality factors as efficiency explaining variables in this study. 


\section{Size}

In most studies hospital size is measured by the number of beds, the same holds for this study. Three groups of hospitals are distinguished in this study, small, large and medium sized hospitals. Small hospitals have less than 250 beds, large hospitals have more than 600 beds, medium-sized hospitals are in between.

\section{Asset specificity, uncertainty and the importance of quality}

Two aspects of asset specificity, human asset specificity and physical asset specificity of the following hospital services are measured by Coles and Hesterly (1998a): respiratory therapy, laboratory, housekeeping, laundry, computer services, foodservices, maintenance, physical therapy, landscaping, outpatient services, emergency room services, pharmacy services and radiology. Human asset specificity is measured by the time it takes to achieve a satisfactory performance level for an individual with previous experience in the service at another hospital. Physical asset specificity is measured by the percentage of time that equipment in that department is not routinely used in the provision of the service at other hospitals.

Uncertainty is measured by Coles and Hesterly (1998a) as the investments in new technology necessary to develop the service. For example, the probability of investments in X-rays as a result of technological developments is higher than for the laundry. We use this measure of Coles and Hesterly (1998a) as a proxy for uncertainty. The importance of quality is measured by a dummy variable for medical services, pharmacy, laboratory and physiotherapy. The importance of good quality for these services is higher than for non-medical services, since mistakes in the medical services will lead to more serious harm compared to non-medical services.

For human and physical asset specificity we use the measures of Coles and Hesterly (1998a) as an operationalization. As a general measure of asset specificity we further make the distinction between medical services (laboratory, physiotherapy and pharmacy) and non-medical services. The first are more asset specific than the second.

\section{Outsourcing: make-or-buy}

For the following hospital services data on make-or-buy decisions are available: salary administration, administration, cleaning inside, laundry, kitchen, maintenance (building), education, laboratory, pharmacy and physiotherapy. The available data are administrative data. Hospitals administer whether $0 \%$ (1), $1 \%$ to $25 \%$ (2), $26 \%$ to $50 \%$ (3), $51 \%$ to $75 \%$ (4) or $76 \%$ to $100 \%$ (5) of the service is contracted by an outside supplier. 


\section{$2.2 \quad$ Method}

The theory of the firm provides numerous possibilities for modeling the production structure and economic behavior of institutions. Blank (see for example Blank et al., 1998a, Blank et al., 1998b and Blank and Merkies, 2004 ) especially has extensively implemented and tested numerous of these theories and its assumptions in Dutch hospitals. The main choices that are to be made in this modeling are:

- The economic behavior of the organization, including the economic constraints.

- The modeling of the function estimated.

- The measurement of efficiency.

Ad 1: The economic behavior of the organization.

As almost all other international studies on efficiency this study assumes costminimizing behavior for hospitals. Cost minimizing behavior implies that hospitals minimize costs where the production is given. In the Dutch case this assumption can be defended by the financing/economic situation of hospitals between 1998 and 2004. Hospitals receive a budget based on appointments made beforehand. The number of patients treated (production) is only slightly endogenous to the hospital management and is therefore be assumed to be given. Blank et al. (1998a) conclude that Dutch hospitals mainly aim for cost-minimization. Of course this assumption does not completely hold. Blank and Merkies (2004) study the validity of this assumption and conclude that this assumption cannot be justified. Next they state that for a proper description of hospital management behavior further research is needed. This study does not aim to study the best description of hospital behavior and uses the best available alternative costminimizing behavior.

Ad 2: The modeling of the function estimated

Different specifications for a cost-model are possible. The main ones are the Ces function, the Leontieff function, the translog function and the Cobb-Douglas function. The Cobb-Douglas is a simplification of the translog function. Based on three criteria we started by choosing a translog function. First, hospital costs are mostly lognormal distributed. Second, because of the flexibility of the translog function. Third, we want to perform this study as good as possible in conjunction with other hospital efficiency studies. When doing our analyses we changed to using the Cobb-Douglas cost function. In most studies the translog cost function, which is an extension of the Cobb-Douglas cost function, is frequently used (Linna, 1998 and Rosko and Chillingerian, 1999). The advantage of the translog cost function over the Cobb-Douglas function is its flexibility. Whether to use translog or Cobb-Douglas is an issue addressed by a number of studies. Some studies in the hospital sector, for example Rosko (2001) conducts a formal test of the Cobb-Douglas specification and reject this specification. Mortimer and Peacock (2002) found no statistical justification for the translog function. We estimated a translog model as well. Some of these models did however not 
converge. As argued by Mortimer and Peacock (2002) Cobb-Douglas is better because of parsimony. Latruffe et al. (2004) further argue that: "Translog tends to be over specified when limited data are available".

\section{Ad 3: The measurement of efficiency}

To estimate efficiency frontier techniques are nowadays mostly used. Instead of classical cost functions, frontier techniques compare firms (hospitals) with the best instead of the average. In short two main techniques for frontier estimation are possible. First a non-parametric method, DEA. This study uses a parametric technique: SFA as developed by Aigner et al. (1977). Which method to choose is not clear and depends on the design and the goals of the study. Chapter 4 provides a brief overview of these two techniques in the hospital sector.

\section{Further assumptions}

This study uses panel data. The use of panel data in a stochastic frontier model has a number of methodological advantages over cross-section data. Linna (1998) shows that hospital efficiency estimates are more plausible when using panel data compared to cross-section data. Further Jondrow et al. (1982) show that consistency issues arise within individual efficiency scores in a cross-section approach.

Based on these assumptions equation 1 provides a general description of the (cost) equation used in this study to estimate efficiency.

$$
\begin{aligned}
& \ln \mathrm{TC}_{k, i t}=\alpha_{k, 0}+\sum_{l=1}^{m_{k}} \alpha_{k, l} Y_{k l, i t}+\sum_{j=1}^{q_{k}} \beta_{k, j} \ln P_{j, i t}+\varepsilon_{k, i t} \\
& \forall k=0, \ldots, 6 \forall i=1, \ldots, N_{k} \quad \forall t=1, . ., T_{k, i}
\end{aligned}
$$

Equation above 1 is a cost function (the explanation of the parameters used is provided below equation 2). Cost functions must meet a number of requirements

1. Costs are always higher than zero.

2. If prices increase, costs do not decrease $\beta_{k, j} \geq 0 \forall k, j$.

3. If a price increases the costs will at most increase with the increase of the price multiplied by the share of the concerning production factor.

4. Cost functions must be linearly homogeneous in input prices. If all prices increase with the same percentage the costs must increase with the same percentage: $\sum_{j} \beta_{k, j}=1 \forall k$.

Most of these requirements might look trivial. They can be implemented before estimating the cost equation but can also help us to evaluate the estimated functions, which will be done for requirements 1 to 3 . Requirement 4 is implied by dividing all the money values with one of the price parameters (see for example Kumbhakar and Lovell, 2001). The results are independent on which parameter is chosen. We choose to use the price of material as denominator, see equation 2. 
$\ln \frac{T C_{k, i t}}{P_{n, i t}}=\alpha_{k, 0}+\sum_{l=1}^{m_{k}} \alpha_{k, l} Y_{k l, i t}+\sum_{j \neq n}^{q_{k}} \beta_{k, j} \ln \frac{P_{j, i t}}{P_{n, i t}}+\varepsilon_{k, i t}$

$\forall k=0, \ldots, 6 \forall i=1, \ldots, N_{k} \forall t=1, . ., T_{k, i}$

$T C_{k, i t}=$ costs of department $\mathrm{k}$ in hospital $\mathrm{i}$ in year $\mathrm{t}$

$\forall k=1, \ldots, 6 i=1, \ldots, N_{k}, t=1, \ldots, T_{k, i}$

$Y_{k l, i t}=$ production of product $\mathrm{I}$ in department $\mathrm{k}$ for hospital $\mathrm{i}$ in year $\mathrm{t}$

$\forall k=0, \ldots, 6, i=1, \ldots, N_{k}, t=1, \ldots, T_{k, i}, I=1, \ldots, m_{k}$

$P_{j, i t}=$ price of input factor $\mathrm{j}$ in department $\mathrm{k}$ for hospital $\mathrm{i}$ in year $\mathrm{t}$

$\forall k=0, \ldots, 6, i=1, \ldots, N_{k}, t=1, \ldots, T_{k, i}, j=1, \ldots, q_{k}$

$P_{n, i t}=$ price for material expenditure at time $t$ in hospital $\mathrm{i}, \forall t=1, \ldots, 5, i=1, \ldots, N_{k}$

$\varepsilon_{k, i t}=$ error term for department $\mathrm{k}$ in hospital $\mathrm{i}$ at time $\mathrm{t}$

$\forall k=1, \ldots, 6 \quad i=1, \ldots, N_{k}, t=1, \ldots, T_{k, i}$

$\alpha_{k, 0}, \alpha_{k, l}, \beta_{k, j}$ are parameters to be estimated

$\mathrm{k}=$ counter for departments, $\mathrm{k}=0$ for the total hospital

$\mathrm{I}=$ counter for products

$\mathrm{m}_{\mathrm{k}}=$ number of products for department $\mathrm{k}, \mathrm{m}_{0}=6$ for model 1 and 5 for model 2 ,

$m_{k}=4$ for the ward, 3 for the outpatient department, 1 in the other departments

$\mathrm{j}=$ counter for prices

$\mathrm{q}_{\mathrm{k}}=$ number of price parameters included for department $\mathrm{k}$, see data section

$\mathrm{i}=$ counter for observations

$\mathrm{N}_{\mathrm{k}}=$ number of observations for department $\mathrm{k}$

$\mathrm{t}=$ counter for price period

$\mathrm{T}_{\mathrm{k}, \mathrm{i}}=$ number of time period available for department $\mathrm{k}$ and hospital $\mathrm{i}$.

A stochastic frontier approach is based on the assumption that the error term can be divided in a random term and a term representing inefficiency see equation 3.

$\varepsilon_{k, i t}=u_{k, i}+v_{k, i t} \forall k=0, \ldots, 6$

$\mathrm{v}_{\mathrm{k}, \mathrm{it}} \sim \mathrm{N}\left(0, \sigma_{\mathrm{v}, \mathrm{k}}^{2}\right)$ represents random statistical noise

$\mu_{k, i} \sim N^{+}\left(\mu, \sigma_{\mu, k}^{2}\right)$ represents time-invariant cost inefficiency.

The specification in formulas 2 and 3 leads to a stochastic frontier approach with efficiency varying for each department per hospital and the total hospital, but assumed to be constant over time. To incorporate time-varying efficiency the parameterization introduced by Battese and Coelli (1992) is used, see equation 4.

$$
\begin{aligned}
& u_{k, i t}=\eta_{k, i t} u_{k, i}=\left\{\exp \left[-\eta_{k}\left(t-T_{i}\right)\right]\right\} u_{k, i} \\
& \forall k=0, \ldots, 6 \quad i=1, . . N_{k} \quad t=1, . ., T_{k, i}
\end{aligned}
$$


$u_{k, i t}=$ time variant inefficiency

$\eta_{k}=$ parameter to be estimated

The parameterization in equation 4 requires one additional parameter to be estimated. This parameterization allows for the efficiency parameter $\mu_{k, i t}$ to remain constant, increase or decrease over time. The $\eta_{k}$ parameters describe whether the efficiency of a department has increased $\left(\eta_{k}>0\right)$ or decreased $\left(\eta_{k}<\right.$ $0)$.

\section{Estimation}

The program frontier 4.1 developed by Coelli (1996) is used to estimate the parameters in equations 1 to 4 . This program uses a maximum likelihood approach with OLS estimates as starting values. According to Schmidt and Sickles (1984) the advantage is that these ML-estimators are consistent and asymptotically efficient as $\mathrm{N} \rightarrow \infty$, regardless of $\mathrm{T}$ for stationary variables. Another advantage of the maximum likelihood approach is the ability to perform statistical tests. To imply the ML-procedure, some assumptions are necessary about the distribution of $v_{k, i t}$ and $\mu_{k, i}$. We assume that

1. $\mathrm{v}_{\mathrm{k}, \mathrm{it}} \sim \mathrm{N}\left(0, \sigma_{\mathrm{v}, \mathrm{k}}^{2}\right)$

2. $\mu_{k, i} \sim N+\left(\mu, \sigma_{\mu, k}^{2}\right)$

3. $v_{k, i t}$ and $\mu_{k, i}$ are distributed independently of each other and the regressors.

The first and third assumption are similar to the assumptions made in 'regular' ML-estimation. The assumption for the distribution of $\mu_{k, i}$ is the subject of a number of studies. Mostly either a gamma distribution or a positive normal distribution is assumed. There is no theoretical motivation to prefer one or the other.

The estimation procedure is performed for the total hospital and the six different departments independently. To improve the estimation procedure, instead of maximizing with respect to the parameters $\sigma^{2}{ }_{\mu}$ and $\sigma^{2}{ }_{v}$, the program maximizes the likelihood equation using the parameters $\gamma$ and $S^{2}$, where

$\gamma=\sigma_{\mu}^{2} /\left(\sigma_{u}^{2}+\sigma_{v}^{2}\right)$

$S^{2}=\sigma_{v}^{2}+\sigma_{u}^{2}$.

Testing the significance of the parameter $\gamma$, i.e. testing the significance of $\sigma^{2}{ }_{\mu}$, shows whether a stochastic frontier function is required at all.

After this maximization procedure, estimators can be derived for $\sigma^{2}{ }_{\mu}$ and $\sigma^{2}{ }_{v}$ from equation 5 .

The efficiency for department $\mathrm{k}$ in hospital $\mathrm{i}$ at time $\mathrm{t}$ can be estimated by 
Equation 6 provides the efficiency estimation for both total hospital organizations and its departments.

\section{Explaining efficiency}

This section described the incorporation of variable explaining efficiency of which the results are just described in chapter 4 and 5: quality and the efficiency of departments in chapter 4 and the make-or-buy decision in chapter 5 . The advantage of describing these methods here is that all the methods used are gathered together in this chapter. This comes with the disadvantage that some referrals to further chapters are necessary.

To explain efficiency, Battese and Coelli (1995) developed a one stage model. In this model the following assumptions are made

1. $\mathrm{v}_{\mathrm{it}} \sim \mathrm{N}\left(0, \sigma_{\mathrm{v}}^{2}\right)$

2. $\mu_{0, \mathrm{i}} \sim$ truncations at zero of the $\mathrm{N}\left(\mathrm{m}_{\mathrm{it}}, \sigma^{2}{ }_{\mu}\right)$

3. $\quad v_{\mathrm{it}}$ and $\mu_{\mathrm{i}}$ are distributed independently of each other and the regressors

$$
m_{i t}=\sum_{p=1}^{N_{p}} z_{p, i t} * \delta_{p}
$$

$\mathrm{z}_{\mathrm{p}, \mathrm{it}}$ are explaining variables which influence the efficiency of the hospital

$\delta_{p}$ are parameters to be estimated

$p$ counter for products

$\mathrm{N}_{\mathrm{p}}$ number variables explaining efficiency.

Note that assumptions 1 and 3 are the same as before and that subscript $\mathrm{k}$ is not necessary, since only the efficiency of the total hospital is used $\left(\sigma^{2}{ }_{v}=\sigma_{\mu}^{2}\right.$ and $\sigma_{\mu}^{2}$ $\left.=\sigma_{0, \mu}^{2}\right)$. Assumption 2 is new and is the key assumption for the one stage model of Battese and Coelli (1995).

In the analysis in chapter 5 we were able to estimate the model described by equations 2 to 7 in the following way. The set of equations (5) and (6) is estimated for the 10 hospital services separately. We use two models which are slightly different:

In the first model in chapter 5 we include four $\left(N_{p}=4\right)$ explanatory variables:

$\mathrm{z}_{1, \mathrm{it}}=$ time

$z_{2, \text { it }}=$ dummy for small hospitals ( 1 if hospital is small, 0 otherwise)

$z_{3, \mathrm{it}}=$ dummy for medium sized hospitals ( 1 if hospital is medium sized, 0 otherwise)

$\mathrm{z}_{4, \mathrm{t}}=$ amount of outsourcing. 
The parameter estimate $\delta_{4}$ is of primary importance, because this parameter provides information about the relation between efficiency and the amount of the service that is outsourced. The dummy variables for the size of a hospital are included in the analysis as covariates to correct for the general differences in efficiency between small, medium sized and large hospitals. Time is included in the analysis as a covariate to correct for differences in efficiency between years. As the parameters $\delta_{1}$ to $\delta_{4}$ determine inefficiency, a negative parameter estimate means there is a positive relation between the variable and efficiency.

In the second model in chapter 5 we include $6\left(N_{p}=6\right)$ explanatory variables respectively for each service:

$\mathrm{z}_{1, \mathrm{it}}=$ time

$z_{2, \mathrm{it}}=$ dummy for small hospitals ( 1 if hospital is small, 0 otherwise)

$\mathrm{z}_{3, \mathrm{it}}=$ dummy for medium sized hospitals ( 1 if hospital is medium sized, 0 otherwise)

$\mathrm{z}_{4, \mathrm{it}}=$ amount of outsourcing ${ }^{*} \mathrm{z}_{2, \mathrm{it}}$

$z_{5, \text { it }}=$ amount of outsourcing ${ }^{*} z_{3, \text { it }}$

$\mathrm{Z}_{6, \mathrm{it}}=$ amount of outsourcing * dummy for large hospitals ( 1 if hospital is large, 0 otherwise).

The most relevant parameters here are $\delta_{4}$ to $\delta_{6}$. These parameters estimate the effect of the amount of outsourcing of small, medium sized and large hospitals on (in)efficiency respectively.

For the analysis in chapter 4 we estimated this one stage model as well. For our data this model does not lead to convergence. Therefore we decided to use a less sophisticated two stage model. The first stage is the model described before in equations 2 to 4 . In the second stage we perform a regression analysis to explain efficiency. We regress the expected value of the efficiency parameters (equation 6 ) on our set of quality variables.

$$
\begin{aligned}
& \mathrm{Eff}_{0, i}=\alpha_{0}+\sum_{j=1}^{4} \beta_{j} \text { quality }_{j, i}+\varepsilon_{i}(8) \\
& \mathrm{Eff}_{0, i}=\sum_{i=1}^{T_{i}} \mathrm{Eff}_{0, i t} / T_{i}, \quad \forall i=1, \ldots, \mathrm{N}_{0}
\end{aligned}
$$

Quality $_{\mathrm{j}, \mathrm{i}}$ is the quality measure for the $\mathrm{j}$-th quality variable for the i-th hospital.

$\alpha_{0}, \beta_{j}$ are parameters to be estimated.

We perform a comparable analysis for the departments:

$\mathrm{Eff}_{0, i t}=\alpha_{0}+\sum_{k=1}^{6} \beta_{k} \mathrm{Eff}_{k, i t}+\varepsilon_{i, t}$ (9) 


\title{
3. Hospital Efficiency: the effects of time and case mix
}

\begin{abstract}
The rapid growth of health care costs calls for more efforts to increase efficiency. This search for efficiency in the hospital sector has led to a number of studies in health economics examining efficiency. Most of the recent studies are based on frontier methods, both parametric and non-parametric. This study starts with a short overview of parametric frontier studies in the hospital sector followed by a stochastic frontier approach based on panel data to measure the efficiency of Dutch hospitals. A time-varying efficiency component is included in the study. Two different models are estimated. The first model measures output based on the classical budget parameters (admissions, patient days and first outpatient visits) for Dutch hospitals. The second model measures output based on case mix weighted admissions, which are not previously available for Dutch hospitals. First the results show that major differences exist between the parameter estimates of the 2 models. These differences are found both on individual and group level. When case mix differences are taken into account the average efficiency is $84 \%$, compared to $77 \%$ in the other model. This underlines the necessity to take case mix into account, when measuring efficiency and when reimbursing hospitals. Further we see that, when output is measured by the number of patients, Dutch hospitals have become less efficient over time. When weighted for case mix differences the average efficiency increases compared to the first model, but a decreasing efficiency over time is still found.
\end{abstract}

Keywords: hospital efficiency; stochastic frontier; time-varying efficiency; case mix. 


\subsection{Introduction}

The costs of health care in the Netherlands have increased rapidly over the last ten years. With an annual budget of more than $€ 10$ billion per year it is understandable that the hospital sector is concerned about cost effectiveness. In this plethora of cost effectiveness studies, there is a small amount of literature that is concerned with the efficiency of hospitals.

Studies of hospital efficiency are hampered by the fact that - contrary to most other areas in health care - effectiveness cannot be studied within a controlled environment or random trial. We therefore have to rely on variations between hospitals or within hospitals over time to assess hospital efficiency. This implies that it is more difficult to identify causal effects in hospital behavior and that sometimes effects may be caused by different processes that can not always be disentangled in a cross-sectional or longitudinal setting. In recent health economic literature more advanced econometric tools, like SFA independently introduced by Aigner et al. (1977) and Meussen and van den Broeck (1977) and DEA, have been used to determine the inefficiency of hospitals. These approaches also incorporate the possibility to measure efficiency in a panel data setting. Zuckerman et al. (1994), Skinner (1994), Newhouse (1994) and Dor (1994) broadly introduced SFA in the hospital sector in the Journal of Health Economics in 1994. In the Netherlands the classical econometric approaches using cost and production functions have been applied to hospitals in the late seventies by van Aert (1977) and van Montfort (1980), but no SFA has been applied yet.

The application of SFA in hospitals has led to more than 16 studies as reviewed by Hollingsworth (2003). SFA has however, not been applied to Dutch hospitals yet. The central aim of this chapter is to gather insight in the possibilities of SFA to estimate efficiency of Dutch hospitals and to apply these insights for the Dutch hospital sector. To gather this insight the next section contains a review of the international literature and the most important lessons to be learned from this literature. This is followed by an application of SFA on Dutch general hospitals. 


\section{Review of the literature}

Since the development of cost functions, these functions have also been applied in the hospital sector. These early approaches could only make comparisons with the average cost output relationship, not with the best. These studies focus on allocative efficiency. In the Netherlands too, cost functions were extensively applied in the hospital sector by van Aert (1977) and van Montfort (1980). Since the development of frontier techniques, it is now possible to perform parametric, stochastic frontier analysis (first introduced in 1977) to arrive at an estimation of the efficiency of individual hospitals and an estimation of the average efficiency of the sector. However, the introduction of these frontier techniques in the hospital sector has taken longer. Table 2 gives an overview of the most recent studies using frontier estimation techniques (both parametric and non-parametric) to estimate the cost efficiency of hospitals. The aim of this table is to give an overview of the papers that provide lessons for answering the questions posed in our study. Table 2 contains studies performed in the hospital sector since 1994 using parametric frontier techniques. 


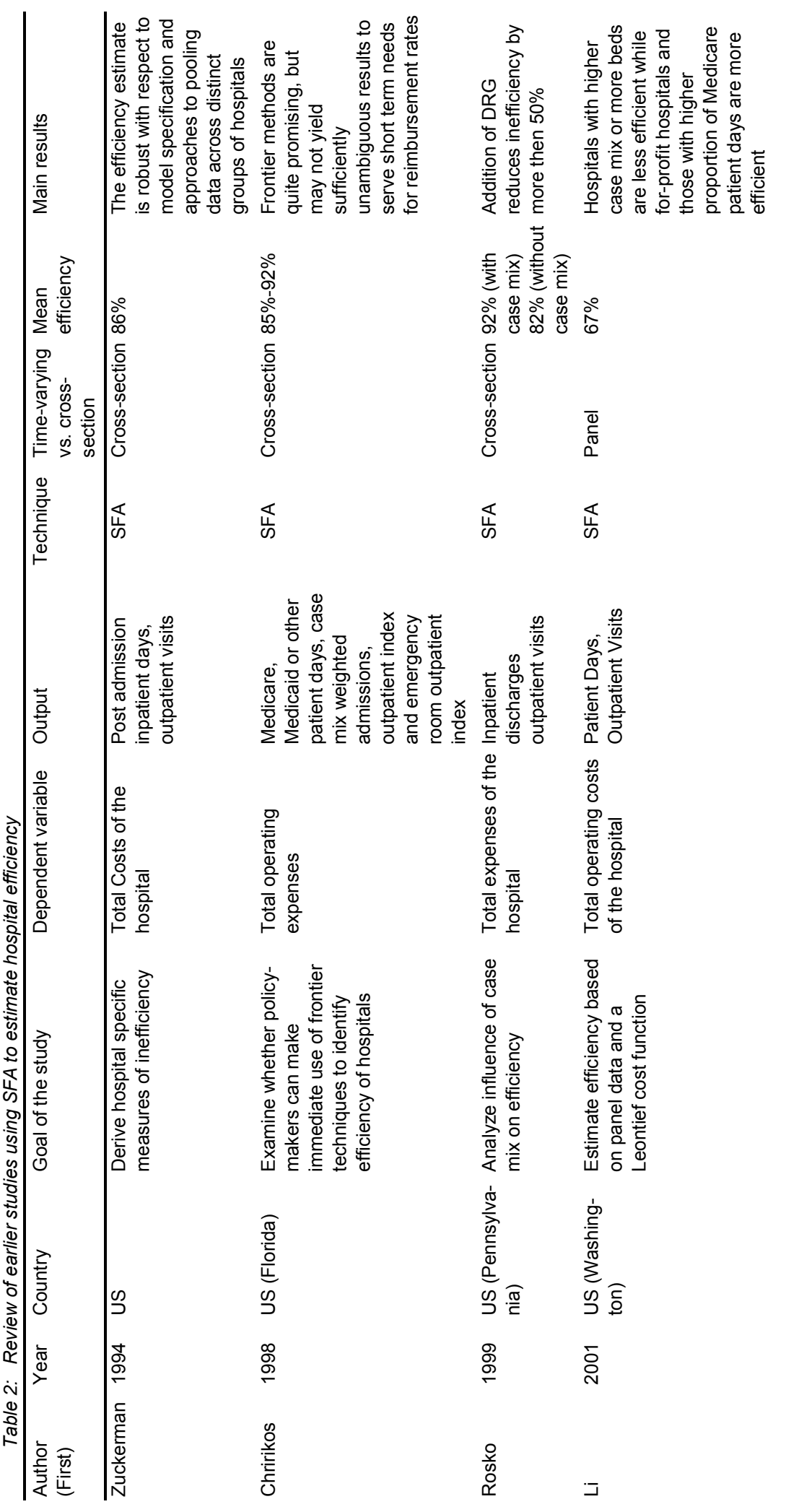




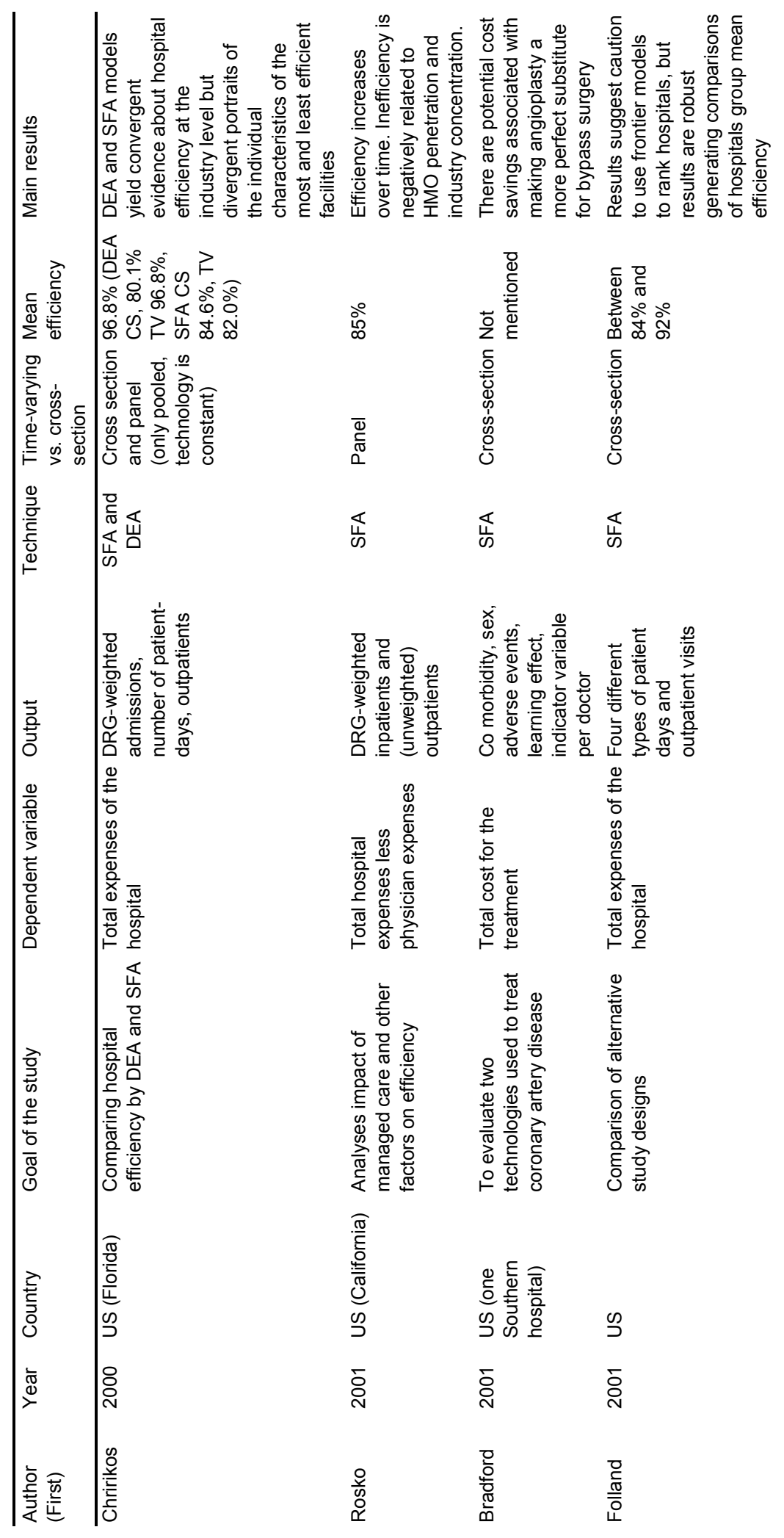




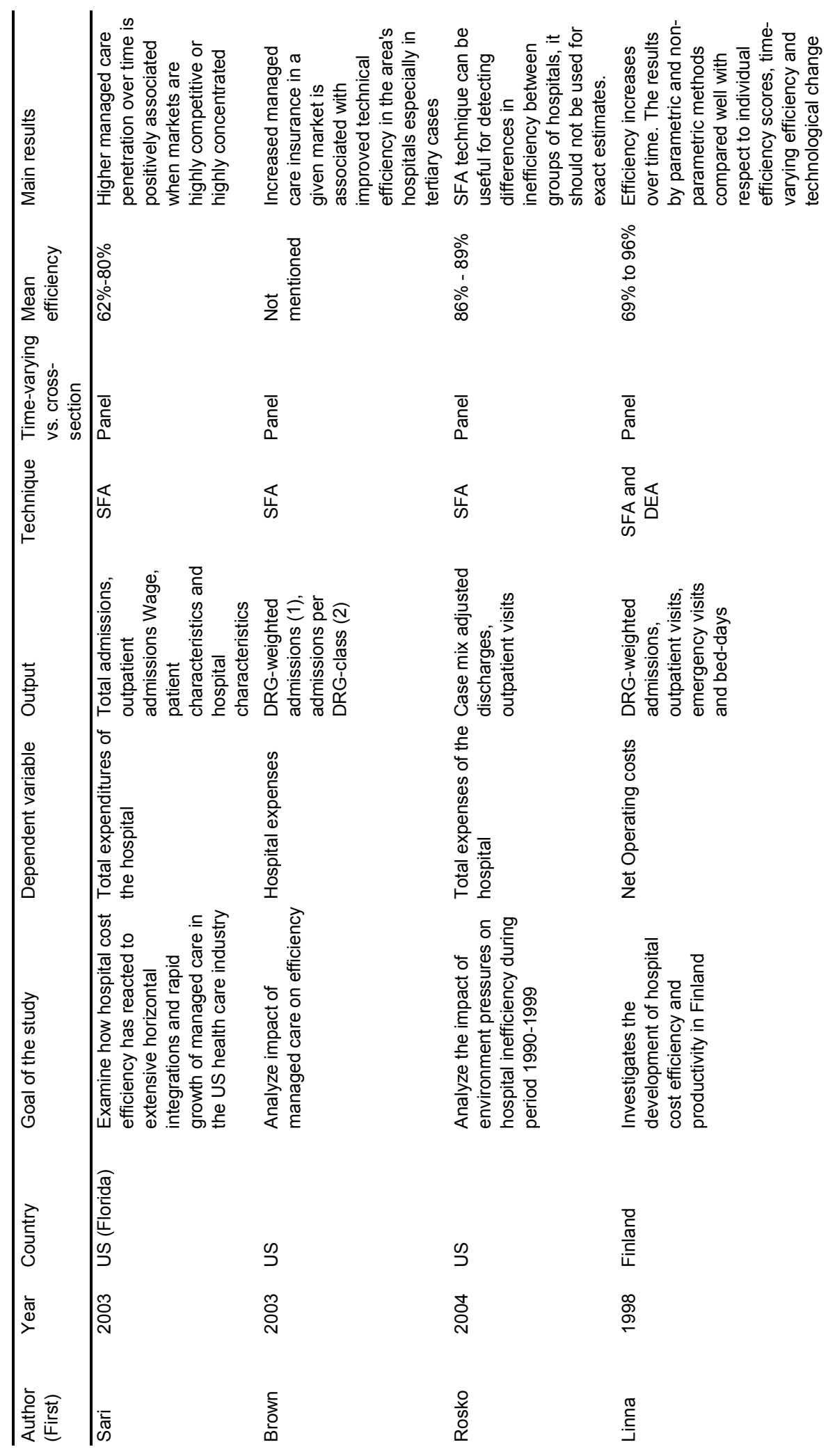




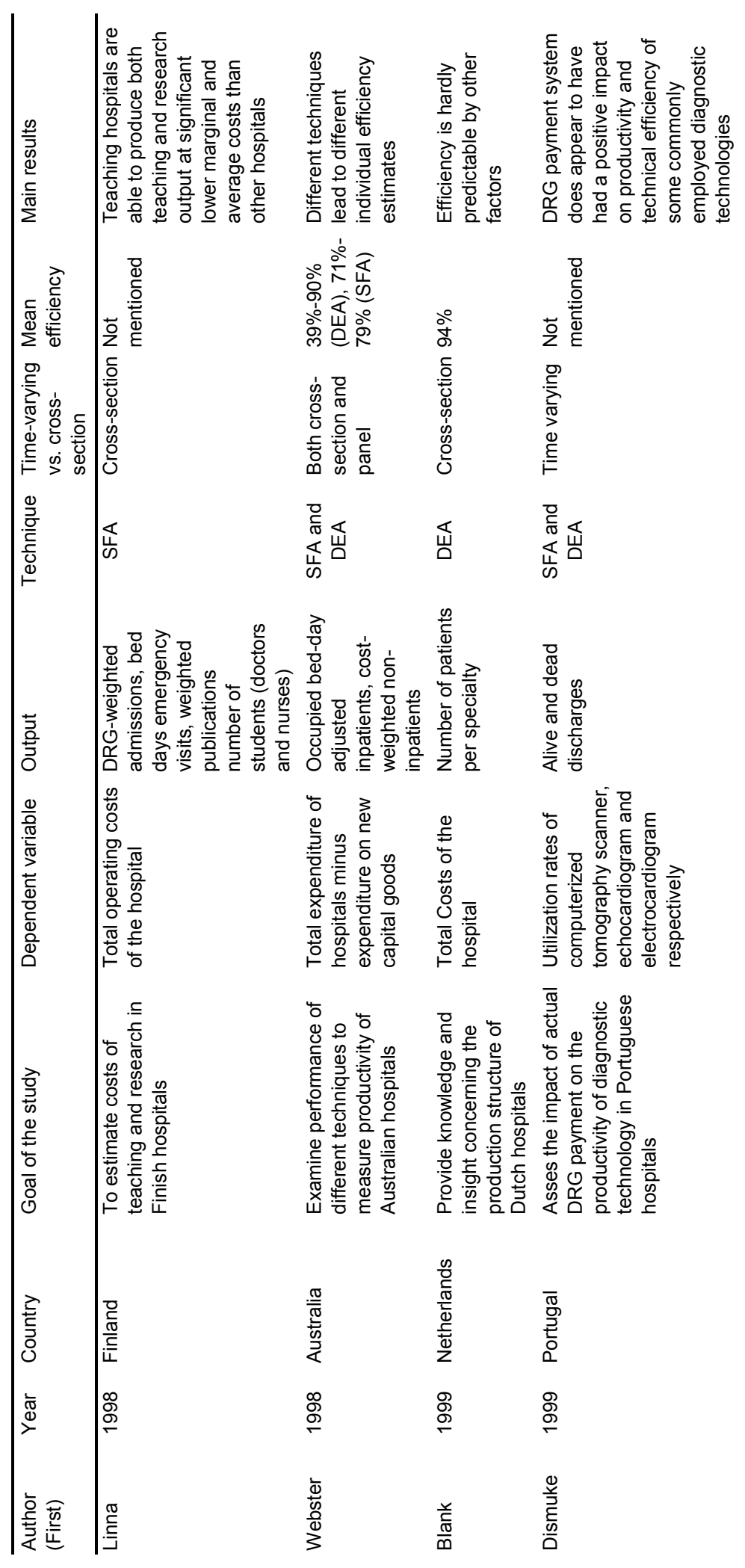




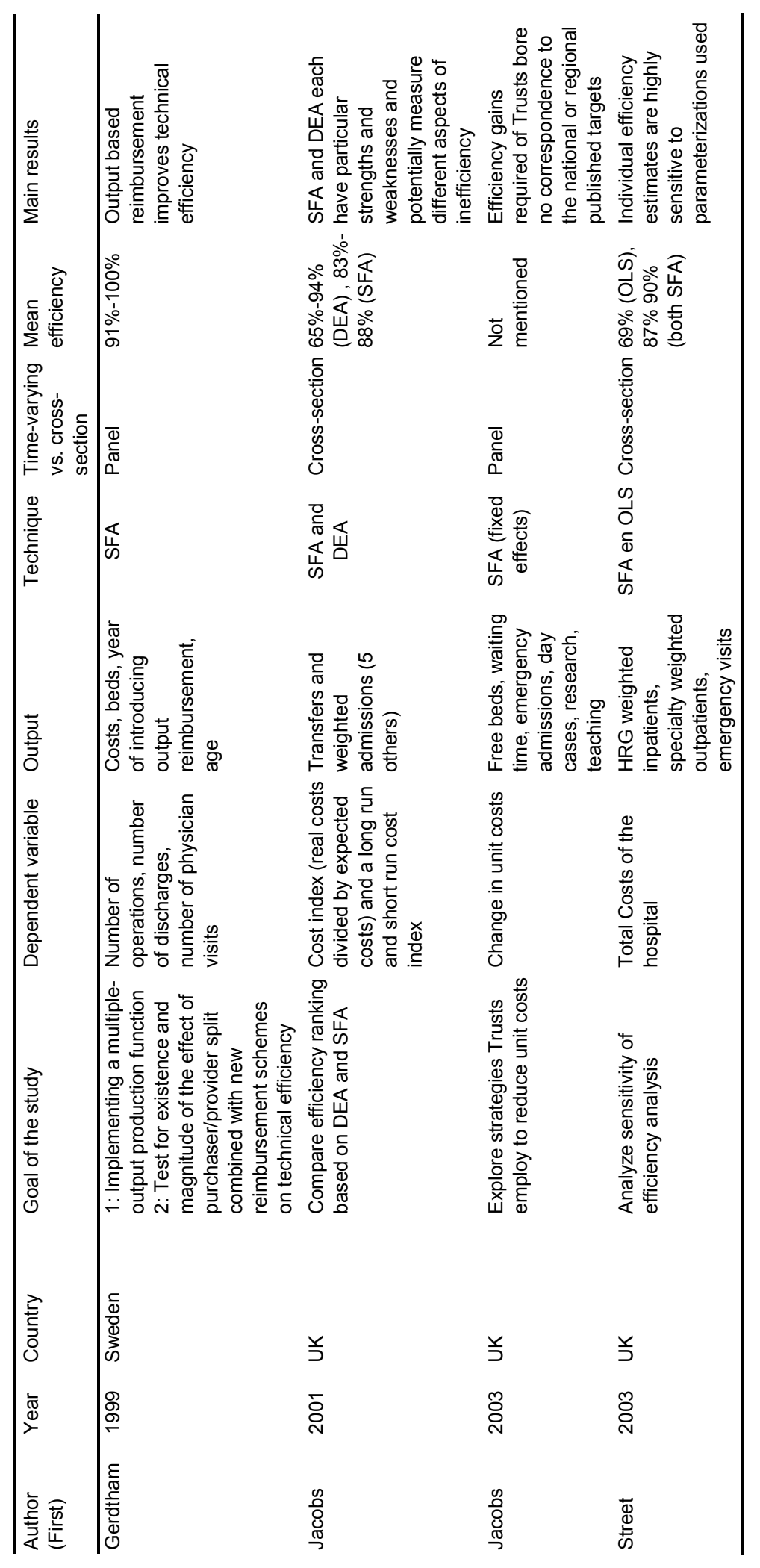


Table 2 shows a number of key issues in studies using frontier techniques: the year the study was published, its first author and the country (and/or state) to which the study pertains, the goal of the study as described by the authors, the dependent variable used in the study (mostly costs, or costs per patient), the output(s) of the hospitals that are used to explain costs, the technique used to estimate the frontier, whether cross-section or panel data are used and the most important results of the study.

In the first studies (Zuckerman, 1994 and Skinner, 1994) the general goal was to describe a new method of measuring efficiency of hospitals and explain its advantages and disadvantages. The emphasis lies on the individual efficiency estimates. These approaches have been criticized on a number of points. Newhouse (1994) states that output between hospitals is difficult to compare and output variables that have been omitted are likely to affect results. Second he wonders whether the inefficiencies found should be interpreted as inefficiencies or rather as differences in quality measured. He suggests that case mix differences should at least be taken into account to make output more comparable between hospitals, but that even within the same DRG: the most commonly used case mix measure, patients appear to be non-homogeneous. In relation to the non-parametric DEA method, he states that efficiency and random fluctuations are mixed. Skinner (1994) gives a theoretical description in which he shows that statistical assumptions influence the robustness of the efficiency estimates. He furthermore argues that the efficiency of the industry as a whole cannot be determined by this approach.

In their critics, Street (2003) and Magnussen (1996) focus on the variability of individual efficiency estimates. Street (2003) calculates confidence intervals of individual efficiency estimates. He concludes that most of the efficiency estimates do not differ significantly from each other and that the confidence intervals of efficiency estimates overlap in almost all the hospitals in the sample. He therefore states that efficiency estimates derived from cross-section data should be treated with extreme care. Magnussen (1996) compares different efficiency estimates achieved from different output measures. He concludes that the average variation of the efficiency within the sector is not influenced by the way output is measured but that both the individual efficiency measures and the scale properties are influenced by the way output is measured. This finding implies, that the efficiency estimates depend on the output measures used. Folland and Hofler (2001) compare different cost functions. They conclude that individual efficiency estimates are being influenced by the assumptions made in the different approaches. They also conclude that the mean efficiency of groups of hospitals does not differ significantly between estimation methods. Chirikos (1998) compares the results of applying different cost functions. He concludes that the frontier technique is promising but results for individual estimates may not be unambiguous enough to use for reimbursement. 
These findings suggest that individual inefficiency estimates cannot be used by themselves, but that estimated means or group means do give insight into the differences between groups of hospitals. A number of other studies for example Jacobs (2001) and Chirikos and Sear (2000) explicitly compare the results of different frontier models, both parametric and non-parametric. These studies draw the same conclusion that individual efficiency estimates differ too much to give confidence in the use of frontier techniques for reimbursement of individual hospitals. Based on these critiques, a number of improvements to the original approaches have been implemented. First: the use of panel data instead of cross-section data. The use of panel data makes results less dependent on distributional assumptions and the results are more robust. Linna (1998) for example concludes that the individual efficiency estimates based on panel data are comparable for the parametric stochastic frontier and non-parametric DEA approach. The use of panel data techniques, which are applied in most recent studies, provides the opportunity to estimate time varying efficiency. Worthington (2004) concludes in his review article, that the efficiency of health care organizations has increased over time. The same conclusion is found in the studies by Linna (1998), Rosko (2001), Dismuke and Sena (1999), Gerdtham et al. (1999), Brown (2003) and Sari (2003). A number of explanations are given for the finding that efficiency increases over time. First, Rosko (2001) cites as an explanation for the increasing efficiency in the Health Maintenance Organization (HMO) in the US, the reduction of services, bed capacity and intensity of services. Second, both Dismuke and Sena (1999) who study the influence of DRG payment on the efficiency of diagnostic procedures and Gerdtham et al. (1999) who study the effect of output reimbursement on technical efficiency conclude that the new reimbursement scheme has a positive effect on efficiency. Third, Brown (2003) and Sari (2003) find that the introduction of managed care has a positive influence on efficiency.

Second, the question how to measure output has been addressed by a number of studies. The measurement of output is one of the main issues in efficiency measurement in health care. The measurement of output is not straightforward and according to Newhouse (1994) output is not comparable between hospitals. Butler (1995) states that hospitals actually produce an increase in the health status of their clients but that this way of using output in studies is not very promising for two reasons. First, the increase in health status is difficult to measure. Second, the increase in health status is only partly a consequence of the hospital's actions. Because of the measurement problems with health status, two other approaches to measuring output in empirical studies can be distinguished. In the first approach the hospital is considered as an organization for curing people, so output is measured as the result of the total number of cases (or admissions) in the hospital. The other approach considers the hospital as a facility centre for medical specialists and measures output as the number of procedures (often patient days) performed by the hospital. The first measure is mostly used in empirical studies and preferable because this way of measuring output best resembles the pure definition of increasing the health status of 
patients. In recent studies (see for example Rosko and Chilingerian, 1999) the total number of cases is mostly measured by the number of case mix adjusted admissions. Folland and Hofler (2001) make an interesting comment on this issue. They state that the claim that: "output variables that are omitted influence the results of the stochastic frontier" cannot itself be tested, because omitted variables are always present. To deal with the problem of omitted output variables Olesen and Petersen (2002) use all 483 different Danish DRGs as an output measure. Their approach can only be implemented in a non-parametric setting and extra assumptions are necessary to prevent an outcome in which all hospitals are efficient by construction.

A third improvement is the way efficiency is explained. The earlier studies that try to explain inefficiency, for example Zuckerman et al. (1994), use a two-stage method. In the first stage efficiency is estimated as part of the cost function. In the second stage the estimated efficiency is used as a dependent variable. Dor (1994) criticizes this estimation procedure on methodological grounds: "there needs to be a theoretical motivation for including a particular variable in one stage as opposed to the other". More recent studies (see for example Rosko, 2001) using variables to explain efficiency use a more robust one-stage estimation procedure designed by Battese and Coelli (1995).

Fourth, the finding that individual efficiency estimates are not robust enough to use for funding purposes has led to the use of frontier analysis for other purposes. A number of analyses have been performed for purposes other than determining individual efficiency estimates. In the US an important policy question is: "what are the effects of managed care on efficiency?" A number of studies have addressed this question using a stochastic frontier approach; see Brown (2003) and Sari (2003). Another issue that has been dealt with using a stochastic frontier model is the cost of medical education (see for example Linna et al., 1998 and Grosskopf et al., 2001). Grosskopf et al. (2001) compare the efficiency estimates of teaching and non-teaching hospitals. Others use frontier estimation to estimate the efficiency of treating a single patient group. Bradford et al. (2001) for example examine the efficiency of the treatment of coronary artery disease. Dismuke and Sena (1999) estimate the efficiency of nine different DRGs.

\section{Main conclusions from earlier studies}

Since Zuckerman et al. (1994) broadly introduced the stochastic frontier approach in health economics in 1994, efficiency estimation in health care has been explored further. While Zuckerman et al. (1994) introduced stochastic frontier analysis in health care as a tool to use for individual efficiency estimates, ongoing research has shown that individual estimates are not robust enough and too sensitive to assumptions made about the output of the hospital and the distribution of the error terms. Other applications of frontier analysis have however proved to be useful. Although conclusions in different studies are not always the same, a number of general lessons can be drawn from these studies. 
1. Individual efficiency estimates are significantly affected by distributional assumptions and the way output is measured. Using individual efficiency estimates for funding purposes for example should therefore be treated with extreme care.

2. The average efficiency of groups of hospitals within the same study is less affected by different estimation techniques.

3. The efficiency estimates based on panel data outperform estimates based on cross-section data because of the robustness of the estimates.

4. The average efficiency of the hospitals varies in most studies between $80 \%$ and $90 \%$, with a number of outliers below and above. Theoretically DEA produces lower efficiency estimates since, in contrast with SFA, chance is interpreted as inefficiency as well.

5. No clear answer to the question whether a parametric or a non-parametric approach should be used can be given yet.

6. It appears that in most studies the efficiency of hospitals increases over time.

These lessons learned from earlier studies provide a good framework for an SFA analysis of Dutch hospitals. Using SFA can provide us the same important insights that earlier studies provided for other countries while we can use the methodological lessons learned from earlier studies. First SFA can give insight into the average efficiency of the Dutch hospitals when compared to each other and therefore provide an estimate of how much efficiency gain and possible savings for the payer can be obtained in Dutch hospitals.

The first research question in this chapter is:

\section{How efficient are Dutch hospitals and to what extent is this efficiency comparable with other international efficiency studies in the hospital sector?}

Second, the use of panel data provides us the extra possibility to examine whether the average efficiency has changed over time and therefore gives insight in the efficiency consequences of policy measures. The effectiveness of new investments in health care is an important political issue in the Netherlands. The costs of health care in the Netherlands grew by approximately $40 \%$ between 1998 and 2002. Policy makers wonder whether this growth has led to more and better care or that it just added to inefficiency in the health care sector. As mentioned before, from earlier studies in other countries an increase in efficiency might be expected. However the main explanations for this increase are a decrease in bed capacity, the reduction of services, other reimbursement schemes and the introduction of managed care. Only the decrease in bed capacity plays a role in the Dutch situation, while the number of services has been increased and no major other policy changes have taken place recently. The use of panel data in a SFA setting will show whether these investments are used for more production or are also partly wasted on inefficiency. 
The second research question in this chapter is:

\section{Has efficiency of Dutch hospitals changed over time?}

Third SFA can be used to see whether there are differences in efficiency when different output measures are used. In the Netherlands until recently no case mix measures have been used to finance hospitals. Only recently a first start has been made in using case mix as a financing parameter for hospitals. Using SFA can show us whether case mix is an important parameter in explaining efficiency of Dutch hospitals.

The third research question in this chapter is:

Does the way output is measured influence the efficiency of a hospital?

The remainder of this chapter is organized as follows: The following section presents the results and a conclusion. This chapter ends with a discussion about the methods used and the results found. 


\subsection{Estimation results}

Table 3: Descriptive statistics of input and output variables

\begin{tabular}{lccccc}
\hline \hline & Min & Max & Mean & Mean 1998 & Mean 2002 \\
\hline $\begin{array}{l}\text { Dependent Variable } \\
\quad \text { Total Costs (*1000) }\end{array}$ & 12,910 & 217,056 & 61,280 & 50,589 & 76,351 \\
& & & & & \\
Explanatory variables & & & & & \\
$\quad$ Length of stay & 4.7 & 11.3 & 8.1 & 8.7 & 7.3 \\
$\quad$ Ward days (*1000) & 29.1 & 302.3 & 109.0 & 113.4 & 105.0 \\
$\quad$ Day-care (*1000) & 1.8 & 24.9 & 7.7 & 6.4 & 9.6 \\
Admissions (*1000) & 3.6 & 36.6 & 13.3 & 12.8 & 14.3 \\
Ambulatory care patients (*1000) & 18.6 & 227.6 & 76.0 & 60.8 & 85.4 \\
DRG case mix index & 0.76 & 1.32 & 0.94 & 0.92 & 0.95 \\
& & & & & \\
Average costs & & & & & 3,101 \\
$\quad$ Cost per patient (inpatient + day-care) & 1,784 & 4,689 & 2,817 & 2,555 & 5,460 \\
$\quad$ Costs per average DRG (inpatient) & 2,999 & 7,151 & 4,754 & 4,158 & \\
\hline \hline
\end{tabular}

Table 3 contains the main descriptive statistics of the variables included in this study. Dutch hospitals are quite different in size. The annual number of admissions varies between 3,500 and more than 30,000 , with an average of approximately 13,000 . The number of patients treated as outpatients varies between 18,500 and more than 227,000 . The number of patients treated in day-care varies between almost 2,000 and almost 25,000 . These differences reflect the differences in size between hospitals in the Netherlands.

Besides the differences in size, hospitals differ in the way patients are treated, measured by the average length of stay and the costs per patient. The costs per patient vary between almost $€ 3,000$ and almost $€ 9,000$. The average length of stay varies between 4.7 and 11.3 days. This gives a first impression that differences in efficiency between hospitals might exist. Another explanation for these differences might be the difference in the patient mix, measured by DRGs. The DRG case mix varies between 0.76 and 1.32 , with an average of 0.94 giving an impression of the differences in case mix between hospitals. The case mix increases over time. The costs per weighted admission vary between $€ 3,000$ and more than $€ 7,000$, affirming the idea that there are differences in efficiency between hospitals.

Table 3 provides a first impression of the differences in production and efficiency over time. The costs per hospital increased from $€ 51$ million in 1998 to $€ 76$ million in 2002, an increase of more than $30 \%$ in four years. This can be partly explained by a decrease of the number of hospitals from 118 in 1998 to 91 in 2002 as a result of mergers, resulting in an increase in the average size of hospitals. The costs per patient also increased from $€ 2,500$ in 1998 to $€ 3,100$ in 2002 , a rise of $21 \%$. There are a number of explanations for this increase. 
Between 1998 and 2002 the number of inpatients increased in relation to the number of outpatients and day-care. The complexity of inpatients, as measured by DRG, rose and inflation between 1998 and 2002 - circa 13\% in total- also led to higher prices. A last explanation is that the differences in efficiency over the years may have led to price differences. The stochastic frontier analysis must answer the question to what extent inefficiency affects the increase in hospitals' costs over time.

Table 4: Results of models $1 \mathrm{a}$ and 2a estimating time-invariant efficiency

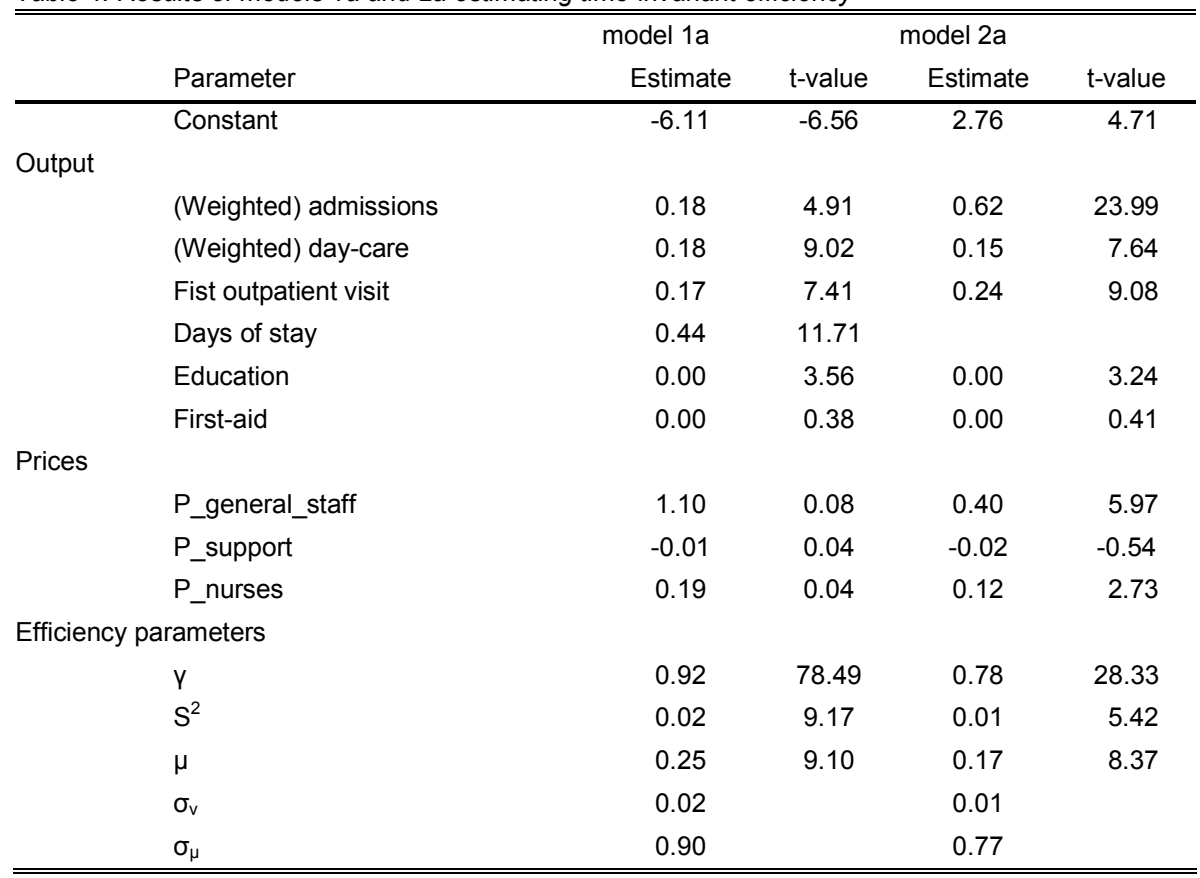

Table 4 shows the estimation results for two models: In the first model (1a), output is measured by the number of admissions, ward days, day-care admissions and first outpatient visits. In the second model (2a), output is measured by weighted admissions, weighted day-care admissions and first outpatient visits.

The parameters which represent the production are highly significant $(p<.01)$ in model 1a. Because model 1a uses the parameters that also are used to fund Dutch hospitals, this result is not surprising. The parameter estimate for the presence of an emergency department is not statistically significant in model 1a. The number of trained medical specialists does have a positive significant influence on hospital costs. The parameter estimates for admissions in day-care and outpatient visits are all about the same magnitude. The extra costs of an admission compared to an outpatient and day-care seem to be captured by extra patient days. 
The parameter estimates for the weighted admissions, day-care and outpatients are also statistically significant $(p<.01)$ in model $2 a$. The parameter estimate for the weighted admission is approximately four times as high as the parameter estimate for day-care and three times as high as the parameter estimate for outpatients. Model 2a shows a significant positive relationship between costs and the number of trained medical specialists. The price parameters for nurses and general staff are significant $(p<.05)$ in both models. The price parameter estimate for supporting staff is not statistically significant in both models. The total of the parameter estimates for the production measures approximately equals one in both models (0.99 in model 1a, 1.01 in model 2a). This indicates the absence of both diseconomies and economies of scale in Dutch hospitals.

The parameter $\mu$ is significant in both models. This shows that an 'ordinary' $\mathrm{N}^{+}\left(0, \sigma_{\mu}\right)$ distribution is rejected. The efficiency is estimated by the parameters: $Y$ and $S^{2}$ (see equation 5 ). Based on this equation the error component $\left(\sigma_{v}\right)$ and efficiency component $\left(\sigma_{\mu}\right)$ can be calculated. $\sigma_{\mu}$ exceeds $\sigma_{v}$ by more than a factor of 50 in both models. This means that inefficiency plays a bigger role than random variation. Together with the significance of the estimates for $\gamma$, which measure the relative size of $\sigma_{\mu}$ compared to $\sigma_{v}$ this suggests first that inefficiency exists in Dutch hospitals and second there are differences in inefficiency between Dutch hospitals. 
Table 5: Results of models $1 b$ and $2 b$ estimating time-varying efficiency

\begin{tabular}{lcccc}
\hline \hline & \multicolumn{2}{c}{ model 1b } & \multicolumn{2}{c}{ model 2b } \\
Parameter & Estimate & t-value & Estimate & t-value \\
\hline Constant & -4.74 & -4.59 & 2.15 & 6.61 \\
Output & & & & \\
$\quad$ (Weighted) admissions & 0.19 & 4.69 & 0.64 & 20.34 \\
(Weighted) day-care & 0.16 & 6.89 & 0.14 & 6.03 \\
First outpatient visit & 0.16 & 6.33 & 0.23 & 8.60 \\
Days of stay & 0.50 & 11.89 & & \\
Education & 0.00 & 2.99 & 0.00 & 3.23 \\
First-aid & 0.01 & 0.59 & 0.01 & 1.01 \\
Prices & & & & \\
P_general_staff & 0.93 & 10.40 & 0.35 & 4.52 \\
P_support & -0.02 & -0.41 & -0.02 & -0.36 \\
P_nurses & 0.19 & 4.60 & 0.13 & 2.96 \\
Efficiency parameters & & & & \\
Y & 0.92 & 62.93 & 0.79 & 30.06 \\
S2 & 0.02 & 5.82 & 0.01 & 5.24 \\
$\mu$ & 0.26 & 11.66 & 0.17 & 6.36 \\
$\eta$ & -0.04 & -3.45 & -0.02 & -0.80 \\
$\sigma_{v}$ & 0.02 & & 0.01 & \\
$\sigma_{\mu}$ & 0.91 & & 0.78 & \\
\hline \hline
\end{tabular}

In model $1 \mathrm{~b}$ and $2 \mathrm{~b}$ (see Table 5) almost identical models are estimated but now the possibility of time-varying efficiency is taken into account. The parameter estimates of the production parameters vary only slightly compared to model $1 \mathrm{a}$ and $2 a$. The estimates for the production parameters and the estimates for the number of educated specialists are significant. No significant parameter estimate is found for the existence of an emergency department. As in model 1a the parameter estimates for inpatients, outpatients and day-care are approximately the same. In model $2 \mathrm{~b}$ the estimate for DRG-weighted admissions is higher, because the ward days are not incorporated in this model. The price of labor is significantly positive $(p<.05)$ for nurses and general staff. The price parameter for supporting staff is not statistically significant $(p>.05)$.

The parameter $\eta$ measures time-varying efficiency. In both model $2 a$ and model $2 b$, the parameter estimate of the time-varying efficiency is negative; in model $2 a$ this effect is statistically significant. This means that the average efficiency of hospitals has decreased over time. The treatment of a patient becomes more expensive over time. This effect can be partly explained by an increase in case mix that is more severe or complex.

Table 6: Efficiency per year

\begin{tabular}{lll}
\hline \hline & Non-weighted admissions & Weighted admissions \\
\hline Time constant average & $76.9 \%$ & $83.6 \%$ \\
1998 & $80.3 \%$ & $84.5 \%$ \\
1999 & $79.8 \%$ & $84.6 \%$ \\
2000 & $78.9 \%$ & $84.2 \%$ \\
2001 & $77.9 \%$ & $84.0 \%$ \\
2002 & $77.7 \%$ & $83.9 \%$ \\
\hline \hline
\end{tabular}


To get an impression of the degree of decreasing efficiency Table 6 presents the average efficiency for model $1 \mathrm{a}$ and model $2 \mathrm{a}$ and the average efficiency over time for both model $1 \mathrm{~b}$ and $2 \mathrm{~b}$. The average efficiency of model $1 \mathrm{a}$ is $77 \%$ and the efficiency of model $2 a$ is higher, $84 \%$. This level of inefficiency is comparable with ranges of inefficiencies found in earlier studies (see Table 2).

Over time the average reduction of efficiency was $2.6 \%$ between 1998 and 2002, when measured by number of treated patients. The average decrease in efficiency was $0.7 \%$ when measured by the number of weighted patients. This leads to the conclusion that decreasing average efficiency can be partly explained by an increasing average complexity of a patient over time. However, when controlling for case mix, the efficiency of Dutch hospitals also decreased between 1998 and 2002.

Table 7: Statistics of individual efficiency estimates

\begin{tabular}{lll}
\hline \hline & Non-time-varying & Time-varying \\
\hline Pearson correlation & 0.83 & 0.82 \\
Rank correlation & 0.85 & 0.84 \\
Average difference & $7.17 \%$ & $5.67 \%$ \\
Maximum difference & $21.80 \%$ & $21.30 \%$ \\
\hline \hline
\end{tabular}

Table 7 focuses on the individual efficiency estimates. Table 7 presents the correlation between the two models both in the time-varying case (model $1 \mathrm{~b}$ and $2 \mathrm{~b}$ ) and in the non-time-varying case (model 1a and 2a). The Pearson correlation coefficient was calculated by the correlation between the individual hospital efficiency estimates, or the average individual hospital estimates over time in the time-varying model. The rank correlation was calculated by ordering the efficiency estimates and calculating the correlation between the individual ranks. The correlations vary between 0.85 and 0.82 . These correlations are higher than correlations found in earlier studies, which estimate the effects of different output measures on the individual efficiency estimates. Magnussen (1996) found a correlation coefficient of 0.67 when he compared the efficiency estimates based on weighted and non-weighted patients.

Table 7 also presents statistics about the absolute differences in efficiency estimates. Efficiency estimates differ between both models with an average of $5.7 \%$ in the time-varying model and $7.2 \%$ in the non time-varying model. This result and the differences found in efficiency between model 1 and 2 show that when case mix is not used in hospitals' cost function this leads to bias in the individual hospital efficiency estimates. 


\subsection{Discussion}

\section{Methodology}

Before we discuss our main results we will first go through some methodological issues. Estimating the efficiency of hospitals is a complex issue because of the measurement problems involved. The main problem is how to measure the output of hospitals. The way output is measured is probably the most important explanation for the efficiency measures found. If every patient would be considered unique - the way doctors consider patients - by definition every hospital would be fully efficient whatever treatment they provide. If every patient would be considered as being equal, hospitals that treat relatively easy patients would be considered more efficient. The way to solve this problem is to measure the number of patients and to control this measurement for differences in case mix. On the other hand differences in case mix (especially DRGs which are widely used and which are used in this study) are partly controlled by hospitals. By controlling for DRGs this study does not account for this problem. This study assumes DRGs are not controlled by hospitals. This is in fact the case because during the periods the data were registered, no case mix reimbursement was applied. Neither were DRGs registered during these periods.

A second methodological issue is how to use the estimation results of a stochastic frontier analysis. A number of studies, for example Dor (1994) Newhouse (1994), Skinner (1994) and Street (2003) have criticized the way frontier methods measure efficiency of individual hospitals. We agree with these authors that one should be careful to use individual estimates for decision-making.

With an annual budget for hospitals in the Netherlands alone of approximately $€ 10$ billion and the widespread results of research that suggest that part of this budget is spent inefficiently, we believe that more effort should be spent on efficiency research in health care. We agree with Olesen and Petersen (2002) that the development of a new theory is a constructive approach to addressing shortcomings. Moreover accounting for the shortcomings of frontier analysis that have been addressed in recent studies leads to better estimates. This study addresses a number of these shortcomings:

- This study did not use individual estimates for funding. It used differences between groups to draw conclusions.

- This study uses panel data to obtain more reliable estimates and to obtain time-varying estimates.

- $\quad$ This study uses two different ways to measure the output of hospitals. 


\section{Results}

This study uses the stochastic frontier approach to calculate efficiency in Dutch hospitals. This study finds an overall average efficiency of $77 \%$ to $85 \%$, depending on whether case mix differences are taken into account. The review of the existing literature shows that average efficiency estimates vary between $39 \%$ and $100 \%$, with the majority between $80 \%$ and $90 \%$. This finding indicates that the difference in inefficiency between Dutch hospitals is in line with differences in inefficiency between hospitals in other countries. This finding does not mean that the hospital sector in the Netherlands is as efficient as the hospital sectors examined in other studies. It does mean however that, when compared to each other, Dutch hospitals show the same variation in efficiency as in many other parts of the developed world. This variation in efficiency means that an average hospital can obtain a maximum $15 \%$ to $23 \%$ efficiency gain. The finding that fewer efficiency differences exist when measuring output based on case mix implicates that case mix differences between hospitals are important and should therefore be used as a financing parameter.

Both case mix-weighted and non-weighted admissions and day-care admissions and outpatients have a positive influence on hospitals' costs. At first sight this finding is not surprising since these parameters are the main parameters for the hospital budgets and therefore can be expected to be the main cost-drivers as well. This finding differs though, from the findings in Blank et al. (1998a). Their analyses show that outpatient admissions have no significant influence on the costs of Dutch hospitals. This might be due to the different time periods used in the studies. This study uses data from 1998 to 2002, whereas Blank et al. (1998a) used data from 1985 to 1995 . Outpatient care has become more important between these time-periods, as a number of treatments have shifted from inpatients to outpatients.

Because of the use of panel data this study was able to estimate time-varying efficiency. This study shows that when output is measured in terms of number of patients and ward-days, efficiency decreases over time. This effect is partly explained when we control for case mix differences, but we still find a decrease in efficiency over time. What one Euro will buy in terms of the number of patients treated has decreased over time between 1998 and 2002. The increase in the complexity of the average patient only partly compensates for this fact. As far as we know, none of the previous studies has found a decrease in efficiency over time. For example Rosko (2004) who uses American hospital data, Hofmarcher et al. (2002) who use data from Austrian hospitals and Linna (1998a) who uses data from Finnish hospitals all find an increasing efficiency over the years. Worthington (2004) concludes in his review analysis that efficiency of health care institutions increases over time.

The main explanation for our divergent finding is the difference in the Dutch situation. No major reforms or reimbursement schemes have been introduced between 1998 and 2002. The main policy measure in this period was the en- 
hancement of budgets to reduce waiting lists and raise wages of nurses, which has partly led to an increase of inefficiency.

The average differences in efficiency of the hospital sector in the Netherlands are higher when case mix adjustments of output are used. Including case mix weights does lead to less varying individual inefficiency estimates. This finding is in line with the findings of Rosko and Chilingerian (1999). Part of the variation in efficiency measured when using the number of patients as an output measure can be explained by differences in case mix. This finding shows that case mix should be used to evaluate hospitals' performance and to finance Dutch hospitals. A lesson perhaps common in many developed countries, but not applied in the Netherlands until recently.

This study has produced some interesting results for policy-makers. Besides it contributes towards solving some methodological problems in estimating the efficiency of hospitals. On the other hand we think that further research should be done to solve these methodological problems. The main problem that has to be solved is the way output should be measured (controlled for quality differences). An interesting step in making output between hospitals more comparable would be to analyze smaller units of the hospital, like departments and homogeneous patient groups. 



\title{
4. Principal agent issues in hospitals: explaining efficiency
}

\begin{abstract}
Inefficiency of hospitals is an important political issue and the subject of numbers of studies. Most studies find evidence for inefficiency but provide neither empirical nor theoretical explanations for differences in efficiency. This study tries to explain differences in efficiency between hospitals by focusing on agency issues hospitals are dealing with. Two types of agency issues are examined: First, quality of care in the relation between hospital and patient. Second the relations between the hospital and its main departments, in short the internal organization. It is found that efficiency and quality come together. This implies that potential harmful information asymmetry between hospitals and patients should not be a major problem, because of efficiency reasons: increasing efficiency seems also to increase the quality of hospitals. Further we find ample relation between the efficiency of departments and the efficiency of the entire hospital. The interests of hospital-departments are currently not in line with the interests of the entire hospital.
\end{abstract}

Keywords: principal agent theory; hospital efficiency; hospital quality. 


\subsection{Introduction}

In 2005, the total budget for health care was about $9 \%$ of GNP in the Netherlands and it is growing rapidly. This alone could explain the recent interest in costs and efficiency of health care among both politicians and researchers. But this interest is certainly not new and a variety of instruments has been applied to get insight in the factors relating to costs and efficiency in health care. To analyze efficiency advanced econometric tools like Stochastic Frontier Analysis (SFA) - independently introduced by Aigner et al. (1977) and Meussen and van den Broeck (1977) - and Data Envelopment Analysis (DEA) have been used. Zuckerman et al. (1994), Skinner (1994), Newhouse (1994) and Dor (1994) first introduced SFA in the hospital sector in 1994. Numerous studies have since applied SFA in a hospital setting (see Hollingsworth, 2003 for a recent review). Studies using SFA, and also DEA, have the advantage over studies using classical cost functions that they compare hospitals with the best instead of the average performing hospital.

However they use the assumption of the "classical economic theory" that organizations strive to realize one common goal and that factors relating to agency issues that could explain differences in costs and efficiency are not addressed.

In this study we examine how factors related to agency issues explain differences in costs, efficiency and quality using SFA.

In economic theory we define an agency relation as an agreement in which the principal delegates certain responsibilities to the agent for which the agent receives a certain reward (Jensen and Meckling, 1976). The agency literature emphasizes that the agent has his own utility function, which he maximizes. This utility function may partly coincide with the utility function of the principal, but may in part also differ. The agent will let his own utility function prevail. The key issue in this relation is the information asymmetry between the agent and the principal. According to Arrow (1985) this asymmetry can have two advantages for the agent. The first occurs because the principal cannot evaluate whether the principal lets his own utility function prevail. Second as the productivity of the agent can only be measured by indicators, the principal cannot judge whether the agent acts in the interest of the principal, or just tries to optimize the indicators. Some examples show where these agency-issues arise in hospitals and how information asymmetry plays a role:

- In the relation between the hospital, or more specific the medical specialist, and the patient. The patient (the principal) has a health problem and delegates the problem to the medical specialist (the agent) to solve this problem. It is hard to judge for the patient how well he is treated by the medical specialist.

- Inside the hospital, the hospital board (the principal) hires medical specialists (agents) to treat patients. The hospital board is not as well informed about the quality, efficiency and effectiveness of the treatment as the medical specialist is. 
- Inside the hospital the same holds for the relation between the hospital board (the principal) and departments, like the ward and the radiology departments (the agents). Again the manager of, for example, the radiology department is much better informed about the quality and necessity of performing an X-ray than the hospital management.

In this study we further analyze two of these principal agent relationships and use them to explain hospital efficiency. The first concerns the relation between the hospital and the patient. Second, we analyze the relation between the hospital management and the departmental managers. The third relation between the hospital managers and the doctors is not analyzed further. Not because this relation is not interesting, it is very interesting indeed, but because good quality data on the productivity of Dutch medical specialists are not available.

\section{Principal agent relations between patients, physicians and managers}

\section{Hospital patient relation in an agency perspective}

The relation between a hospital and a patient is a typical principal agent relation. The patient has to rely on the specialized knowledge of the doctor and there is an asymmetry in information about the treatment of the health problem. It is difficult for the patient to measure the performance of the hospital. The hospital might thereby prefer to optimize its own utility function, minimizing costs as is mostly assumed in efficiency studies. This may go at the cost of the utility of the patient, who has an interest in receiving high quality care. The reasoning of Newhouse (1994) is in line with this assumed relationship. He states that differences in efficiency might be completely attributed to differences in (unobserved) quality. Many other studies have emphasized the need to include quality measures in efficiency studies. Jacobs and Dawson (2003), for example, criticize the current way of efficiency measurement in hospitals, because quality measures are not taken into account. This study (Jacobs and Dawson, 2003) and other studies (e.g. Fizel and van Nunninkhoven, 1993) argue that an increase in quality of health care is likely to require additional inputs per unit of output, thereby implying lower relative efficiency for higher quality providers.

In contrast with the criticism on frontier studies that inefficiency might be explained by quality differences, studies that are more management and organizational oriented argue that quality and efficiency are complements. Porter and Olmsted Teisberg (2004), for example state that: "in health care, as in most industries cost and quality can improve simultaneously as providers prevent errors, boost efficiency, and develop expertise." A similar reasoning is found in van Merode et al. (2004) who argue that departments in a hospital often strive to optimize their own functioning independent from other departments. From the hospital point of view this is a way of suboptimizing. Hospitals that do not suboptimize follow a more integrative approach where the hospital is organized to- 
wards the client (focused factories). In this approach quality and efficiency problems are solved simultaneously. This reasoning finds its origin in target engineering where quality and price preferences are the starting point in engineering services, products and production systems van Merode (2004) states that this kind of organization leads to more quality from the perspective of the client, more efficiency because the number of transfer points is minimized and learning can be systematically performed. This latter reasoning does not imply that principal agent issues do not arise between hospitals and patients. It does imply that the utility functions of hospitals and patients do not differ that much. The patient wants high quality of care. The hospital will primarily be concerned with efficiency, but this is positively associated with quality.

In short we can state that because of asymmetric information between patients and doctors, hospitals might economize on quality to gain efficiency. However this behavior may not occur if hospitals which are efficient deliver good quality care as well.

\section{Hypothesis 1: Hospital efficiency and quality come together}

A core concept of the principal agent theory is the rejection of the assumption that individuals in organizations share and pursue one common goal. According to the principal agent theory the interests within organizations (i.e. hospitals) differ. To get a good understanding of these different interests in hospitals, it is useful to describe the hospital organization. Van Merode (2004) states that most hospitals "have a functionalistic structure: surgeons in the surgery department, clinical chemistry in the laboratories etc." (see figure 2). 


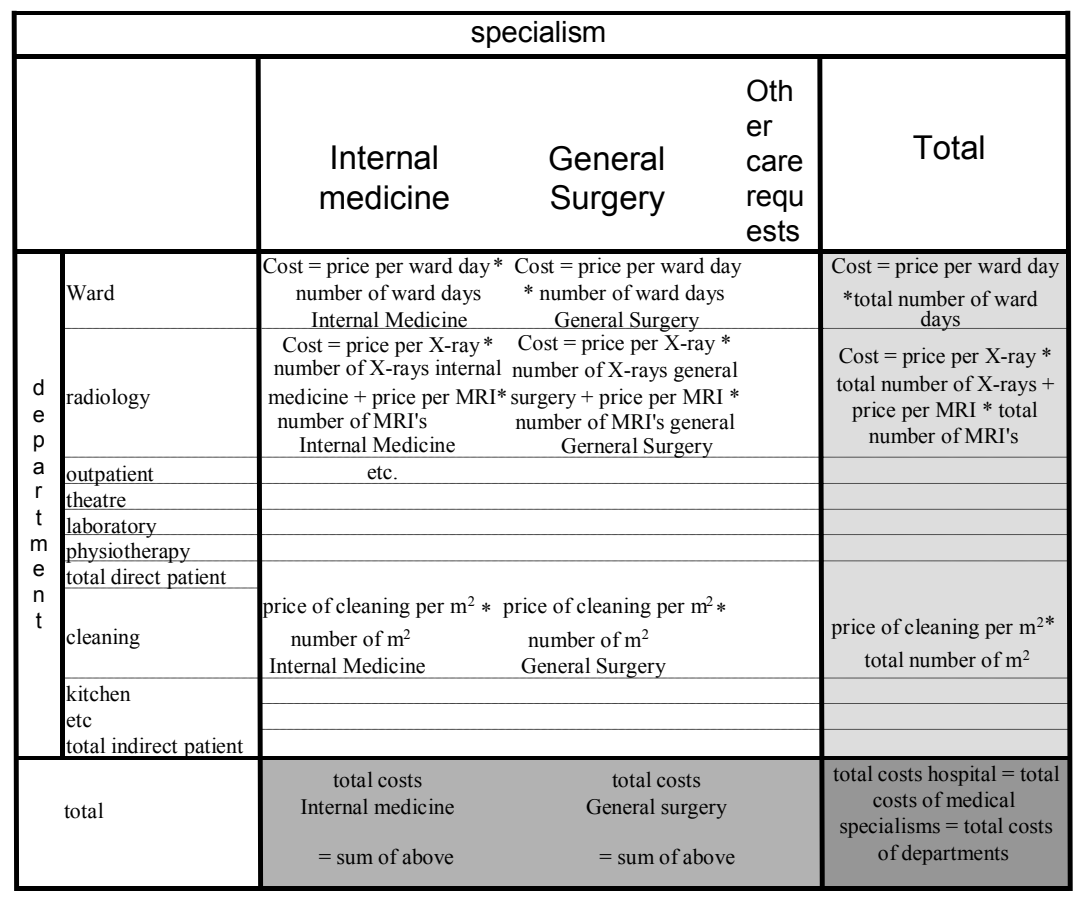

Figure 2: Hospital as a functionalistic organization

Most Dutch hospitals are organized as a functionalistic organization of medical disciplines and facilitating departments as shown in figure 2. According to van Merode et al. (2004) a functionalistic organization implies that it is difficult to realize integration. To get an insight in the different utility functions of hospitals and departments we need to understand how Dutch hospitals are financed.

Hospitals in the Netherlands receive a budget from the government. This budget is mainly based on the number of:

- beds;

- medical specialists;

- outpatients;

- day-care patients;

- inpatients;

- ward days.

Within the hospital the budget is divided over the departments by the hospital management. The amount of this budget is mostly fixed for a year. Over the years variations in the departmental budgets depend on the number of (intermediate) products delivered by the departments, for example number of ward days 
by the ward, number of X-rays by the radiology department. The principal agent issues in the hospital can be understood from this perspective. The hospital board (the agent), may be assumed to strive towards efficient treatment of all patients. Physicians strive towards efficient treatment of the patients within their medical discipline while departments strive towards efficient production of their own intermediate products. This optimization of intermediate products might interfere with the interest of the hospital towards efficient client treatment. For example the ward might prefer efficient ward days, because the internal budget system works that way. Efficient ward days are partly in the interest of the hospital management as well. The hospital though may also aim at shortening the length of stay, which may interfere with the interest of the ward. This implies that departments which are efficient, measured by their own output, do in fact not contribute to the efficiency of the hospital.

\section{Hypothesis 2: Hospital efficiency and departmental efficiency are only} partly related

As Herzlinger et al. (1997) argue there is no or little relation between the inefficiency of departments and the inefficiency of the total hospital: losses in one part of the organization are compensated by profits obtained in other parts. The nature of planning in hospitals has many similarities with those of job shops. Departments are only concerned with maximizing the efficiency of their own processes. The same reasoning we find in van Merode (2004) who states that in a functionalistic organization, departments put their professional in the centre: everything is organized around the health care professional, but not around the patient. This leads to our third hypothesis:

Hypothesis 3: There is no relation between the efficiency of the different hospital departments 


\subsection{Estimation results}

The variables used in this study are listed in Table 8. This table shows the descriptive statistics (see for a description chapter 2).

Table 8: Descriptive statistics of variables used in this study

\begin{tabular}{|c|c|c|c|c|c|c|}
\hline & Min & Max & Mean & $\mathrm{Sd}$ & Mean 1998 & Mean 2002 \\
\hline \multicolumn{7}{|l|}{ Dependent Variable } \\
\hline Total Costs $\left({ }^{*} € 1000\right)$ & 12,910 & 217,056 & 61,280 & 34,327 & 50,589 & 76,351 \\
\hline \multicolumn{7}{|l|}{ Explanatory variables } \\
\hline Length of stay & 4.7 & 11.3 & 8.1 & 1.0 & 8.7 & 7.3 \\
\hline Ward days & 29,112 & 302,328 & 108,921 & 52,256 & 113,390 & 104,924 \\
\hline Day-care & 1,838 & 24,921 & 7,658 & 3,795 & 6,369 & 9,568 \\
\hline Admissions & 3,597 & 36,576 & 13,257 & 5,897 & 12,778 & 14,291 \\
\hline Ambulatory care patients & 18,551 & 227,531 & 75,927 & 34,775 & 60,781 & 85,405 \\
\hline Clinical DRG-weight & 0.76 & 1.32 & 0.94 & 0.09 & 0.92 & 0.95 \\
\hline \multicolumn{7}{|l|}{ Average costs } \\
\hline Cost per patient (inpatient + daycare) & 1,784 & 4,689 & 2,817 & 512 & 2,555 & 3,101 \\
\hline Costs per average DRG (inpatient) & 2,999 & 7,151 & 4,754 & 749 & 4,158 & 5,460 \\
\hline \multicolumn{7}{|l|}{ Quality variables } \\
\hline Care & 0 & 17 & 9.5 & 3.9 & & \\
\hline Organization & -3 & 15 & 4.9 & 3.2 & & \\
\hline Cooperation & -5 & 13 & 3.8 & 4.2 & & \\
\hline Patient friendly & -3 & 16 & 6.2 & 4.1 & & \\
\hline \multicolumn{7}{|l|}{ Cost prices intermediate products } \\
\hline Ward & 216 & 377 & 290 & 43 & 195 & 256 \\
\hline Outpatient & 38 & 113 & 78 & 17 & 80 & 85 \\
\hline Operating theatre & 611 & 1,282 & 918 & 160 & 952 & 957 \\
\hline Radiology & 0.81 & 1.18 & 0.97 & 0.09 & $\mathrm{~N} / \mathrm{A}$ & 0.95 \\
\hline Laboratory & 1.80 & 3.69 & 2.52 & 0.43 & 102 & 106 \\
\hline Physiotherapy & 0.8 & 3.1 & 1.3 & 0.4 & 1.13 & 1.45 \\
\hline
\end{tabular}

The figures in Table 8 reflect the increasing costs per hospital in the Netherlands. This is a consequence of the decreasing number of hospitals, an increasing production, and increasing salaries. Hospitals still vary considerably in size. The costs are varying by a factor 10 between the smallest and the largest hospital in our database. Also in quality scores we see a variation between hospitals. The difference between the minimum and maximum scores on all four quality measures is about 20. The standard deviation is around 4 for all measures. These results show that professionals perceive differences in quality between hospitals. Both quality and costs vary between hospitals and hospital departments. The stochastic frontier analysis must answer the question to what extent 
efficiency affects the increase in hospitals' costs over time and to what extent quality and departmental efficiency are related to hospital efficiency.

Table 8 further presents the average costs per treatment in the different departments after the removal of outliers (see the appendix for a description of the main descriptive statistics without removing outliers). We see that the removal of outliers results in a reduction of the difference between the maximum and the minimum prices to approximately a factor 2 for most departments and at most a factor 5 for the physiotherapy department. The standard deviation has decreased by at least 20 percent. However the large variation in the physiotherapy department may be due to registration effects. Physiotherapy is frequently also performed for outpatients for whom registration is often poor. The remainder of this section presents the results of the efficiency analysis based on the data without outliers.

Table 9: Parameter estimates of stochastic frontier analysis for the total hospital

\begin{tabular}{lcc}
\hline \hline Parameter & Estimate & T-value \\
\hline Constant & 2.15 & 6.61 \\
Output & & \\
(Weighted) admissions & 0.64 & 20.34 \\
(Weighted) day-care & 0.14 & 6.03 \\
First outpatient visit & 0.23 & 8.60 \\
Education & 0.00 & 3.23 \\
First-aid & 0.01 & 1.01 \\
Prices & & \\
P_general_staff & 0.35 & 4.52 \\
P_support & -0.02 & -0.36 \\
P_nurses & 0.13 & 2.96 \\
Efficiency parameters & & \\
Y & 0.79 & 30.06 \\
$S^{2}$ & 0.01 & 5.24 \\
$\mu$ & 0.17 & 6.36 \\
$\eta$ & -0.02 & -0.80 \\
$\sigma_{v}$ & 0.01 & \\
$\sigma_{\mu}$ & 0.78 & \\
\hline \hline
\end{tabular}

Table 9 and Table 10 present the results of the SFA for the total hospital and the 6 individual departments. Table $9^{1}$ shows the estimation results for the total hospital. The parameters that represent the production are highly significant $(p<$ .01). The parameter estimate for the weighted admission is approximately four times as high as the parameter estimate for day-care and three times as high as the parameter estimate for outpatients. The total of the parameter estimates for the production measures approximately equals one. This indicates the absence of both diseconomies and economies of scale in Dutch hospitals. The parameter $\mu$ is statistically significant, this shows that an 'ordinary' $N^{+}\left(0, \sigma_{\mu}\right)$ distribution is rejected. Efficiency is estimated by the parameters $Y$ and $S^{2}$, see equation 5 . Based on this equation the error component $\left(\sigma_{v}\right)$ and efficiency component $\left(\sigma_{\mu}\right)$

\footnotetext{
${ }^{1}$ Table 9 presents the same results as model $2 \mathrm{~b}$ in Table 5 . For reasons of completeness this table is also presented in this chapter.
} 
can be calculated. $\sigma_{\mu}$ exceeds $\sigma_{v}$ by more than a factor of 50 . This indicates that inefficiency plays a bigger role than random variation. Together with the significance of the estimates for $\gamma$, which measures the relative size of $\sigma_{\mu}$ compared to $\sigma_{v}$ this suggests that inefficiency exists in Dutch hospitals and that there are differences in inefficiency between Dutch hospitals. 
Table 10: Parameter estimates of stochastic frontier analysis for departments

\begin{tabular}{|c|c|c|c|c|c|c|}
\hline \multirow{2}{*}{ No. Obs. } & \multirow{2}{*}{$\begin{array}{c}\text { Ward } \\
258\end{array}$} & \multirow{2}{*}{$\begin{array}{c}\text { Outpatient } \\
282\end{array}$} & \multirow{2}{*}{$\begin{array}{c}\begin{array}{c}\text { Operating } \\
\text { theatre }\end{array} \\
278\end{array}$} & \multicolumn{3}{|c|}{ Radiology LaboratoryPhysiotherapy } \\
\hline & & & & 173 & 193 & 237 \\
\hline \multicolumn{7}{|l|}{$\mathrm{R}^{2} \mathrm{OLS}$} \\
\hline Const & $\begin{array}{l}-1.50 \\
(-1.3)\end{array}$ & $\begin{array}{l}-10.86 \\
(-10.5)\end{array}$ & $\begin{array}{l}3.11 \\
(1.3)\end{array}$ & $\begin{array}{l}-1.39 \\
(-1.0)\end{array}$ & $\begin{array}{l}-3.85 \\
(-1.5)\end{array}$ & $\begin{array}{l}-8.49 \\
(-2.5)\end{array}$ \\
\hline \multicolumn{7}{|c|}{ Explanatory variables (production) } \\
\hline First ward day & $0.41(5.8)$ & & & & & \\
\hline Other ward days & $0.40(7.0)$ & & & & & \\
\hline Day-care & $\begin{array}{c}0.25 \\
(5.53)\end{array}$ & & & & & \\
\hline First outpatient visit & & $\begin{array}{l}0.52 \\
(6.3)\end{array}$ & & & & \\
\hline Other outpatient visits & & $\begin{array}{l}0.49 \\
(6.6)\end{array}$ & & & & \\
\hline Weighted procedure & & $\begin{array}{l}0.01 \\
(0.2)\end{array}$ & & & & \\
\hline Weighted operations & & & $\begin{array}{c}0.87 \\
(26.3)\end{array}$ & & & \\
\hline Weighted X-rays & & & & $\begin{array}{c}0.99 \\
(38.9)\end{array}$ & & \\
\hline Weighted lab-research & & & & & $\begin{array}{c}0.88 \\
(33.3)\end{array}$ & \\
\hline Weighted physiotherap & & & & & & $\begin{array}{c}0.80 \\
(15.0)\end{array}$ \\
\hline \multicolumn{7}{|c|}{ Explanatory variables (prices) } \\
\hline P_general_staff & $0.23(2.8)$ & $\begin{array}{l}0.33 \\
(2.5)\end{array}$ & $\begin{array}{l}-0.06 \\
(-0.4)\end{array}$ & $\begin{array}{l}-0.07 \\
(-0.7)\end{array}$ & $\begin{array}{l}-0.13 \\
(-1.2)\end{array}$ & $\begin{array}{l}0.09 \\
(0.5)\end{array}$ \\
\hline P_nurses & $0.43(3.8)$ & $\begin{array}{l}0.81 \\
(4.9)\end{array}$ & $\begin{array}{l}0.22 \\
(1.3)\end{array}$ & & & \\
\hline P_Students & $0.01(0.8)$ & & & & & \\
\hline P_support & $0.06(0.5)$ & $\begin{array}{l}0.22 \\
(1.7)\end{array}$ & $\begin{array}{l}0.29 \\
(1.9)\end{array}$ & $\begin{array}{l}0.19 \\
(1.6)\end{array}$ & $\begin{array}{l}0.42 \\
(2.4)\end{array}$ & $\begin{array}{l}0.63 \\
(2.0)\end{array}$ \\
\hline \multicolumn{7}{|c|}{ Variables explaining efficiency } \\
\hline$S^{2}$ & $\begin{array}{c}0.02 \\
4.6\end{array}$ & $\begin{array}{c}0.07 \\
5,8\end{array}$ & $\begin{array}{l}0.04 \\
4.87\end{array}$ & $\begin{array}{l}0.02 \\
5.20\end{array}$ & $\begin{array}{l}0.03 \\
4.60\end{array}$ & $\begin{array}{l}0.19 \\
2.56\end{array}$ \\
\hline Y & $\begin{array}{c}0.66 \\
(13.3)\end{array}$ & $\begin{array}{l}0.78 \\
(5.8)\end{array}$ & $\begin{array}{c}0.73 \\
(4.87)\end{array}$ & $\begin{array}{c}0.68 \\
(5.20)\end{array}$ & $\begin{array}{c}0.82 \\
(4.60)\end{array}$ & $\begin{array}{c}0.88 \\
(2.56)\end{array}$ \\
\hline$\mu$ & $\begin{array}{l}0.21 \\
(5.6)\end{array}$ & $\begin{array}{l}0.48 \\
(8.6)\end{array}$ & $\begin{array}{l}0.31 \\
(4.2)\end{array}$ & $\begin{array}{l}0.21 \\
(4.8)\end{array}$ & $\begin{array}{l}0.30 \\
(4.3)\end{array}$ & $\begin{array}{l}0.42 \\
(2.0)\end{array}$ \\
\hline$\eta$ & $\begin{array}{l}-0.12 \\
(-2.8)\end{array}$ & $\begin{array}{l}-0.03 \\
(-1.6)\end{array}$ & $\begin{array}{l}0.01 \\
(0.4)\end{array}$ & $\begin{array}{l}-0.01 \\
(-0.2)\end{array}$ & $\begin{array}{l}0.01 \\
(0.3)\end{array}$ & $\begin{array}{l}-0.09 \\
(-3.5)\end{array}$ \\
\hline$\sigma_{v}$ & 0.011 & 0.057 & 0.028 & 0.011 & 0.024 & 0.168 \\
\hline$\sigma_{\mu}$ & 0.649 & 0.725 & 0.704 & 0.671 & 0.791 & 0.715 \\
\hline
\end{tabular}


Table 10 shows the results of the stochastic frontier estimation for the departments. A stochastic frontier analysis is performed for each department separately. The parameters representing the production variables are statistically significant $(p<.01)$ for all departments. This suggests that the production parameters distinguished in this study reflect differences in the true production of the departments. This is also shown by the $\mathrm{R}^{2}$-measures for the OLS-equations which vary between 0.76 and 0.95 . The price parameters provide a less consistent picture. Most estimates are not statistically significant at the $5 \%$ level. Some parameter estimates are even statistically non-significant and negative. This is probably due to multicollinearity in the price variables. All correlation coefficients between the price variables are statistically significant and positive and vary between 0.08 for the correlation between the price of students and support staff, and 0.43 between the price of support staff and nurses. The statistically significant parameter estimates confirm our expectations. The price of nurses significantly influences the costs of the ward. The price of technical staff has a significant effect on the costs of the operating theatre, the laboratory and the physiotherapy department.

The significance of the efficiency differences of the departments between hospitals is measured by the significance of the parameter estimate for $\gamma$. The finding that $y$ is highly statistically $(p<.01)$ significant for all departments leads to the conclusion that efficiency differences of hospital departments between hospitals exist. The finding that $\sigma_{\mu}$, which measures the variation in efficiency, is much (at least a factor 35 ) larger than $\sigma_{v}$, which measures random variation, adds to this conclusion. The conclusion holds for all six departments included in this study: ward, outpatient, operating theatre, radiology, laboratory and physiotherapy.

Table 11: Mean efficiency per department per year

\begin{tabular}{lcccccc}
\hline \hline Department & 1998 & 1999 & 2000 & 2001 & 2002 & Total \\
\hline Ward & $88.4 \%$ & $86.5 \%$ & $84.8 \%$ & $83.1 \%$ & $81.1 \%$ & $84.9 \%$ \\
Outpatient & $64.4 \%$ & $62.8 \%$ & $61.6 \%$ & $59.7 \%$ & $60.0 \%$ & $61.8 \%$ \\
Operating theatre & $72.0 \%$ & $73.5 \%$ & $73.4 \%$ & $72.4 \%$ & $71.5 \%$ & $72.6 \%$ \\
Radiology & N/A & $81.6 \%$ & $80.5 \%$ & $80.8 \%$ & $79.8 \%$ & $80.7 \%$ \\
Laboratory & $75.7 \%$ & $74.2 \%$ & $73.7 \%$ & $73.6 \%$ & $72.9 \%$ & $74.0 \%$ \\
Physiotherapy & $74.7 \%$ & $73.4 \%$ & $70.5 \%$ & $67.7 \%$ & $64.3 \%$ & $69.9 \%$ \\
\hline \hline
\end{tabular}

To obtain more insight in the variation in efficiency between departments Table 11 contains the mean efficiency estimates for the six different departments. The highest mean efficiency is found for the ward: $85 \%$. The lowest mean efficiency is found for the outpatient department, being $62 \%$.

Table 11 further presents the change in efficiency over time, measured by the parameter $\eta$. Two departments, the operating theatre and the laboratory, increased their efficiency over time. These departments are less dependent on 
staff ( $46 \%$ of both departments). The other departments show a decreasing efficiency over time. The estimated time varying efficiency change is statistically significant for both the ward and the physiotherapy department. The processes of these departments depend more on staff (respectively $73 \%$ and $77 \%$ of costs), and therefore efficiency gains are probably more difficult to achieve.

Table 12: Correlations and regressions of mean efficiency on four quality variables

\begin{tabular}{llcccc}
\hline \hline & Correlation & \multicolumn{3}{c}{ Regression } \\
\hline & Correlation coefficient & p-value & Beta & t-value & $p$-value \\
Constant & & & $8.02 \mathrm{E}-01$ & 34.42 & 0.00 \\
Patient friendly & 0.35 & .00 & $4.67 \mathrm{E}-03$ & 2.08 & 0.04 \\
Cooperation & 0.28 & .01 & $2.06 \mathrm{E}-03$ & 0.72 & 0.47 \\
Organization & 0.21 & .06 & $2.14 \mathrm{E}-03$ & 0.84 & 0.41 \\
Care & -0.10 & .39 & $-3.26 \mathrm{E}-03$ & -1.54 & 0.13 \\
\hline \hline
\end{tabular}

Table 12 presents the relation between efficiency and the quality of the hospital. First, Table 12 shows that three out of four quality parameters are positively and statistically significant correlated to efficiency. The fourth parameter, quality of care, is correlated negatively but non-statistically significant with efficiency. This indicates that more efficient hospitals also are better organized, have a better cooperation with other health care providers, and are more patient friendly.

Table 12 further presents the results of the regression analysis where efficiency is the dependent variable and the quality variables are the explanatory variables. In the regression analysis only one of the individual efficiency parameter estimates, the parameter estimate for patient friendly treatment, is positive and statistically significantly different from 0 . The lack of statistically significance in the regression analysis for the variables which are statistically significantly correlated with efficiency can be explained by multicollinearity. The four quality variables together explain $15.8 \%$ (adjusted $R^{2}=.158$ ) of the inefficiency of hospitals. This $15.8 \%$ can be interpreted as possible savings that can maximum be realized by improving quality. This is an interesting figure, especially if we realize that the annual costs of general hospitals are about $€ 10$ billion.

Table 13: Correlations between efficiency of departments and the total hospital

\begin{tabular}{|c|c|c|c|c|c|c|c|}
\hline Department & & Total & Ward & Outpatient & $\begin{array}{l}\text { Operating } \\
\text { theatre }\end{array}$ & Radiology & Laboratory \\
\hline \multirow[t]{2}{*}{ Ward } & correlation & 0.29 & & & & & \\
\hline & p-value & 0.00 & & & & & \\
\hline \multirow[t]{2}{*}{ Outpatient } & correlation & 0.09 & -0.01 & & & & \\
\hline & p-value & 0.11 & 0.87 & & & & \\
\hline \multirow[t]{2}{*}{ Operating theatre } & correlation & 0.40 & 0.14 & -0.13 & & & \\
\hline & p-value & 0.00 & 0.06 & 0.04 & & & \\
\hline \multirow[t]{2}{*}{ Radiology } & correlation & 0.12 & 0.03 & 0.16 & -0.01 & & \\
\hline & $p$-value & 0.12 & 0.74 & 0.04 & 0.90 & & \\
\hline \multirow[t]{2}{*}{ Laboratory } & correlation & -0.01 & 0.00 & 0.05 & 0.10 & -0.03 & \\
\hline & p-value & 0.87 & 0.95 & 0.51 & 0.19 & 0.74 & \\
\hline \multirow[t]{2}{*}{ Physiotherapy } & correlation & 0.31 & 0.24 & -0.02 & 0.32 & 0.02 & 0.25 \\
\hline & p-value & 0.00 & 0.00 & 0.72 & 0.00 & 0.83 & 0.00 \\
\hline
\end{tabular}


Table 13 presents the correlation coefficients between the efficiency estimates of the total hospital and the efficiency estimates of the individual departments. Table 13 shows that the correlations between the efficiency of the different departments and the total hospital are all below 0.40 . The efficiency of the ward, the physiotherapy department and the operating theatre are significant and positively correlated with the efficiency of the total hospital. The efficiency of the outpatient department, the radiology and the laboratory are not significantly correlated with the efficiency of the hospital. The mutual correlations between the efficiency estimates of the departments are all below 0.32 and 10 out of 15 correlation estimates are not statistically significant.

Our general conclusion is that the efficiency of departments in a hospital is mostly independent of the efficiency of other departments in the same hospital and is independent of the efficiency of the total hospital. The departmental efficiency is for three out of six departments not statistically significantly correlated with the efficiency of the total hospital. For the departments whose efficiency is significantly correlated with hospital efficiency, the correlation coefficient is less than 0.40 .

As we described in the introduction this lack of relation between the efficiency of departments and the efficiency of the total hospital can be explained by the fact that departments and hospitals do not strive towards common goals. It seems that departments have an incentive to maximize efficiency of their department which may conflict with maximizing the efficiency at the hospital level. Whether this is really the case can be tested. If the lack of relation between hospital efficiency and departmental efficiency is due to a bad cooperation as we presume, we expect that a high efficiency score for its departments and a low efficiency for the total hospital comes together with low cooperation. Cooperation is one of the quality variables in this study. Table 14 provides the scores of this variable for 4 groups of hospitals. These groups are based on the efficiency scores of the total hospital organization and of the departments of the hospitals. Hospitals are divided in 2 groups on both variables. $50 \%$ of the hospitals with the highest scores in group 1,50\% with the lowest scores in group 2.

Table 14: Score of quality measure cooperation in high and low hospital and department efficiency groups

\begin{tabular}{lccc}
\hline \hline & & \multicolumn{2}{c}{ Efficiency of total hospital } \\
\hline & & High & Low \\
& \multirow{3}{*}{ High } & 5.7 & 3.1 \\
Efficiency of the & $(0.6)$ & $(0.9)$ \\
departments & & 4.5 & 5.1 \\
& \multirow{2}{*}{ Low } & $(0.8)$ & $(0.7)$ \\
\hline \hline
\end{tabular}

As we can see from Table 14 hospitals which have both a high total hospital efficiency and a high departmental efficiency also have the highest score on the variable cooperation. The group of hospitals with a low efficiency of the total hospital and the departments scores second best. We see an interaction be- 
tween hospital efficiency and departmental efficiency on the score of cooperation. The statistical effect of this interaction can be tested by a simple Anova Ftest. This F-test shows that both the efficiency of the hospital and the efficiency of the department have no statistically significant relation with cooperation. The interaction effect though is significant at the $5 \%$ level $(p=0.04)$. This result confirms our expectation that departments with a high efficiency within a hospital with a low efficiency at the hospital level show worst cooperation. Cooperation is a key issue for hospitals to get both high efficiency on total hospital level and department level. 


\subsection{Discussion}

In this study we have analyzed efficiency of hospitals and of hospital departments. Corroborating our first hypothesis and findings of most previous studies, we do not find that efficiency can be explained by a lack of quality. On the contrary, we find that efficiency and quality go together. They are complements rather than substitutes. This provides new evidence that efficiency differences between hospitals cannot simply be explained by quality differences.

We find supportive evidence for our second hypothesis that hospital efficiency differs from departmental efficiency. In most Dutch hospitals departments are financed for the intermediate products they produce. This leads to an interest that is (partly) different from the interests of the entire hospital. Our results show that cooperation is a key issue in getting high efficiency in both the departments and the total hospital organization.

Our third hypothesis was confirmed as well: there is hardly any relation between the efficiency of different hospital departments. First, this finding can be a result of the capitation system of hospitals. Because hospitals receive a budget, efficiency in one department can compensate for inefficiency in another department. Second, this finding can be a result of the way a hospital is organized (van Merode, 2004), because this finding suggests that the inefficiency of departments depends mainly on department managers and less on the general board of the hospital. This idea is supported by our finding that hospitals which score low on departmental efficiency and high on hospital efficiency and vice versa score lower on the quality measure cooperation, than hospitals that score high on both measures.

Our findings imply that striving for efficiency within hospital departments only partly contributes to increased efficiency in hospitals. This finding has policy and managerial implications, since the organizational and financial structures of Dutch hospitals are often functional and aimed at creating efficient departments. Organizational structures that facilitate efficient treatment of patients are less common. This implies that Dutch hospitals accept inefficiency in their organizations because of their functionalistic structure. In this structure goals of department managers partly differ from goals of the hospital, since the internal budgeting system of most Dutch hospitals maximizes the efficiency of intermediate products instead of maximizing the utility of the total hospital. The changing financing system of Dutch hospitals, where case mix based funding is introduced instead of financing individual procedures, might help in improving the efficiency of hospitals. A case mix based funding might lead to a client driven organizational structure for hospitals as well. However, a case mix based funding is not sufficient to maximize efficiency. Even in case mix reimbursement systems, the practice is often that third party payers buy packages of often unrelated services to avoid (in the phrasing of health care providers) cherry picking (van Merode, 2004). Inefficiency as a result of bad integration of the health care chain inside 
to avoid (in the phrasing of health care providers) cherry picking (van Merode, 2004). Inefficiency as a result of bad integration of the health care chain inside (and outside) the hospital will only disappear if case mix reimbursement is applied without package buying and if efficiency and effectiveness is rewarded at the case level and not at the intermediary product level.

To conclude, if we consider the finding that quality and efficiency come together from an agency perspective, it could be concluded that potential quality problems which may arise because of information asymmetry between hospitals and their patients may not be as harmful as is commonly believed. This conclusion could be true because the interest of the patient (good quality) comes together with the interest of the hospital (efficiency) if the latter has the utility of the patient in mind. Although this is perhaps an unexpected finding in efficiency studies in health care, studies in management science, for example Porter and Olmsted Teisberg (2004) and van Merode (2004) already considered that efficiency and quality are complements. These studies emphasize that the way a hospital is organized, influences both quality and efficiency simultaneously and in the same direction. Hospitals that are focused on the client both perform better on quality and efficiency. 


\section{Appendix: Direct and indirect costs per department}

Using data on a cost centre level gives us the opportunity to find the actual causes of hospital efficiency. However data at cost centre level presents an issue: Cost allocation to the departments must be accurate. In the main text, we provided insight in the process of gathering the data:

1. We use administrative data, which are being gathered for decades for direct staff costs.

2. We allocate data regarding to the indirect staff, in order to make the hospitals better comparable.

3. We allocate material costs based on the national cost calculation scheme.

4. We analyze the data after removing outliers.

In this appendix, we give further insight in the statistics of the data used in the different steps.

Table A.1, A.2, and A.3 provide the main statistics of costs, output and costprices per department respectively.

Table A.1: Main statistics of costs $\left({ }^{*} € 1000\right)$ for each department

\begin{tabular}{llcccccc}
\hline \hline Department & Statistic & 1998 & 1999 & 2000 & 2001 & 2002 & Total \\
\hline \multirow{4}{*}{ Ward } & Average & 22,902 & 23,829 & 25,593 & 28,280 & 31,967 & 26,326 \\
& Sd & 11,023 & 12,483 & 12,457 & 13,999 & 17,549 & 13,880 \\
& Max & 59,996 & 62,742 & 59,760 & 68,584 & 81,310 & 81,310 \\
& Min & 7,344 & 7,769 & 8,048 & 9,395 & 8,353 & 7,344 \\
\hline \multirow{5}{*}{ Outpatient } & Average & 4,844 & 5,450 & 6,055 & 6,599 & 7,543 & 6,073 \\
& Sd & 2,670 & 2,732 & 3,071 & 3,308 & 4,534 & 3,436 \\
& Max & 13,310 & 13,498 & 13,737 & 16,243 & 25,494 & 25,494 \\
& Min & 1,482 & 1,254 & 705 & 1,285 & 278 & 278 \\
\hline \multirow{5}{*}{ Operating theatre } & Average & 6,866 & 7,063 & 7,566 & 8,457 & 9,421 & 7,846 \\
& Sd & 3,834 & 4,015 & 3,995 & 5,134 & 6,207 & 4,764 \\
& Max & 18,546 & 19,129 & 19,766 & 24,592 & 34,639 & 34,639 \\
Radiology & Min & 1,855 & 1,982 & 2,099 & 2,842 & 816 & 816 \\
\hline & Average & N/A & 3,550 & 4,048 & 4,148 & 4,711 & 4,116 \\
& Sd & N/A & 1,777 & 1,839 & 1,990 & 2,138 & 1,968 \\
& Max & N/A & 7,528 & 8,513 & 8,212 & 9,686 & 9,686 \\
& Min & N/A & 1,106 & 1,616 & 1,034 & 1,871 & 1,034 \\
\hline \multirow{5}{*}{ Laboratory } & Average & 4,263 & 4,388 & 4,493 & 4,900 & 5,524 & 4,736 \\
& Sd & 2,439 & 2,822 & 2,545 & 2,728 & 3,366 & 2,829 \\
& Max & 11,901 & 12,961 & 12,439 & 12,233 & 14,429 & 14,429 \\
& Min & 1,080 & 1,542 & 1,423 & 1,368 & 1,261 & 1,080 \\
\hline \hline
\end{tabular}

Table A.1 presents the costs for the six departments distinguished in this study. We see that most costs are made in the ward on average $€ 26.3$ million per hospital. The other departments have on average about the same costs together. The lowest average costs we find in the physiotherapy department being $€ 1.0$ million. We see that the average costs of all departments tend to rise between 1998 and 2002. The same holds for the standard deviation. For all 
departments we find standard deviations of costs between the hospitals above half of the average costs. For the physiotherapy the standard deviation is about the same as the average costs. This indicates a large variation of costs between hospitals. The minimum and maximum also vary largely between hospitals. Although these findings may be expected since there are large differences in size between hospitals, we also see some figures indicating data problems. For example, the minimum costs in the physiotherapy departments are below $€ 15,000$ in 2000, 2001 and 2002. Also in the outpatient department and the operating theatre we see variations between the minimum and maximum of factors above 40 . This may indicate that data of some hospitals are not valid.

Table A.2: Main statistics of outputs for each department

\begin{tabular}{llcccccc}
\hline \hline Department & Statistic & 1998 & 1999 & 2000 & 2001 & 2002 & Total \\
\hline \multirow{4}{*}{ Ward } & Average & 120,124 & 115,624 & 118,970 & 114,601 & 121,084 & 118,161 \\
& Sd & 55,038 & 55,720 & 52,939 & 51,458 & 59,261 & 54,692 \\
& Max & 317,846 & 300,604 & 265,050 & 276,928 & 320,128 & 320,128 \\
& Min & 35,979 & 35,038 & 36,569 & 37,610 & 38,648 & 35,038 \\
\hline \multirow{5}{*}{ Outpatient } & Average & 59,662 & 75,074 & 80,657 & 83,089 & 89,735 & 77,304 \\
& Sd & 23,534 & 31,861 & 31,880 & 34,939 & 40,886 & 34,359 \\
& Max & 130,436 & 168,955 & 160,837 & 173,143 & 199,675 & 199,675 \\
Operating & Min & 18,551 & 27,666 & 28,998 & 30,896 & 31,533 & 18,551 \\
\hline \multirow{2}{*}{ theatre } & Average & 7,410 & 7,879 & 8,875 & 9,215 & 10,516 & 8,746 \\
& Sd & 4,445 & 4,446 & 4,821 & 5,178 & 6,405 & 5,176 \\
& Max & 22,076 & 23,404 & 24,981 & 27,023 & 31,874 & 31,874 \\
& Min & 1,946 & 2,501 & 2,512 & 2,660 & 2,067 & 1,946 \\
\hline \multirow{5}{*}{ Radiology } & Average & N/A & $3,687,585$ & $4,175,316$ & $4,203,910$ & $4,861,799$ & $4,234,703$ \\
& Sd & N/A & $1,801,458$ & $1,861,434$ & $1,882,940$ & $2,244,379$ & $1,983,311$ \\
& Max & N/A & $7,922,489$ & $8,371,968$ & $8,100,130$ & $10,457,331$ & $10,457,331$ \\
& Min & N/A & $1,330,296$ & $1,385,734$ & $1,520,845$ & $1,528,157$ & $1,330,296$ \\
\hline \multirow{5}{*}{ Laboratory } & Average & $11,310,249$ & $11,519,620$ & $11,129,957$ & $12,418,353$ & $16,180,457$ & $12,605,969$ \\
& Sd & $6,680,185$ & $7,472,528$ & $6,619,680$ & $7,454,441$ & $17,656,982$ & $10,479,066$ \\
& Max & $30,644,513$ & $30,809,362$ & $31,759,090$ & $33,035,172$ & $122,520,846$ & $122,520,846$ \\
& Min & $3,210,899$ & $3,356,560$ & $3,566,277$ & $4,011,963$ & $4,183,550$ & $3,210,899$ \\
\hline \hline
\end{tabular}

Table A.2 presents the total output per department. See the data section in the main text for a description of the output per department. Next to the costs we see a rising trend of production for all departments. An exception is the ward, since more patients are treated in an outpatient setting and the average length of stay is decreasing. Further we see differences in output between departments. However the relative difference between the minimum and maximum amount is smaller for output than for costs. The amount of output of the departments varies between the hospitals as indicated by the standard deviations and minimum and maximum values. However, the standard deviation of outputs compared to the average output is lower than for the inputs. The same holds for the difference between the minimum and maximum score. Since the outputs used in this study 
are a financing parameter of hospitals it could be expected that those are measured relatively well and data validity is less an issue.

Table A.3 Main statistics of costs per unit of output (€) for each department

\begin{tabular}{llcccccc}
\hline \hline Department & Statistic & 1998 & 1999 & 2000 & 2001 & 2002 & Total \\
\hline \multirow{4}{*}{ Ward } & Average & 190.25 & 205.29 & 213.86 & 243.73 & 258.73 & 220.73 \\
& Sd & 22.23 & 27.68 & 28.53 & 28.94 & 33.12 & 37.65 \\
& Max & 258.83 & 284.82 & 311.34 & 322.63 & 347.68 & 347.68 \\
& Min & 140.35 & 124.47 & 156.75 & 165.81 & 166.04 & 124.47 \\
\hline \multirow{4}{*}{ Outpatient } & Average & 80.18 & 72.71 & 74.24 & 79.79 & 83.39 & 78.07 \\
& Sd & 24.49 & 21.47 & 21.09 & 21.82 & 26.39 & 23.39 \\
& Max & 151.92 & 157.42 & 157.02 & 162.65 & 151.12 & 162.65 \\
& Min & 21.90 & 26.57 & 18.36 & 26.55 & 5.04 & 5.04 \\
\hline \multirow{4}{*}{ Operating theatre } & Average & 950.94 & 908.92 & 876.78 & 939.56 & 927.80 & 920.96 \\
& Sd & 186.90 & 179.12 & 186.59 & 230.38 & 292.67 & 218.44 \\
& Max & $1,658.02$ & $1,292.82$ & $1,314.03$ & $1,553.77$ & $1,592.16$ & $1,658.02$ \\
& Min & 554.00 & 601.62 & 463.26 & 464.69 & 78.25 & 78.25 \\
\hline \multirow{4}{*}{ Ladiology } & Average & $\mathrm{N} / \mathrm{A}$ & 0.96 & 0.98 & 0.98 & 0.98 & 0.98 \\
& Sd & $\mathrm{N} / \mathrm{A}$ & 0.11 & 0.11 & 0.14 & 0.12 & 0.12 \\
& Max & $\mathrm{N} / \mathrm{A}$ & 1.18 & 1.28 & 1.30 & 1.27 & 1.30 \\
& Min & $\mathrm{N} / \mathrm{A}$ & 0.71 & 0.76 & 0.68 & 0.81 & 0.68 \\
\hline \hline \multirow{6}{*}{ Physiotherapy } & Average & 0.39 & 0.41 & 0.42 & 0.42 & 0.40 & 0.41 \\
& Sd & 0.07 & 0.11 & 0.08 & 0.09 & 0.12 & 0.10 \\
& Max & 0.57 & 0.78 & 0.59 & 0.61 & 0.83 & 0.83 \\
& Min & 0.25 & 0.10 & 0.28 & 0.27 & 0.11 & 0.10 \\
\hline \hline
\end{tabular}

Table A.3 presents the prices (cost/output) of the different departments. We see some large variations between hospitals. The least variation we find for the ward and the radiology department, although also for these departments the variation in price is still about a factor 2. Concerning other departments we see variations between hospitals which are in each year above 2 till more than 10 and higher for the physiotherapy department.

Together with our finding that some cost data might not be valid, these findings indicate that some invalid data are present in our dataset and outliers should be removed. 



\title{
5. Hospital efficiency: the effects of transaction costs
}

\begin{abstract}
The make-or-buy decision of organizations is an important issue in the transaction cost theory, but is usually not analyzed from an efficiency perspective. Hospitals frequently have to decide whether to outsource or not. The main question we address: Is the make-or-buy decision affected by the efficiency of hospitals? A one stage stochastic cost frontier equation is estimated for Dutch hospitals. The make-or-buy decision of ten different hospital services is used as explanatory variables to explain efficiency of hospitals.

It is found that for most services the make-or-buy decision is not related to efficiency. Kitchen services are an important exception. Large hospitals tend to outsource less, which is supported by efficiency reasons. For most hospital services, outsourcing does not significantly affect the efficiency of hospitals. The focus on the make-or-buy decision may therefore be less important than often assumed.
\end{abstract}




\subsection{Introduction}

In the Netherlands, approximately $9 \%$ of Gross National Product (GNP) is spent on health care (CPB, 2006a). The rapid increase in health care expenditures - at a rate of $7 \%$ per year during the last decade - has raised concerns about the efficiency of health care. Governments in Western Europe have tried to increase efficiency by applying budget pressures on health care institutions such as hospitals.

Hospitals have responded to this by distinguishing between core and non-core activities and have considered outsourcing of some of the non-core activities. Many hospital managers consider outsourcing as a way to improve efficiency. Little is known about the efficiency of outsourcing, even though the make-or-buy decision is the archetypical question of TCE.

The concept of transaction costs has been introduced by Coase (1937) and further developed by Williamson (1975, 1985 and 1996). According to Williamson (1996, p.12) "TCE is an effort to identify, explicate and mitigate contractual hazards". TCE, at its core, focuses on: 'transactions and the costs that attends completing transactions by one institutional mode rather than another' (Williamson, 1975, pp.1-2). The main phenomenon of interest of TCE has been defined by Coase (1937) as the question: "Given that there are markets, why are there firms?" Williamson (1998) states that answering this question should be done by working up an archetypical problem. The archetypical problem for TCE has been vertical integration (Williamson, 1998) or in other words: "make-or-buy".

The importance of TCE has been recognized in health care. Ferlie and McGiven (2003) present a research agenda for the inter organization relationships in the (UK) health field in which TCE has an important part. Preker (2000) presents theoretical insights from the Neo-Institutional Economics (NIE) for the make-orbuy decision of health care goods in developing countries. Snail and Robinson (1998) present a conceptual framework for organizational diversification in American hospitals.

Most of the studies using TCE are conceptual studies that aim at classifying activities within a NEI framework. Empirical studies using TCE are scarce. Coles and Hesterly (1998a) consider transaction costs as a basis for the make-or-buy decisions of hospitals. More specifically they examine the impact of quality and economies of scale on these decisions. Coles and Hesterly (1998b) study the impact of uncertainty and the interaction with asset specificity in determining the influence on the make-or-buy decision. Even in these few studies that do analyze the make-or-buy decision, no link with efficiency is made.

In this study we focus on the relationship between the make-or-buy decision and the efficiency of hospitals. The question we want to answer is: Is the make-orbuy decision related to the efficiency of hospitals? 
As was pointed out above, the make-or-buy issue is the archetypical problem of TCE. The decision to make-or-buy a certain good aims to economize on transaction costs. The key issue in this decision is the so called asset specificity (Williamson, 1975). In general, TCE states that it is more efficient to buy services with no asset specificity and where asset specificity is slight, because of bureaucratic costs of internal governance. Internal organization is favored when asset specificity is high (Williamson, 1996).

Asset specificity can take various forms. Williamson (1996) distinguishes six of them: site specificity, physical asset specificity, human asset specificity, dedicated assets, brand name capital and temporal specificity.

There are a number of empirical applications of this theoretical concept of asset specificity. Coles and Hesterly (1998a) distinguish the physical and human asset specificity of a number of hospital services. Based on this classification, they conclude that human asset specificity has a significant influence on the contracting decision for hospital specific services, while physical asset specificity has an effect on non-medical services.

The latter finding points towards another aspect of asset specificity: industry specificity. Services that are more industry specific, like medical services in hospitals, are less likely to be outsourced. A reason for this is that the gains of economies of scale may not be sufficient for out-contracting to be profitable. For example computers are bought by different kinds of organizations, while X-rays are almost solely sold to hospitals. Also medical services can be expected to be more dedicated than non-medical services.

In their study on asset specificity of hospitals, Coles and Hesterly (1998a) ignore the relation with hospital efficiency. In this study we will focus on the relation between asset specificity and the efficiency of the make-or-buy decision. In line with the theory of transaction costs, we expect that outsourcing services with high asset specificity will decrease efficiency while outsourcing services with low asset specificity will increase efficiency.

Taking asset specificity as the sole explanation of the efficiency of a make-orbuy decision is oversimplifying as economies of scale and scope are neglected (Williamson, 1996, p.67). Therefore production costs need to be taken into account as well. Williamson (1996, p.68) states that when asset specificity of the production is low, markets can achieve more economies of scale than production within the firm. Further Williamson (1996, p.69) states that when firms produce more, the disadvantage of diseconomies of scale compared to market transactions become smaller. Based on this theory it can be expected that economies of scale influence the make-or-buy decision. Outsourcing services for which there are economies of scale is probably more efficient for small hospitals than for large hospitals. 
However, Lyons (1995) - who explicitly examines the relation between outsourcing, asset specificity and economies of scale - found that this effect is "much reduced in the presence of asset specificity." He also finds that "in the presence of asset specificity, economies of scale have no influence." Furthermore Coles and Hesterly (1998a) even find that large hospitals are contracting out more nonmedical (less asset specific) services than small hospitals. So the empirical findings differ from what might theoretically be expected. Based on these findings our second research question is: do economies of scale matter in the makeor-buy decision of medical and non-medical services?

According to TCE, determinants of the make-or-buy decision are assetspecificity, uncertainty and quality (Coles and Hesterly, 1998a). Both items are especially important in a hospital setting, since the harm that can be done by bad quality service delivery can be large and the uncertainty of goods delivered may differ between hospital services. In general, both the harm of uncertainty and of bad quality is greater in medical services - like e.g. laboratory services and pharmacy - than in the non-medical services - like e.g. laundry services and cleaning. It is intuitively easy to understand that the lack of quality of lab results may do more harm than non-spotless clothes due to a bad laundry service. Therefore, we hypothesize that it is more efficient to outsource non-medical services than medical services. 


\subsection{Data and method}

In general the data and method used in this chapter are comparable to what is described in chapter 2. There are some important differences which are described in this section.

Considering the data, the data used in this chapter are more extensive than the data used in the earlier chapters, mainly because more data were necessary to estimate a one stage model (see equation 7 ). We have data available for eight years, from 1996 to 2003. In this dataset a merger of two hospitals is considered as a new hospital. Because of mergers and because of missing data our data set consists of 109 cross-sections with 576 observations in total over eight years.

The model we estimate is described in equation 2, 3 and 5 in chapter 2 . There are some differences though. Since there are 4 to 6 parameters more to be estimated in formula 5 compared to the earlier chapters, we removed some explanatory variables from formula 2 and 3 to keep a relatively sparse model. First, since price parameters are shown in the earlier chapter to have little influence, the staff is analyzed in one category with one price parameter. Second, 3 output parameters are used: DRG-weighted admissions, DRG-weighted daycare admissions and outpatient visits.

This implies that formula 2, 3, and 5 of chapter 2 are estimated with the following settings:

$\mathrm{m}_{\mathrm{k}}=3$

$\mathrm{q}_{\mathrm{k}}=1$

$\operatorname{Max}\left(T_{k, i}\right)=8$ 


\subsection{Estimation results}

Table 15: Descriptive statistics

\begin{tabular}{lcccccccc}
\hline \hline & \multicolumn{2}{c}{\begin{tabular}{c} 
Small hospitals \\
\multicolumn{2}{c}{$(\mathrm{N}=36)$}
\end{tabular}} & \multicolumn{2}{c}{ Medium sized hospitals } & \multicolumn{2}{c}{ Large hospitals } & \multicolumn{2}{c}{ Total } \\
& Mean & SD & Mean & SD & Mean & SD & Mean & SD \\
& 5,663 & 1,289 & 10,703 & 4,030 & 20,239 & 4,856 & 12,391 & 6,374 \\
& 3,528 & 1,366 & 6,289 & 2,400 & 11,410 & 3,722 & 7,184 & 3,801 \\
Inpatients & 36,567 & 10,676 & 61,821 & 18,584 & 114,211 & 28,835 & 71,476 & 33,982 \\
Day-care patients & 23,060 & 5,814 & 45,778 & 16,844 & 96,087 & 23,693 & 55,295 & 31,054 \\
Outpatients & 4,100 & 549 & 4,279 & 553 & 4,791 & 683 & 4,385 & 638 \\
Cost $\left.{ }^{*} 1000\right)$ & $21 \%$ & 0.18 & $19 \%$ & 0.22 & $15 \%$ & 0.20 & $18 \%$ & 0.21 \\
Cost per patient & $3 \%$ & 0.08 & $6 \%$ & 0.10 & $8 \%$ & 0.15 & $6 \%$ & 0.11 \\
Salary administration & $76 \%$ & 0.24 & $55 \%$ & 0.36 & $62 \%$ & 0.33 & $60 \%$ & 0.35 \\
Administration & $77 \%$ & 0.16 & $72 \%$ & 0.28 & $79 \%$ & 0.25 & $75 \%$ & 0.26 \\
Cleaning inside & $8 \%$ & 0.23 & $9 \%$ & 0.25 & $8 \%$ & 0.23 & $9 \%$ & 0.24 \\
Laundry & $34 \%$ & 0.26 & $30 \%$ & 0.26 & $33 \%$ & 0.25 & $32 \%$ & 0.26 \\
Kitchen & $52 \%$ & 0.25 & $47 \%$ & 0.32 & $43 \%$ & 0.33 & $47 \%$ & 0.31 \\
Maintenance (building) & $21 \%$ & 0.21 & $13 \%$ & 0.12 & $17 \%$ & 0.24 & $15 \%$ & 0.18 \\
Education & $37 \%$ & 0.40 & $13 \%$ & 0.27 & $22 \%$ & 0.37 & $19 \%$ & 0.33 \\
Laboratory & $17 \%$ & 0.35 & $6 \%$ & 0.20 & $5 \%$ & 0.19 & $7 \%$ & 0.23 \\
Pharmacy & $25 \%$ & 0.19 & $11 \%$ & 0.13 & $15 \%$ & 0.17 & $14 \%$ & 0.16 \\
Physiotherapy & $39 \%$ & 0.08 & $36 \%$ & 0.12 & $38 \%$ & 0.12 & $37 \%$ & 0.11 \\
Average medical & & & & & & &
\end{tabular}

Table 15 contains the summary statistics of the variables used in this study. The figures in Table 15 reflect the trend of higher total costs and higher costs per patient. Part of the increase in costs per patient may be explained by a decrease in efficiency. Other factors such as changes in case mix may play a role as well. The large differences in costs between hospitals confirm the need for good explanatory studies for differences in efficiency.

Table 15 also presents the scores for the make-or-buy decision in hospitals. The percentage of goods that is outsourced varies between hospitals and the different types of services. Cleaning (60\%) and laundry (75\%) are services which are most frequently outsourced. Physiotherapy $(7 \%)$, administration $(6 \%)$ and the kitchen $(9 \%)$ are the services which are mostly provided by the hospital organization itself.

The share of activities being outsourced differs between the medical and nonmedical hospital services. Since medical services depend more on the quality by which these services are delivered (Coles and Hesterly, 1998a) and require more certainty in delivery, fewer $(14 \%)$ medical services are outsourced than non-medical hospital services (37\%). Further for some services we observe a variation in the amount of outsourcing between small and large hospitals. Especially for the medical services we see that medium sized and large hospitals tend to produce more within their own organization than small hospitals. For the nonmedical services there are no differences between small, medium sized and large hospitals. 
Table 16: Panel data estimates of the effect of size on the amount of outsourcing

\begin{tabular}{lcc}
\hline \hline Department & Parameter estimate & t-value \\
\hline Salary administration & 0.05 & 0.7 \\
Administration & 0.01 & 0.2 \\
Cleaning inside & 0.27 & 2.5 \\
Laundry & 0.05 & 0.6 \\
Kitchen & -0.11 & -1.7 \\
Maintenance (building) & -0.08 & -1.1 \\
Education & 0.05 & 0.5 \\
Laboratory & 0.03 & 0.6 \\
Pharmacy & -0.41 & -4.0 \\
Physiotherapy & -0.21 & -2.9 \\
Medical services & -0.20 & -3.0 \\
Non medical services & 0.02 & 0.5 \\
\hline \hline
\end{tabular}

Table 16 contains the results of the panel data analysis with the number of beds as the dependent variable and the share of the service that has been outsourced as the explanatory variable. This panel data analysis has been performed for all 10 departments separately. This analysis has also been performed for the group of medical services and non-medical services. Table 16 shows that the amount of outsourcing does not differ much between large and small hospitals. For three out of ten departments we see a statistically significant (at the $5 \%$ level) relationship between size and the amount of outsourcing: Cleaning is a service being outsourced significantly more often by small hospitals, while pharmacy and physiotherapy are also in the group of medical services that are significantly more outsourced by large hospitals. There are no significant differences in outsourcing of non-medical services between large and small hospitals. 
Table 17: Results of one stage stochastic frontier model (model 1)

\begin{tabular}{lccccc}
\hline \hline \multirow{2}{*}{ Service } & & & & & $\delta$ \\
Salary administration & $\gamma$ & $\delta_{\text {time }}$ & $\delta_{\text {small }}$ & $\delta_{\text {middle }}$ & outsourcing \\
\hline \multirow{3}{*}{ Administration } & 0.48 & 0.01 & -0.11 & -0.07 & 0.04 \\
& $(2.4)$ & $(5.0)$ & $(-5.2)$ & $(-5.9)$ & $(2.0)$ \\
Cleaning inside & 0.52 & 0.01 & -0.11 & -0.07 & 0.01 \\
& $(2.9)$ & $(4.7)$ & $(-5.0)$ & $(-5.7)$ & $(0.3)$ \\
Laundry & 0.52 & 0.01 & -0.12 & -0.07 & 0.02 \\
& $(2.7)$ & $(4.8)$ & $(-5.2)$ & $(-5.9)$ & $(1.3)$ \\
Kitchen & 0.52 & 0.01 & -0.06 & 0.02 & -0.01 \\
& $(6.2)$ & $(4.7)$ & $(-0.9)$ & $(1.3)$ & $(-0.4)$ \\
Maintenance (building) & 0.49 & 0.02 & -0.11 & -0.07 & -0.04 \\
Education & $(2.1)$ & $(5.3)$ & $(-5.1)$ & $(-5.9)$ & $(-2.0)$ \\
& 0.48 & 0.02 & -0.11 & -0.07 &.-0.04 \\
Laboratory & $(2.1)$ & $(5.2)$ & $(-5.2)$ & $(-6.0)$ & $(-2.3)$ \\
Pharmacy & 0.51 & 0.01 & -0.11 & -0.07 & -0.03 \\
& $(2.5)$ & $(5.0)$ & $(-5.2)$ & $(-6.0)$ & $(-1.0)$ \\
Physiotherapy & 0.53 & 0.01 & -0.12 & -0.07 & 0.01 \\
& $(3.1)$ & $(4.5)$ & $(-5.1)$ & $(-5.7)$ & $(0.6)$ \\
Medical services & 0.52 & 0.01 & -0.12 & -0.07 & 0.03 \\
Non medical services & $(5.2)$ & $(4.8)$ & $(-5.3)$ & $(-5.6)$ & $(2.0)$ \\
& 0.52 & 0.01 & -0.11 & -0.07 & -0.02 \\
\hline \hline & $(3.1)$ & $(4.6)$ & $(-5.0)$ & $(-5.8)$ & $(-1.1)$ \\
& 0.53 & 0.01 & -0.12 & -0.07 & 0.03 \\
& $(2.9)$ & $(4.6)$ & $(-5.2)$ & $(-5.7)$ & $(1.1)$ \\
& 0.52 & 0.01 & -0.11 & -0.07 & 0.06 \\
& $(2.8)$ & $(4.6)$ & $(-5.1)$ & $(5.8)$ & $(1.5)$ \\
\hline
\end{tabular}

To further examine the efficiency of the make-or-buy decisions in relation to the size of hospitals Table 17 shows the results of the one stage stochastic frontier model (model 1) as described in chapter 2. As in the previous tables analyses have been performed for the group of medical and group of non-medical specific services respectively. Table 17 presents both the parameter estimates and the tvalues (between parentheses) for the different services. Only the parameter estimates for $\mathrm{Y}$ and $\delta_{1}$ to $\delta_{4}$ are presented in Table 17. The other parameter estimates are of limited interest for the aim of this study and we will therefore not describe them in detail. All production parameters and the price parameter are statistically significant different from 0 in all models. The parameter $\alpha_{1}$ varies between 0.64 and 0.65 , the parameter $\alpha_{2}$ varies between 0.07 and 0.10 , the parameter $\alpha_{3}$ varies between 0.34 and 0.36 . The price parameter $\beta$ varies between 0.09 and 0.11 in the different models.

The parameter estimate $\delta_{1}$ is statistically significant and positive in all models. This implies that efficiency has decreased over time. Further the parameters $\delta_{2}$ and $\delta_{3}$ are negative and statistically significant in almost all models. This implies that small and medium sized hospitals are more efficient than large hospitals. Regarding the parameter estimates $\delta_{4}$, we see that for five of the twelve ${ }^{2}$ services there is a statistically (at the $5 \%$ level) significant relationship between

${ }^{2}$ For the department maintenance of the garden the maximum likelihood method did not converge to an optimum, therefore no results are available for this service. 
efficiency and the amount of outsourcing. The five services for which this is the case are the salary administration, cleaning (inside), the kitchen, maintenance of the building and the pharmacy department. For the kitchen and building maintenance services there is a positive relationship between the amount of outsourcing and efficiency. So it appears to be best to outsource these services. Outsourcing the salary administration, the cleaning (inside) and the pharmacy are mostly done in hospitals which are less efficient. For these three services it seems therefore advisable not to outsource them and have them performed by the hospital itself. In general we see that both for medical and for non-medical services outsourcing has no statistically significant relationship with the efficiency of a hospital. At a $1 \%$ level of statistically significance, there is no relation between any of these services and efficiency.

Table 18: Amount of outsourcing, asset specificity and efficiency of outsourcing

\begin{tabular}{|c|c|c|c|c|c|c|c|}
\hline Department & $\begin{array}{c}\text { Amount } \\
\text { outsourced }\end{array}$ & $\begin{array}{l}\text { Physical } \\
\text { specificity }\end{array}$ & $\begin{array}{l}\text { Personal } \\
\text { specificity }\end{array}$ & Uncertainty & $\begin{array}{l}\text { Quality } \\
\text { (harm) }\end{array}$ & Total & $\begin{array}{c}\text { Relation } \\
\text { with } \\
\text { efficiency }\end{array}$ \\
\hline Laboratory & $15 \%$ & 1.95 & 2.49 & 2.77 & 1.00 & 8.21 & - \\
\hline Pharmacy & $19 \%$ & 1.93 & 2.70 & 2.51 & 1.00 & 8.14 & -- \\
\hline Physiotherapy & $7 \%$ & 1.93 & 2.37 & 2.22 & 1.00 & 7.52 & + \\
\hline Maintenance (building) & $32 \%$ & 1.90 & 2.42 & 1.85 & 0.00 & 6.17 & ++ \\
\hline Kitchen & $9 \%$ & 1.89 & 2.11 & 1.66 & 0.00 & 5.66 & ++ \\
\hline Cleaning inside & $60 \%$ & 1.84 & 1.90 & 1.37 & 0.00 & 5.11 & - \\
\hline Laundry & $75 \%$ & 1.68 & 1.84 & 1.22 & 0.00 & 4.74 & + \\
\hline
\end{tabular}

Table 18 compares the results of model 1 with the asset specificity of the different services as found by Coles and Hesterly (1998a). The first column presents the amount of service outsourced. The second, third, fourth and fifth columns present the physical and personal asset specificity, the uncertainty and the quality respectively. The sixth column presents the relation with efficiency. A + means outsourcing is positively related with efficiency, a ++ means this relationship is statistically significant at the $5 \%$ level. The opposite holds for the - and -signs. The table is sorted by physical asset specificity.

We see that for the two most specific services, pharmacy and laboratory, outsourcing takes place in less efficient hospitals. Outsourcing of less specific services is more likely to take place in more efficient hospitals. So the general prediction of TCE that services with high asset specificity should not be outsourced and vice versa appears to be confirmed. There is one exception to this rule: the cleaning (inside) service. Because of the low asset specificity it would be expected that outsourcing is efficient. This is not what we find. 
Table 19: Results of one stage stochastic frontier model (model 2)

\begin{tabular}{llllllll}
\hline \hline Service & & & & & $\delta_{\text {outsourcing }}$ & $\begin{array}{l}\delta_{\text {outsourcing }} \\
\text { middle }\end{array}$ & $\begin{array}{l}\delta_{\text {outsourcing }} \\
\text { big }\end{array}$ \\
\hline \multirow{2}{*}{ Salary administration } & 0.49 & 0.01 & -0.11 & -0.05 & 0.08 & 0.01 & 0.12 \\
& $(2.6)$ & $(4.9)$ & $(-3.9)$ & $(-3.7)$ & $(1.3)$ & $(0.2)$ & $(3.1)$ \\
Administration & 0.53 & 0.01 & -0.13 & -0.08 & 0.19 & 0.00 & -0.01 \\
& $(3.2)$ & $(4.5)$ & $(-4.5)$ & $(-5.4)$ & $(1.4)$ & $(0.1)$ & $(0.1)$ \\
Cleaning inside & 0.52 & 0.01 & -0.11 & -0.05 & 0.04 & 0.0 & 0.04 \\
& $(2.7)$ & $(4.8)$ & $(-2.4)$ & $(-2.3)$ & $(0.7)$ & $(0.2)$ & $(1.7)$ \\
Laundry & 0.52 & 0.01 & -0.06 & -0.10 & -0.12 & 0.01 & -0.03 \\
& $(6.2)$ & $(4.7)$ & $(-0.9)$ & $(-3.3)$ & $(-1.6)$ & $(0.5)$ & $(-1.0)$ \\
Kitchen & 0.47 & 0.02 & -0.11 & -0.07 & -0.02 & -0.07 & -0.01 \\
& $(1.8)$ & $(5.0)$ & $(5.0)$ & $(-5.3)$ & $(-0.3)$ & $(-2.5)$ & $(-0.4)$ \\
Maintenance (building & 0.44 & 0.02 & -0.10 & -0.10 & -0.00 & -0.07 & 0.01 \\
& $(1.7)$ & $(5.1)$ & $(3.6)$ & $(-5.1)$ & $(-0.1)$ & $(-3.4)$ & $(0.3)$ \\
Education & 0.50 & 0.01 & -0.09 & -0.06 & -0.03 & 0.01 & 0.05 \\
& $(3.0)$ & $(4.9)$ & $(-3.8)$ & $(-4.6)$ & $(-1.0)$ & $(0.5)$ & $(2.8)$ \\
Laboratory & 0.41 & 0.01 & -0.15 & -0.05 & 0.19 & -0.14 & 0.02 \\
\multirow{4}{*}{ Pharmacy } & $(1.5)$ & $(4.3)$ & $(-4.4)$ & $(-3.1)$ & $(3.3)$ & $(-2.3)$ & $(0.5)$ \\
& 0.50 & 0.01 & -0.10 & -0.07 & -0.00 & 0.04 & 0.03 \\
Physiotherapy & $(2.5)$ & $(4.7)$ & $(-4.2)$ & $(-5.3)$ & $(-0.1)$ & $(2.1)$ & $(1.2)$ \\
& 0.50 & 0.01 & -0.11 & -0.08 & -0.02 & 0.01 & -0.10 \\
Medical services & $(2.7)$ & $(4.9)$ & $(-4.7)$ & $(-5.9)$ & $(-0.7)$ & $(0.5)$ & $(-2.3)$ \\
Non medical services & 0.53 & 0.01 & -0.13 & -0.07 & 0.06 & 0.04 & 0.01 \\
& $(3.0)$ & $(4.3)$ & $(-4.0)$ & $(-4.9)$ & $(0.9)$ & $(0.9)$ & $(0.3)$ \\
\hline \hline & 0.52 & 0.01 & -0.06 & 0.00 & 0.06 & -0.00 & 0.19 \\
& $(2.8)$ & $(4.6)$ & $(-0.9)$ & $(0.1)$ & $(0.4)$ & $(-0.1)$ & $(2.8)$ \\
\hline
\end{tabular}

The results of model 2 are presented in Table 19. Model 2 adds the variable size to the results presented in model 1 . We go through the main results. The parameters $\delta_{1}$ to $\delta_{3}$, which measure the influence of size and time, are comparable to model 1. A second conclusion is that outsourcing the salary administration is inefficient for all hospitals. This relation is statistically significant at the $5 \%$ level for large hospitals. For the administration, as in model 1, no statistically significant relations are found. The same holds for the cleaning services, although in contrast with model 1 for medium sized and large hospitals the finding that outsourcing is inefficient is statistically significant at the $10 \%$ level. Outsourcing the laundry is efficient for small hospitals (statistically significant at the $10 \%$ level). Outsourcing the kitchen is efficient for all hospitals. This relation is statistically significant at the $5 \%$ level for medium sized hospitals. Outsourcing the maintenance of the building is statistically significant for medium sized hospitals. For the laboratory we see that outsourcing is statistically significantly efficient at the $5 \%$ level for small hospitals. For large hospitals no statistically significant relationship is found. For the pharmacy we see that outsourcing is inefficient for medium sized and large hospitals. This result is statistically significant for medium sized hospitals. Outsourcing the physiotherapy department is statistically significant efficient for large hospitals. 
Reviewing these results we conclude that among small hospitals it is efficient to outsource some departments but that this is inefficient in large hospitals, while for other departments this is the other way around. The relation between size and the efficiency of outsourcing is not straightforward and for most hospitals no evidence is found that the decision whether or not to outsource has a statistically significant relation with efficiency. 


\subsection{Discussion}

The relation between outsourcing, size and the efficiency of hospitals is mixed. Outsourcing is efficient for a number of services, in particular for kitchen services and the maintenance of the building. For other services outsourcing is inefficient. This holds for the salary administration and the pharmacy. Also the relationship with size is mixed. There is no clear relation between size of the hospital and outsourcing.

Some caveats by these findings are in order. Asset specificity and uncertainty is not measured in the administrative data that we use and we have imported these variables based on classifications developed in earlier research in the United States. This implies that we have no direct information of the individual specificity and uncertainty of assets in hospitals. Further it is not clear whether specificity measured in US hospitals is similar to Dutch hospitals, although the results for US hospitals on the amount of outsourcing are similar to that in Dutch hospitals.

We examined the relation between outsourcing and the efficiency of the hospital. Our findings suggest that for some services such a relation exists. This study however did not examine the causality of this effect. Efficiency might be a result of good make-or-buy decisions. However it may also be that efficient hospitals have better management. Better management may also make better make-orbuy decisions.

To test the relation between efficiency and outsourcing a number (48 to be exact) of t-tests for the statistical significance of parameters were performed. Eleven of these t-tests showed statistically significant results, using $5 \%$ level of coincidence as the cut-off point. Even if no real relation would exist it would be expected that we would have found 2 or 3 "statistically significant" results.

This methodological consideration, together with the finding that none of the ttests showed a statistically significant result at the $1 \%$ level, adds to the conclusion that the make-or-buy decision is not highly related with the efficiency of the hospital. This finding should be seen in perspective, since the biggest hospital services, the ward, the operating theatre and outpatient department are not outsourced at all, so no analysis for these departments could be made.

From a transaction cost perspective the question whether or not to outsource a certain service mainly depends on the asset specificity of a service. In this study we found some evidence confirming the predictions of TCE. First, we saw that there is a clear relation between the amount of a service that is outsourced and the asset specificity of the service. Second we found that in general there is a relation between the efficiency of outsourcing a service and the asset specificity 
of the service. Outsourcing more asset specific services is less efficient while outsourcing less specific services is in general more efficient. Both findings add proof to the TCE assumption that asset specificity is an important driver in the outsourcing decision.

According to TCE it is less efficient for a large hospital to outsource than for small hospitals, because of economies of scale. This prediction is partly confirmed by our findings, because we find that it is more efficient for large hospitals not to outsource non-medical services than for small hospitals. On the individual service level, however there are mixed results on the relation between outsourcing and size. Outsourcing physiotherapy for example is efficient for large hospitals while no efficiency-effects are found for other hospitals. These empirical findings are in line with the findings of Coles \& Hesterly (1998a) and Lyons (1995) who both find that scale effects play less or no role when asset specificity is present.

From a managerial perspective our findings are interesting since hospitals devote a lot of effort to decide whether or not to outsource services. This study shows that in general the make-or-buy decision does not have much effect on the efficiency of the hospital. For most individual services no relation between the efficiency of the hospital and the amount of outsourcing is found. If a relation is found it is not highly statistically significant and only a small part of efficiency is explained. Of the services for which it is recommendable to outsource the most intriguing one is the kitchen. Although it appears to be efficient to outsource this service, in practice only $9 \%$ of these services are outsourced. In general though the results show that there is no unequivocal statement to make about which service to outsource and which service not to outsource. 



\section{Synthesis}

\subsection{Introduction}

The aim of this thesis is to examine the efficiency of Dutch hospitals. More specifically this thesis provides answers to two questions:

1. How efficient are Dutch hospitals?

2. Why does hospital inefficiency occur?

Concerning the level of efficiency in Dutch hospitals three specific questions are asked:

1. What is the average efficiency of Dutch hospitals?

2. Does efficiency change over time?

3. Does the way output is measured change efficiency estimates?

To answer research question 2 the influence of the following factors on the efficiency of Dutch hospitals are analyzed:

- Quality.

- The efficiency of individual departments.

- The make-or-buy decision.

In this section the results of this thesis in relation to existing studies examining efficiency in health care and the NEI theory are discussed. The next section discusses the choices made in the analyses which are performed and thereby brings the results into perspective. Next, both research questions are discussed subsequently. The relevance of this study was shown in chapter 1 by the amount of money involved in health care and the finding that this amount is growing rapidly. Money spent inefficiently is thereby of interest to politicians and hospital managers alike. The political and managerial implications of this research are summarized next, followed by a discussion of the theories and methods used. 


\subsection{Main findings}

In summary this thesis provides the following results:

First regarding hospital efficiency at the organization level the following three relevant results are found:

- Inefficiency exists in Dutch hospitals. The average efficiency is $84 \%$.

- Efficiency in Dutch hospitals has decreased over time.

- Different output measures lead to different efficiency estimates.

Second regarding the causes of hospital efficiency the following results were found:

- Quality and efficiency come together.

- Inefficiency exists within departments.

- Departmental efficiency is only partly related to total hospital efficiency; cooperation is a key issue in getting both departmental efficiency and efficiency in the total hospital.

- The make-or-buy decision of most hospital services is of little importance for the efficiency of the total hospital organization.

Before going through these results some caveats must be made.

First, the quality of the data used, of course, influences the results of the analyses performed. At the general hospital level these data may be assumed to be quite reliable, since most of these data are also data gathered for the annual report of the hospital and/or the budgeting system of the hospital. At the departmental level however this is less true and the quality of the data relies on the quality of individual hospital employees and the quality of the ICT-system in hospitals. Some general checks were performed, these checks however do not exclude all data errors, as was shown in chapter 4.

Second, the choice of the model to estimate efficiency influences our results. The aim of this thesis is to measure and explain efficiency. To do so (advanced) econometric models are used. The aim of this thesis is not to test and improve these econometric methods. This implies that a number of assumptions regarding the models used have been made without extensively testing these assumptions.

First, we have chosen a statistical method to measure efficiency: SFA. Thereby we have chosen not to use the also commonly used method: DEA. This choice has been made because SFA provides opportunities for statistical testing and SFA distinguishes between chance and efficiency. However it is not the intention to state that SFA is better than DEA. As shown in chapter 3 a number of studies (for example, Chirikos and Sear, 2000 and Linna, 1998) comparing DEA and SFA in a hospital setting have been performed. These studies do not provide a clear answer which method is better. However it is shown that these methods do 
provide (significant) differences in the amount of efficiency measured per hospital.

Second, we have applied SFA by using a cost function. This implies that we assume that hospitals minimize costs and consider their output level as given. This assumption is common in studies estimating hospital efficiency. Further this assumption can be defended by the current hospital system in the Netherlands and in most other countries. Patients enter the hospital having a health problem and hospitals (almost) always treat these patients: hospitals thereby consider their production as given. Further hospitals receive a budget to treat these patients and thereby are assumed to minimize costs. However this budgeting system does not alone imply minimizing costs. As long as the budget is not completely depleted there is no reason to minimize costs. Further Blank and Merkies (2004) show that the assumption of cost-minimization is questionable in Dutch hospitals. However they do not provide a clear alternative.

Third, when estimating our cost function we assumed a Cobb-Douglas form for this function. This choice has been made because of simplicity reasons. A CobbDouglas function can be estimated, whilst for example the more advanced translog function could not be estimated.

Fourth, in SFA a functional form for the efficiency term has to be assumed. We have chosen a positive normal function: $\mathrm{N}^{+}\left(u, \sigma^{2}\right)$. This function was tested against a $\mathrm{N}^{+}\left(0, \sigma^{2}\right)$ function and accepted. On the other hand other functional forms for the efficiency term are possible of which the gamma distribution is also often applied in efficiency studied in hospitals. Both a normal and a gamma distribution can be assumed, without any preference. Studies comparing gamma and normal distributions show some statistical differences in the estimated hospital efficiency.

Fifth, we have made choices about the output and input (price) parameters included in our analyses. Also we made choices about which of these variables are exogenous and which are endogenous. These choices have been based on both earlier studies and common sense. However no extensive econometric testing has been applied. A Hausman test to test the differences in the parameter estimates with respect to which prices are used, has been applied. But no further endogeneity and exogeneity tests have been applied.

\section{Average Dutch hospital efficiency is $84 \%$}

When production is measured by the number of DRGs the average efficiency of Dutch hospitals between 1998 and 2002 is $84 \%$. The benchmark group used for this study to get this result consisted of Dutch hospitals. The main reason for this choice is the comparability of output- and input data. However by using a benchmark group of Dutch hospital we only analyzed to what extent hospitals are efficient compared to each other. We do not analyze the average efficiency 
of Dutch hospitals compared to other countries or to other sectors, for example nursing homes.

There are considerable differences between hospitals in efficiency. Efficiency varies from $99 \%$ to $70 \%$ between hospitals. The literature review in chapter 2 shows that the individual efficiency estimates should be treated with care. Different specifications for the error term or for the variables included lead to different individual estimates. The literature review further shows that the average efficiency, $84 \%$, is in line with other international studies examining the efficiency of hospitals. Hollingsworth (2003) finds in his review that most studies estimate an average efficiency between $80 \%$ and $90 \%$ in the hospital sector. This suggests that average differences in efficiency in the Netherlands are in line with other countries.

\section{Efficiency has decreased over time}

In this thesis panel data are used. Both from an econometric perspective as shown by Jondrow et al. (1982), and from the perspective of application of SFA in a hospital setting as shown by Linna (1998), results received from panel data are more reliable than results based on cross-section data. Using panel data further gives the possibility to estimate time-varying efficiency. Efficiency slightly decreased over time from $84.5 \%$ in 1998 to $83.9 \%$ in 2002 . This is rather unexpected, considering that other studies (e.g. Linna, 1998 and Rosko, 2001) using SFA on panel data in the hospital sector find an increasing efficiency over time. The explanations given in other studies for the finding that efficiency increases over time are mostly major policy measures and technical change. In the Netherlands no major policy measures have taken place between 1998 and 2002 . Further the economic growth has lead to an increase in costs, especially salaries. Apparently this increase in costs has led to less efficiency.

\section{Different output measures lead to different efficiency estimates}

The simplest form of measuring efficiency is comparing the amount of output produced per input. Although this is an oversimplification of measuring efficiency it emphasizes that the measurement of output is essential in efficiency analyses. The measurement of output of hospitals is not as straightforward as for most other industries. Hospitals produce in essence health gain, which is till now still unmeasured. Therefore we measure the number of patients treated, weighted by the complexity of the patient. Complexity is thereby measured by DRGs. This way of measuring output is better than measuring intermediate products as $X$ rays and ward days, because these intermediate products do not by definition add to the health gain of the patient. To lesser extent this is also true for DRGs. For example, medical errors leading to readmissions imply more DRGs, but less health gain and therefore more output and can thereby increase efficiency as measured in the thesis.

In chapter 2 it was shown that the way output is measured is relevant. If output is measured by the classical output measures for Dutch hospitals: the number of 
inpatients, the number of ward days, the number of day-care patients and the number of outpatients the estimated average efficiency is $77 \%$. This is considerably lower than the average estimated efficiency (84\%) when output is measured by the number of DRGs. The finding that inefficiency is higher when output is measured by the number of patients without weighting for case mix is not surprising as it is in line with other studies (see e.g. Rosko and Chillingerian, 1999)

\section{Quality and efficiency come together}

As shown in chapter 1 , if quality is measured from a stakeholder's perspective quality and efficiency are no opposites. On the contrary a positive relation between quality and efficiency is found. This finding is supported by other studies incorporating quality measures in efficiency estimation. These studies find no relation between quality and efficiency; see for example Zuckerman et al. (1994) and Dismuke and Sena (1999). Efficiency and quality are therefore no substitutes and can even be complements.

\section{Inefficiency exists within departments}

Inefficiency not only occurs within the total hospital organization, it also occurs within individual hospital departments. In chapter 4 the efficiency of six departments, the ward, the outpatient department, the operating theatre, the laboratory, the radiology department and the physiotherapy department is analyzed. Average inefficiency varies between departments from $15 \%$ to $38 \%$. The inefficiency in these six departments is only partly related to the inefficiency of the total hospital organization. The correlation between departmental efficiency and the efficiency of the total hospital organization varies between 0.40 and -0.01 . The approach used in this study to estimate departmental inefficiency is new, so no comparable results of other studies exist yet, probably due to a lack of data. This point is further discussed later in this chapter.

\section{The make-or-buy decision of most hospital services is of little importance for the efficiency of hospitals}

The results in this thesis show that efficiency is hardly influenced by the makeor-buy decision. To get this result the influence of outsourcing each department separately was tested. Thereby a one stage model could be estimated. This comes with the disadvantage that the effect of each parameter was estimated separately. A one stage model with all factors does not converge. This implies that we were able to test the influence of the outsourcing decision of each department separately, but no test for the total outsourcing decision (and the NEI theory) could be applied.

Ten hospital services were examined and for most services no significant relation between hospital efficiency and departmental efficiency is found. Even if a significant relation is found, it appears that most hospitals have already chosen the most efficient decision. This finding is remarkable, since outsourcing hospital 
services is an important issue both from a practical and a theoretical point of view. The fact that we did not find this relation should be seen in perspective. The largest hospital services, e.g. the ward and the operating theatre, were not taken into account because no examples of outsourcing these services were found in the Netherlands. The services which were analyzed are thus less costly and therefore the impact on the efficiency of the hospital is expected to be smaller. Notwithstanding this, it is still expected to exist. Little justification can therefore be found to focus on outsourcing to increase inefficiency 


\subsection{Political and managerial implications}

Efficiency of hospitals is an important concept, because of the amount of resources or, in more mundane terms, money involved. In this thesis it was shown that a considerable amount of money is wasted through inefficiency. This finding in itself does not come as a surprise. It is an illusion to think all hospitals will always be $100 \%$ efficient. The average inefficiency for Dutch hospital as found in this thesis is $16 \%$. These findings implicate that approximately $€ 1.5$ billion of hospital costs of general hospitals is wasted yearly through inefficiency. An amount that shows that efficiency gains in Dutch general hospitals can lead to significant savings. An amount that is also in range with the average inefficiency estimates in studies in other countries. The finding that inefficiency is present in Dutch hospitals is probably not surprising to politicians and hospital managers, which does not imply that the search for inefficiency should be stopped. It is even quite alarming that, in contrast to the findings of other studies in other countries, inefficiency appears to be increasing over time in the Netherlands.

The most convincing explanation for this different finding in this thesis lies in the political and economic situation in the time period studied. Between 1998 and 2002 the economy grew rapidly in the Netherlands. This had its influence on hospitals as well. The salaries of nurses and other hospital staff were raised and probably not compensated by increasing productivity. This negatively influenced efficiency. This finding supports that in Dutch health care Beaumol mechanisms are operating leading to decreasing efficiency. Furthermore no major financial reforms in hospital care took place in this period. An increase of inefficiency is undesirable and calls for policy measures to improve efficiency.

The Dutch government has found this restructuring of the hospital sector also a key issue as can be read from the coalition agreement. The main care policy measures regarding health care of the current Dutch government are according to the coalition agreement:

- $\quad$ The introduction and enlargement of the free market.

- The simplification of the DBC system.

- The introduction of yardstick competition to improve the relation between quality and efficiency.

- The introduction of financial risk for hospitals with respect to all their costs, including the costs of capital.

- Insures will bear more risk.

- $\quad$ The introduction of more ICT in hospitals.

All these issues are related to cost containment and emphasize the importance of the issues addressed in this thesis. Therefore it is within the scope of this thesis to understand how the results of the analysis performed help to evaluate these issues and how to achieve them. 
The finding in this thesis that the efficiency of individual departments is less than the efficiency of a hospital supports the policy of the enlargement of market competition with freely negotiable prices. Hospitals are complex organizations which are (probably because of this reason) mainly managed per department. As has been shown this way of managing and financing hospitals can be quite inefficient. The introduction of a free market has until now led to only some health care institutions specializing in one group of patients, for example cataract patients. Based on our findings this choice for specialization is understandable and expected to be extended even further. Specializing in one group of patients implies focusing on patients instead of departments. This patient focus leads to more efficiency and more quality alike as we saw in chapter 4 , and thereby works in the public interest.

Specialization may lead to restructuring of general hospitals. In general this restructuring could lead to more focus towards the client (the patient): focused factories. How this process works can be illustrated by looking at figure 2 . The first change compared to the current situation is that instead of focusing the financial and quality incentives at the departments (the rows in figure 2) the focus should be placed on the activities in the columns. The second change is that instead of the specialisms, the columns should contain patient oriented services. For example oncology instead of internal medicine and general surgery and vasectomy instead of cardiology and general surgery, see figure 3 . 


\begin{tabular}{|c|c|c|c|c|}
\hline \multicolumn{5}{|c|}{ Care request } \\
\hline & & $\begin{array}{l}\text { Mama } \\
\text { oncology }\end{array}$ & $\begin{array}{l}\text { Oth } \\
\text { er } \\
\text { care } \\
\text { requ } \\
\text { ests }\end{array}$ & Total \\
\hline \multirow{9}{*}{$\begin{array}{l}\mathrm{d} \\
\mathrm{e} \\
\mathrm{p} \\
\mathrm{a} \\
\mathrm{r} \\
\mathrm{t} \\
\mathrm{m} \\
\mathrm{e} \\
\mathrm{t}\end{array}$} & Ward & $\begin{array}{cc}\begin{array}{c}\text { Cost }=\text { price per ward day } \\
\text { number of ward days }\end{array} & \text { Cost }=\text { price per ward day } \\
\text { Cataract patients } & \text { number of ward days } \\
\text { Mama oncology }\end{array}$ & & $\begin{array}{c}\text { Cost }=\text { price per ward day } \\
* \text { total number of ward } \\
\text { days }\end{array}$ \\
\hline & radiology & $\begin{array}{cc}\text { Cost }=\text { price per X-ray * } & \text { Cost }=\text { price per X-ray * } \\
\text { number of X-rays internal number of X-rays general } \\
\text { medicine + price per MRI * } \\
\text { nurgery + price per MRI * * * } \\
\text { number of MRI's } & \text { number of MRI's general } \\
\text { Cataract patients } & \text { Mama oncology }\end{array}$ & & $\begin{array}{c}\text { Cost }=\text { price per X-ray * } \\
\text { total number of X-rays }+ \\
\text { price per MRI * total } \\
\text { number of MRI's }\end{array}$ \\
\hline & outpatient & etc. & & \\
\hline & theatre & & & \\
\hline & $\begin{array}{l}\text { laboratory } \\
\text { physiotherapy }\end{array}$ & & & \\
\hline & total direct patient & & & \\
\hline & cleaning & $\begin{array}{cc}\text { price of cleaning per } \mathrm{m}^{2 *} & \begin{array}{c}\text { price of cleaning per } \mathrm{m}^{2 *} \\
\text { number of } \mathrm{m}^{2}\end{array} \\
\text { number of } \mathrm{m}^{2} \\
\text { Cataract patients } & \text { Mama oncology }\end{array}$ & & $\begin{array}{c}\text { price of cleaning per } \mathrm{m}^{2 *} \\
\text { total number of } \mathrm{m}^{2}\end{array}$ \\
\hline & \begin{tabular}{|l} 
kitchen \\
etc \\
total indirect patient
\end{tabular} & & & \\
\hline & total & $\begin{array}{ll}\begin{array}{l}\text { total costs cataract } \\
\text { patients }\end{array} & \begin{array}{l}\text { total costs } \\
\text { mama oncology }\end{array} \\
=\text { sum of above } & =\text { sum of above }\end{array}$ & & $\begin{array}{l}\text { total costs hospital }=\text { total } \\
\text { costs of medical } \\
\text { specialisms }=\text { total costs } \\
\text { of departments }\end{array}$ \\
\hline
\end{tabular}

Figure 3 new hospital structure

This focus as described in figure 3 and above is not completely new to the Dutch hospital sector. Many hospitals in the Netherlands have implemented parts of this concept. Some hospitals have indeed tried to reorganize their organization by focusing of specialisms, so called "kantelen" or turning over of hospitals. Another example: hospitals that focus in one location on acute care and the other on emergency care. Interestingly enough these processes have not always been successful. And some hospitals have even redone their restructuring. This fact can be explained by the issue of cooperation. A hospital organization structured as presented in figure 3 demands a lot of cooperation. This structure is characterized by cooperation between doctors and nurses, cooperation between administrative staff and caring staff and cooperation between doctors of diverse medical specialisms. First, a restructuring as proposed in figure 3 requires a change of procedures structures financing systems and culture which has crept in hospitals for ages. Second, the education of both specialists and nurses is primarily aimed at knowledge of their own discipline. Therefore radical restructur- 
ing of the formal organization of hospitals requires also a change of hospital culture, systems, financial incentives, management style, ICT-systems, and staff. Also the education of hospital managers, doctors and nurses should focus more on cooperating with other disciplines within the hospital. 


\subsection{Methodological considerations}

In this thesis all the analyses are performed excluding both the costs and the prices of capital of buildings. This is quite uncommon. In most international efficiency studies capital is included in the analysis. Further it might be seen as quite illogical from an economic point of view, since capital is, together with personnel and material, one of the three classical input parameters for a firm. It is argued in chapter 2 to 5 that both the costs and the prices of capital can hardly be influenced by hospital management, since these costs are completely covered by budgets. In a study of hospital efficiency, such costs should not be included.

Which prices to include in cost-efficiency studies is an issue which is solved differently in different international studies. Roughly two approaches are chosen. In the first approach the individual prices of the hospitals are used. In the second approach the average prices of all hospitals are used. The assumption of the first approach is that prices can be influenced by hospital management. The second approach assumes prices cannot be influenced. In the different analyses of this thesis I even used a third approach in which regional prices were used. Comparing the efficiency estimates of these 3 different methods shows the differences were quite small and in most cases not statistically significant. Therefore we can conclude that the results in this thesis are not sensitive to the input prices used.

\section{What are outputs and how do we measure them?}

The measurement of hospital output is a major issue in efficiency studies. This is also shown in this study. In chapter 2 two different sets of output parameters are applied. First the output measures as used for the capitation system of Dutch hospitals. Second the more commonly used case mix adjusted output, as measured by DRGs. It is shown that different output measures lead to the differences in outcome in both the average efficiency and in the individual estimates. In chapter 4 it is shown that the efficiency of departments which produce intermediate products differs from total hospital efficiency.

One of the main issues from a methodological point of view in efficiency studies is the inclusion of quality variables. Newhouse (1994) states that: differences in efficiency between hospitals might be completely attributed to quality differences. The claim behind this statement is that providing more quality for patients costs more money. Newhouse makes the comparison with airline companies. Business class is far more expensive than economy class, while the output appears to be the same. Most studies (e.g. Dismuke and Sena, 1999 and Zuckerman, 1994) incorporating (derived) quality measures in efficiency studies found no relation between efficiency and quality though.

While the essence of incorporating quality when measuring hospital efficiency is approved by many (Newhouse, 1994 and Jacobs, 2001) the same holds for the 
difficulty to measure quality of hospitals. Quality is usually measured by outcome measures like the number of deaths or readmissions. As discussed in chapter 3 these measures have serious disadvantages. The main issue is that these measures can only partly be influenced by the hospital since they are case mix dependent. A more promising avenue is to measure quality by applying the perspective of the stakeholders of the hospital. This approach is used in this thesis. Naturally this measure has some disadvantages. The main disadvantage is that evaluators have only a limited amount of information and experience to compare hospitals. The main advantage is that these measures do not depend on case mix, which varies between hospitals, and are therefore better comparable between hospitals.

What efficiency benchmark group will be used to compare the output divided by input measure?

In this study the efficiency of Dutch hospitals is examined. This means that the efficiency of Dutch hospitals is compared with the efficiency of other Dutch hospitals. This estimate tells us something about the differences in efficiency between hospitals and groups of hospitals in the Netherlands. Since in both this study and in almost all other (hospital) efficiency studies only one country is taken into account, it does not provide information on the efficiency of the Dutch hospital sector as a whole. To get more insight in the efficiency of the total hospital sector, international comparisons are necessary. The main issue in doing so would be the comparability of data. It would take enormous effort to make costing data and output data comparable. This is probably the reason why no such studies yet exist. The fact that it will take significant effort however should be seen as a challenge, especially since it can provide valuable insight which is not existent yet.

\section{What functional forms and methods are used to relate input to output?}

To answer the research questions we build on an advanced econometric method to measure efficiency, the parametric SFA-technique developed by Aigner, et al. (1977) and Meussen and van den Broeck (1977) and first implemented in the hospital sector by Zuckerman et al. (1994). This technique is a more advanced technique compared to the classical cost-functions. It compares hospitals with the best hospital, where the classical cost functions estimate the average costs. As opposed to the commonly used non-parametric DEA-technique, SFA is able to distinguish differences between chance and efficiency. The parametric SFAapproach gives the opportunity to perform statistical tests. However this method has some drawbacks as well. The first concerns model selection. There are multiple options for the functional form of the cost function, of which CobbDouglas, Translog, Leontieff, and Diewert are most often used. Second, there are multiple possibilities for the distribution of the error term. Most often the truncated or positive normal distribution is used. Other distributions, for example the Gamma distribution are possible as well. Empirical research (Folland and Hoffler, 2001 and Street, 2003) has shown that individual efficiency estimates can vary considerably depending on the options chosen. 
DEA has some advantages over SFA. No functional form is demanded and multiple outputs are easier to incorporate. Olesen and Petersen (2002) for example, incorporated all 483 different Danish DRGs as an output measure. Concluding, Jacobs (2001, p.103) states that: "the methods each have particular strengths and weaknesses and potentially measure different aspects of efficiency". However the average efficiency found is less sensitive to which ever method is used, so the general finding that inefficiency is present can be considered to be reliable.

\section{Explaining efficiency: Economic theories of the hospital}

Modern econometric techniques like DEA and SFA which is used in this thesis proved useful in estimating the efficiency of individual Decision Making Units. In this thesis this is applied to hospitals and departments of hospitals. These techniques have been used in numerous studies in health care. Most issues in these techniques have nowadays been discussed and a good handbook Jacobs et al. (2006) on using these techniques in health care is available. This implies the focus of efficiency studies should extend to factors explaining inefficiency. Many studies attempt to find some explanations for the efficiency differences found. However, first these explanations for efficiency play only a secondary role. Second, explanations given are mostly not based on economic theories. This might explain why most studies do not succeed in explaining much of the variation in efficiency between hospitals. In this thesis explaining efficiency based on the Neo Institutional Economic theory is the core concept. Two parts of NEI where used, the Principal Agent theory and Transaction Cost Economics. Both theories were used to deduce hypothesis where and why hospital inefficiency occurs. The Principal Agent theory was used to show that different interests from the principal and the agent might lead to different interests. More specific we used this theory to deduce that patients might have different interests than the hospital. The client is interested in quality and the hospital in efficiency. Since there is a big information asymmetry this is a potential harmful conflict of interest between the principal (the client) and the agent (the hospital). However our results show that quality and efficiency come together. Furthermore the principal agent relation between the hospital and the departments was examined. It appears that departmental efficiency is mainly independent of hospital efficiency. So the interest of the department manager is not in line with the interest of the general hospital management. A conflict of interest between the principal and the agent that is harmful for the hospital. Our results further show that this conflict of interest is less when cooperation is higher. Principal Agent issues do arise in hospitals and cooperation helps to solve this issue. Gaining efficiency should therefore be found by cooperation between departments and not by setting targets on the efficiency of individual departments.

TCE focuses on the transaction costs of different organization settings. The archetypical question of TCE is whether to make or buy. This theory was applied to show that hospital services with little asset specificity are less outsourced while hospital services with high asset specificity are more outsourced, as 
predicted by TCE. However most hospitals already have organized their make of buy decision efficiently yet and no major efficiency gains can be expected from better make-or-buy decisions. A promising way to further examine the origins of hospital inefficiency from a TCE point of view, is by comparing different organizational alternatives. This is especially promising since we found that the most costly hospital services, the outpatient department, the ward and the theatre are not outsourced at all. Different organizational forms do however exist. In view of the limited influence of the make-or-buy it would be interesting to investigate different organizational forms and their impact, on efficiency.

Although some statistically significant explanations for differences in efficiency were found, still the largest part of efficiency differences between hospitals remains unexplained. This again shows inefficiency of hospital is a rather complex issue. Inefficiency cannot easily be completely eliminated. 


\subsection{Concluding remarks}

In this thesis a number of explanations for hospital inefficiency are tested and discussed. It is found that some common beliefs do not hold: inefficiency is not just a matter of better quality; inefficiency has hardly any relation with the difference between making and buying; inefficiency is only partly explaining inefficiency of departments. This thesis demonstrates that the perceived quality of a hospital comes together with efficiency. Further the analyses in chapter 4 show that the efficiency of the main individual departments is only partly related to the overall hospital efficiency. For these two findings a couple of explanations that are closely related can be provided:

- As argued by van Merode et al. (2004) client centered hospitals lead to better process quality and more efficiency because the number of transfer points is minimized.

- $\quad$ As argued by Porter and Olmsted Teisberg (2004) in health care, as in most industries, cost and quality can improve simultaneously as providers prevent errors, boost efficiency, and develop expertise.

- General health care organizations have a functionalistic structure: surgeons at the surgery department, clinical chemistry in the laboratories. The nature of planning in these organizations often only concerns maximizing the efficiency of departmental processes and not the entire production process.

- Because hospitals receive a budget at hospital level, efficiency in one department can compensate for inefficiency in other departments.

- The contribution of (in)efficiency of departments to overall hospital (in)efficiency depends mainly on the way departments within the hospital are managed and financed and less on their own (in)efficiency. 



\section{References}

Aert, J.H. van 1977. Hospital costs: an econometric perspective. Leiden: Stenfert Kroese BV. (in Dutch).

Aigner, D., Lovell, C.A.K., Schmidt, P. 1977. Formulation and estimation of stochastic production function models. Journal of Econometrics; 6: 21-37.

Arrow, K. 1985. The economics of agency. In Principals and agents - The structure of business, Pratt, J., Zeckhauser, R. Boston: 37-51.

Battese, G.E., Coelli, T.J. 1992. Frontier production functions, technical efficiency and panel data with application to paddy farmers in India. Journal of Productivity Analysis; 3: 153-169.

Battese, G.E., Coelli, T.J. 1995. A Model for Technical Inefficiency Effects in a Stochastic Frontier Production Function for Panel Data. Empirical Economics; 20: 325-332.

Blank, J.L.T., Eggink, E., Merkies, A.H.Q.M. 1998. Between bed and budget. Den Haag: Sociaal en Cultureel Planbureau / Elsevier Bedrijfsinformatie. (in Dutch).

Blank, J.L.T., Eggink, E., Merkies, A.H.Q.M. 1998. The choice of an appropriate economic model for the structure of production: the case of Dutch general hospitals. Den Haag: Sociaal en Cultureel Planbureau, Werkdocument 49. (in Dutch).

Blank, J.L.T., Koolmees, W., Vogelaar, I., Waaijers, J. 2002. Between desk and bed. Rotterdam: Ecorys Nederland BV. (in Dutch).

Blank, J.L.T., Merkies, A.H.Q.M. 2004. Empirical assessment of the economic behaviour of Dutch general hospitals. Health Economics; 13 (3): 265-280.

Bradford, W.D., Kleit, A.N., Krousel-Wood, M.A., Re, R.N. 2001. Stochastic frontier estimation of cost models within the hospital. The Review of Economics and Statistics; 83 (2): 302-309.

Brown, H.S. 2003. Managed care and technical efficiency. Health Economics; 12: 149-158.

Butler, J.R.G. 1995. Hospital Cost Analysis. Dordrecht: Kluwer Academic Publishers.

Centraal Planbureau 2006a. Central Economic Plan 2006. Den Haag: Centraal Plan Bureau. (in Dutch).

Centraal Planbureau 2006b. Macro Economic Explorations 2007. Den Haag: Centraal Planbureau. (in Dutch).

Chirikos, T.N. 1998. Identifying efficiently and economically operated hospitals: The prospects and pitfalls of applying frontier regression techniques. Journal of Health Politics; 23: 879-904.

Chirikos, T.N., Sear, A.M. 2000. Measuring Hospital Efficiency: A Comparison of Two Approaches. Health Service Research; 34 (6): 1389-1408.

Coase, R.H. 1937. The nature of the Firm. Economica N.S.; 4: 386-405.

Coles, J.W., Hesterly, W.S. 1998a. Transaction costs, quality, and economies of scale: examining contracting choices in the hospital industry. Journal of Corporate Finance; 4 : 321-345.

Coles, J.W., Hesterly, W.S. 1998b. The impact of firm specific assets and the interaction of uncertainty: an examination of make-or-buy decisions in public and private hospitals. Journal of Economic Behavior and Organization; 36: 383-409.

Coelli, T.J., 1996. A guide to Frontier Version 4.1: A Computer Program for Stochastic Frontier Production and Cost Function Estimation. CEPA Working Paper 96/07. 
Daft, R.L. 1995. Organization theory and design. St. Paul: West Publishing Company. (fifth edition).

David, R.J. 2004. A Systematic Assessment of the Empirical Support for Transaction Cost Economics. Strategic Management Journal; 25: 39-58.

Davies, H.T.O., Crombie, I.K. 1995. Assessing the quality of care. British Medical Journal; 311: 766 .

Dismuke, S.E., Sena, V. 1999. Has DRG payment influenced the technical efficiency and productivity of diagnostic technologies in Portuguese public hospitals? An empirical analysis using parametric and non-parametric methods. Health care Management Science; 2: 107-116.

Dor, A. 1994. Non-minimum cost functions and the stochastic frontier: On applications to health care providers. Journal of Health Economics; 13: 329-334.

Douven, R., Ligthart, M., Mannaerets, H., Woittiez, I. 2005. A scenario for health care costs 2008-2011. Den Haag: Centraal Plan Bureau. (in Dutch).

Elsevier 2004. The best hospitals. Elsevier 25-09-2004: 36-50. (in Dutch).

Ferlie, E., McGiven, G. 2003. Relationships between Health Care Organisations. A critical overview of the literature and a research agenda. London: Centre for Public Services Organisation.

Fetter, R.B., Shin, Y., Freeman, J.L., Averill, R.F., Thompson, J.D. 1980. Case mix Definition by Diagnosis-Related Groups. Medical Care; 18 (2): February, Supplement.

Fizel, J.L., Nunnikhoven, T.S. 1993. The efficiency of nursing-home chains. Applied Economics; 25: 49-55.

Folland, S.T., Hofler, R.A. 2001. How reliable are hospital efficiency-estimates? Exploiting the dual homothetic production. Health Economics; 10 (8): 683-698.

Gerdtham, U.-G., Löthgren, M., Tambour, M., Rehnberg, C. 1999. Internal markets and Health care Efficiency: A Multiple-Output Stochastic Frontier Analysis. Health Economics; 8: 151-164.

Herzlinger, R. 1997. Market Driven Health Care. Cambridge: Harvard Business School, Perseus Books.

Hollingsworth, B. 2003. Non Parametric and Parametric Applications Measuring Efficiency. Health care Management Science; 6: 203-218.

Hofmarcher, M.M., Paterson, I., Riedel, M. 2002. Measuring Hospital Efficiency in Austria A DEA Approach. Health care Management Science; 5: 7-14.

Jacobs, R. 2001. Alternative Methods to Examine Hospital Efficiency: Data Envelopment Analysis and Stochastic Frontier Analysis. Health care Management Science; 4: 103115.

Jacobs, R., Dawson, D. 2003. Hospital Efficiency Targets. Health Economics; 12: 669-684.

Jacobs, R., Smith, P.C., Street, A. 2006. Measuring Efficiency in Health Care. Cambridge: Cambridge University Press.

Jensen, M., Meckling, W. 1976. Theory of the firm - Managerial behavior, agency costs and ownership structure. Journal of Financial Economics; 3: 305-360.

Jondrow, J., Materov, I., Lovell, K., Schmidt, P. 1982. On the Estimation of Technical Inefficiency in the Stochastic Frontier Production Function Model. Journal of Econometrics; 19 2/3: 233-238.

Kumbhakar, S.C., Lovell, C.A.K. 2001. Stochastic frontier analysis. Cambridge: Cambridge University Press.

Li, T., Rosenman, R. 2001. Cost Inefficiency in Washington Hospitals: A Stochastic Frontier Approach using Panel Data. Health care Management Science; 4: 73-81. 
Linna, M. 1998. Measuring hospital cost efficiency with panel data models. Health Economics; 7: 415-427.

Linna, M., Häkkinen, U., Linnakko, E. 1998. An econometric study of costs of teaching and research in Finnish hospitals. Health Economics; 7: 291-305.

Lyons, B., 1995. Specific investment, economies of scale, and the make-or-buy decision: a test of transaction cost theory. Journal of Economic Behavior and Organization; 26: 431-443.

Magnussen, J. 1996. Efficiency Measurement and the Operationalization of Hospital Production. Health Services Research; 31 (1): 21-36.

Mant, J., Hicks, N. 1995. Detecting differences in quality of care: the sensitivity of measures of process and outcome in treating acute myocardial infarction. British Medical Journal; 311: 793-796.

McGuinness, T. 1994. Markets and Managerial Hierarchies. In Markets, Hierarchies and Networks. Thompson, G. et al. (Eds.) London Sage: 66-81.

Meeusen, W., Broeck, J. van den 1977. Efficiency estimation from Cobb-Douglas production functions with composed error. International Economic Review; 18: 435-444.

Merode, G.G. van 2004. A prelude of the 2004 Antwerp Quality conference: Targets and target values: integrating quality management and costing. Accreditation and Quality Assurance; 9: 168-171.

Merode, G.G. van, Groothuis, S., Hasman, A. 2004. Enterprise Resource Planning for Hospitals. International Journal of Medical Informatics; 73: 493-501.

Milgrom, P., Roberts, J. 1992. Economics, Organization and Management. New Jersey: Prentice Hall International Economics.

Montfort, A.P.W.P. van 1980. Production Functions for general hospitals. Dissertation: Tilburg University.

Mortimer, D., Peacock, S. 2002. Hospital Efficiency Measurement: Simple Ratios vs. Frontier Methods. Centre for health program evaluation: working paper 135.

Newhouse, J.P. 1994. Frontier estimation, how useful a tool for health economics? Journal of Health Economics; 13: 317-322.

Olesen, O.B., Petersen, N.C. 2002. The use of Data Envelopment Analysis with Probabilistic Assurance Regions for Measuring Hospital Efficiency. Journal of Productivity Analysis; 17: 83-109.

Porter, M.E., Olmsted Teisberg, E.O. 2004. Redefining Competition in Health Care. Harvard Business Review; June 2004.

Preker, A.S. 2000. The Economics of Public and Private Roles in Health Care: Insights from Institutional Economics and Organizational Theory. Washington DC: The World Bank.

Rosko, M.D. 2001. Cost efficiency of US hospitals: A stochastic frontier approach. Health Economics; 10: 539-551.

Rosko, M.D. 2004. Performance of U.S. Teaching Hospitals: A Panel Analysis of Cost Inefficiency. Health care Management Science; 7: 7-16.

Rosko, M.D., Chillingerian, J.A., 1999. Estimating Hospital Efficiency: Does case mix Matter? Journal of Medical Systems; 23: 57-71.

Sari, N. 2003. Efficiency Outcomes of market concentration and Managed Care. International Journal of Industrial Organization; 21: 1571-1589.

Schmidt, P., Sickles, R.C. 1984. Productivity Frontiers and Panel data. Journal of Business and Economic Statistics; 2: 367-374.

Skinner, J. 1994. What do stochastic frontier cost functions tell us about inefficiency? Journal of Health Economics; 13: 323-328. 
Snail, T.S., Robinson, J.C. 1998. Organizational diversification in the American Hospital. Annual review of public health; 19: 417-453.

Street, A. 2003. How much confidence should we place in efficiency-estimates? Health Economics; 12: 895-907.

Tijdink, J.L.J.L. 1996. Neo-institutional economics. A clear answer to public administrative questions? Blad Bestuurskunde; 5: 246-254. (in Dutch).

Vandermeulen, L.E., Barneveld, E. van, Visser, J. 2004. Case mix and performance differences. Utrecht: Prismant. (in Dutch).

Webster, R., Kennedy, S., Johnson, L. 1998. Comparing techniques for measuring the Efficiency and Productivity of Australian Private Hospitals. Working Paper in Econometrics and Applied Statistics; No. 98/3.

Williamson, O.E. 1975. Markets and Hierarchies: Analysis and Antitrust Implications. New York: Free press.

Williamson, O.E. 1985. The Economic Institutions of Capitalism. New York: Free press.

Williamson, O.E. 1998. Transaction Cost Economics: How it works where it is headed. De Economist; 146: 23-58.

Worthington, A.C. 2004. Frontier Efficiency Measurement in Health care: A Review of Empirical Techniques and Selected Applications. Medical care research and review; 61 (2): 135-170.

Zuckerman, S., Hadley, J., lezzoni, L. 1994. Measuring hospital efficiency with frontier cost functions. Journal of Health Economics; 13: 255-280. 


\section{Dankwoord}

Reeds tijdens mijn studietijd en wellicht zelfs tijdens mijn middelbare schooltijd heb ik serieus overwogen te promoveren en de tijd te nemen om een onderwerp goed uit te diepen. Ik realiseerde mij echter ook toen mijn studietijd afliep dat ik verder wilde kijken dan de universitaire wereld. Ik hield overigens wel de gedachte in mijn achterhoofd om ooit de kans op een promotie te grijpen. Toen ik aan de Universiteit van Tilburg, een master in management of public affairs volgde, kwam de gedachte om te promoveren weer boven drijven. Voor het eerst verdiepte ik mij vanuit praktische problematieken in economische theorieën. Mijn eerste werkzaamheden in de zorgsector bij Prismant versterkten het gevoel te willen promoveren en maakten ook mijn interesse concreter. Wat gebeurt er eigenlijk met het geld in de zorg en wordt dit geld op een efficiënte manier besteed? Binnen Prismant hebben diverse mensen, waaronder Ton Eijkenaar, Peter Lems en Michel Dutree mij gestimuleerd dit idee uit te werken. Ik kwam tot de conclusie dat een dergelijke vraag best naast een fulltime baan zou kunnen worden beantwoord. Ik dacht immers: "Ik hoef slechts de data van Nederlandse ziekenhuizen te verzamelen, een operationele definitie van het begrip efficiëntie te kiezen, de neo institutionele economische theorie erbij te pakken en lekker te gaan spelen met statistische programma's." Eén en ander heb ik achteraf gezien inderdaad juist ingeschat, maar dat het zo veel werk zou zijn, dat had ik van tevoren vast niet willen weten. Ik weet namelijk niet of $u$ dan antwoord op de vraag "In hoeverre zijn Nederlandse ziekenhuizen efficiënt" had ontvangen, althans, niet van mij of niet in de vorm van een dissertatie.

Anyway, mijn boek is af. Punt. Versie 43 ligt voor $u$. En dan te bedenken dat ik zelf al best tevreden was met versie 2. Maar mijn broer, Fulco Ludwig, die dit traject voor mij heeft afgelopen, heeft gelijk. Het verschil tussen versie 12 en 13 is vaak moeilijk te zien. Het verschil tussen de laatste versie en de eerste versie daarentegen is heel duidelijk zichtbaar. Verontschuldigingen en dankbaarheid tegenover iedereen die met rust en geduld heeft gereageerd op mijn gemopper en gepruttel over weer een nieuwe verbetering op detailniveau, ik geef het ruiterlijk toe, ik beschouw veel als detailniveau, is op zijn plaats.. Bij deze.

Klaar. Ik kan niet anders zeggen dan wat een heerlijk gevoel dat dat geeft. Graag wil ik dan ook in deze golf van enthousiasme mijn dank overbrengen aan de volgende mensen. Uiteindelijk zijn zij het die, in mindere of meerdere mate, mij de mogelijkheid hebben geboden mijn dissertatie te schrijven.

Allereerst gaat mijn dank uit naar mijn beide promotoren, prof. dr. Wim Groot en prof. dr. Frits van Merode. Met genoegen kijk ik terug op onze gedachtewisselingen in Maastricht. Dergelijke afspraken waren voor mij inspirerend: per trein 
vanuit mijn woonplaats Leiden al koffiedrinkend, krantlezend en leesvoer wegwerkend naar Maastricht, een uur proefschriftsessie op hoog niveau, zowel qua tempo als qua intelligentie, en weer per trein terug naar mijn werkplek Utrecht, opnieuw met koffie, maar ditmaal met een hoofd vol nieuwe ideeën die om rangschikking, ordening en bezinning vragen. Ik heb bewondering en respect voor de snelle reacties op mijn per email verstuurde versies die ik steevast op vrijdagmiddag over de heg gooide en op zaterdagavond van commentaar voorzien, terugontving. Het motto: alles wat binnenkomt, wordt altijd binnen drie dagen verwerkt, dwingt respect af. Het was erg prettig samenwerken. Ook de geduldige reacties op mijn ongeduld, waarbij jullie overigens ook nooit het eindresultaat uit het oog hebben verloren, werd en wordt zeer gewaardeerd. Bedankt.

Dan wil ik graag mijn dank betuigen aan mijn (ex)werkgevers Prismant en Casemix. Gedurende de zes jaren dat ik in vlagen aan mijn proefschrift werkte, werd ik ook met vlagen in tijd gesteund. De oplettende lezer merkt overigens een causaal verband op. De ene keer werd ik uit de wind gehouden wat opdrachten betreft, de andere keer werd mijn target lager gehouden. Zonder deze steun hadden er nog veel meer zondagen in mijn proefschrift gezeten en een mens, ik in ieder geval, moet ook ontspannen, langs het strand uitwaaien om nieuwe ideeën op te doen. Hartelijk dank.

Mijn (ex)collegae, Leo Vandermeulen, Joost Zuurbier, Johan Visser, Yvonne Krabbe en Frederieke Bakker en alle anderen ben ik dankbaar voor hun getoonde interesse, het aanhoren van grappen over het proces van het schrijven van een proefschrift, het corrigeren van teksten, het overnemen van opdrachten op de momenten dat ik uit de wind werd gehouden en bovenal voor hun positieve input die maakte dat ik weer beter gemutst achter mijn laptop zat. Merci.

Zonder namen te noemen een woord van dank aan familie en vrienden die al zes jaar informeren hoe het met mijn proefschrift staat. Nou lieve mensen, het is af. Echt helemaal af? Ja, echt helemaal af! Een nieuw onderwerp mag ter tafel komen! En in willekeurige volgorde, daar alfabetische volgorde ook maar een keuze zou zijn, noem ik de volgende mensen bij naam die een bijdrage hebben geleverd aan het uiteindelijke manuscript: Lucia Snoei voor het originele design van de cover, en dat met een deadline van twee weken, niet dat ik niet wist dat er geen voorkant aan een proefschrift zit, maar eenmaal in de laatste fase van het formele traject van een promotie, wil mijn hersenpan geen nieuwe input meer. Hartelijk dank voor je snelle handelen. Paranimfen Martijn Peeters \& Sander Holman als geestelijk ondersteuners, motivators c.q. Engelse taal correctoren. Fantastisch dat jullie uit Duitsland en Hongkong overkomen om dit mooie moment met mij te delen. Justus, als inspiratiebron voor het leven naast de theorie, ook jij bedankt voor je aanwezigheid. Mijn schoonouders Rien en Leny de Bruijn voor het nalezen van verschillende versies van mijn proefschrift. De korte en krachtige directeursaantekeningen worden gewaardeerd. Mijn (schoon)broers Fulco Ludwig en Louis de Bruijn voor het delen van het plezier 
en de smart van een zelfde proces. Mijn ouders Piet Hein en Marijke Ludwig: ik ben trots dat jullie mijn boek hebben zien afronden en mij altijd hebben geïnspireerd om mezelf intellectueel uit te dagen en de "waarom" vraag te stellen.

Ten slotte wil ik graag mijn lieve partner Saskia de Bruijn bedanken voor het samen delen van het leven én het schrijven van twee proefschriften. Twee proefschriften in één huishouden is volgens velen niet te doen. Van jou heb ik geleerd dat het in ieder geval makkelijker is dan één proefschrift: we hebben één gezamenlijke uitdaging. Waar ik zelf altijd het schrijven van mijn analyses en gedachten als een noodzakelijk kwaad heb gezien, heb ik van jou geleerd dat het zelfs een leuk onderdeel is. Ik besef mij ook dat ik op jouw nuttige en waardevolle opmerkingen niet altijd enthousiast en dankbaar heb gereageerd. Bij deze Sas: ik ben oprecht dankbaar voor jouw toegewijde en liefdevolle aandacht voor mijn leven en mijn proefschrift. 



\section{Curriculum Vitae}

Martijn Ludwig was born on December 6, 1970. In 1989 he finished his Atheneum $B$ degree (A-levels equivalent). Immediately after, he began his study econometrics at the Erasmus University Rotterdam, and graduated in business econometrics in 1995. Meanwhile he started to study psychology at the Leiden University. He graduated again in 1997 in methodology of psychology research. He did his first university graduation with prof. dr. Teun Kloek. He studied the usability of Arch and Garch models for exchange rates. His psychology was done together with dr. Wim van der Kloot. They studied the applicability of regression models for psychological "preference data".

In 1995 Martijn started to work in the social security sector, specializing in the financial aspects of the introduction of markets in this sector. In 1998 he started a post doctoral study of master of public management at the Tilburg Institute of Advanced Studies (TIAS), and finished his first year with a study on the efficiency of the Dutch social security sector.

In 1999 he began as an economist in the health care sector, and specialized in the introduction of a new financing system for Dutch hospitals. In 2002 Martijn started a PhD study with prof. dr. Frits van Merode and prof. dr. Wim Groot on the efficiency of Dutch hospitals. He currently works as a senior-consultant at Casemix, specialized in applying data based solutions in the cure sector. 